LA W RENCE LIVERM ORE NATIO NAL LABORATORY
FATIGUE LIFE PREDICTION FOR STEELS IN PULSATING IRRADIATED SYSTEMS

J. C. Farmer, K. J. Kramer, D. J. Williams

May 3, 2012 
This document was prepared as an account of work sponsored by an agency of the United States government. Neither the United States government nor Lawrence Livermore National Security, LLC, nor any of their employees makes any warranty, expressed or implied, or assumes any legal liability or responsibility for the accuracy, completeness, or usefulness of any information, apparatus, product, or process disclosed, or represents that its use would not infringe privately owned rights. Reference herein to any specific commercial product, process, or service by trade name, trademark, manufacturer, or otherwise does not necessarily constitute or imply its endorsement, recommendation, or favoring by the United States government or Lawrence Livermore National Security, LLC. The views and opinions of authors expressed herein do not necessarily state or reflect those of the United States government or Lawrence Livermore National Security, LLC, and shall not be used for advertising or product endorsement purposes.

This work performed under the auspices of the U.S. Department of Energy by Lawrence Livermore National Laboratory under Contract DE-AC52-07NA27344. 
Farmer, Kramer \& Williams, Fatigue Life Prediction for Steels in Pulsating Irradiated Systems, LLNL-TR-554731, Lawrence Livermore National Laboratory, Livermore, California 94550

\section{LLNL-TR-554731}

\section{FATIGUE LiFE PREDICTION FOR STEELS IN PULSATING IRRADIATED SYSTEMS}

Joseph C. Farmer PhD, Kevin J. Kramer PhD \& Dennis K. Williams PhD

National Ignition Facility \& Photon Sciences Directorate

Lawrence Livermore National Laboratory

Livermore, California 94550

Revision 0 -October $3^{\text {rd }} 2011$

Revision 1-April $29^{\text {th }} 2012$ 


\title{
Fatigue Life Prediction for Steels in PULSATING IRRADIATED SYSTEMS
}

\author{
Joseph C. Farmer PhD, Kevin J. Kramer PhD \& Dennis K. Williams PhD \\ National Ignition Facility \& Photon Sciences Directorate \\ Lawrence Livermore National Laboratory \\ Livermore, California 94550
}

\section{EXECUTIVE SUMMARY}

Continuous energy pulses at a repetition rate of $10 \mathrm{~Hz}$ and the use of ferritic-martensitic (FM) steel for construction are assumed for a hypothetical high-temperature neutron source under study. Initial analyses based upon published literature data and established fracture mechanics models indicate that the service life of such a system would be limited by fatigue, and that viability would require designers to limit the magnitude of the alternating stress, keeping it well below $10 \mathrm{MPa}$ in order to achieve a service life of 1 year with an assumed availability of 85 percent. These standard analyses use analytical expressions from published sources such as Roark's Handbook. The applied static stress is either assumed, or taken from parallel predictions made with finite element model (FEM) codes. The alternating stress is predicted with formulae that account for (1) thermal stress pulses associated with isochoric heating of the structural material; and (2) pressure pulses from any working fluid in contact with the vessel wall. With published mechanical property data for the irradiated structural material, including the yield strength $\left(\sigma_{Y S}\right)$ and fracture toughness $\left(K_{C}\right)$, the critical flaw size for initiation of a fatigue crack $\left(a_{c}\right)$ can then be estimated. The calculated critical flaw size $\left(a_{c}\right)$, and the largest expected manufacturing defect in the surface $\left(a_{0}\right)$ are required to calculate the number fatigue cycles to failure $\left(N_{f}\right)$ as a function of applied stress $(\sigma)$. The fatigue limit $\left(\sigma_{C R}\right)$ can be estimated once the required number of fatigue cycles are specified, which in this case are in excess of 200 million $(268,056,000)$ cycles. Given the fatigue limit and the yield stress, the Soderberg equation is used to establish the most conservative bounds for the mean and alternating stresses, levels that cannot be exceeded for safe operation. Less conservatively, and given the fatigue limit and ultimate tensile strength of the material, the Goodman equation can be used to establish these bounds. Even more optimistic estimates can be made with the Gerber equation. Of course, more complicated alternating stress waveforms can be accounted for using the damage accumulation model, with cycle counting based upon the rainfall criterion. Model parameters were based experimental data for FM steels from a number of published sources, and recently published data on the mechanical testing of EUROFER97 and EUROFER97 HT after irradiation to 71 dpa in the BOR-60 reactor in Russia. These data indicate that radiation-induced damage, strengthening and hardening, and ductile brittle transition temperature (DBTT) increases approach saturation levels after a damage level of 10 to 20 displacements per atom (dpa) is reached. 
Farmer, Kramer \& Williams, Fatigue Life Prediction for Steels in Pulsating Irradiated Systems, LLNL-TR-554731, Lawrence Livermore National Laboratory, Livermore, California 94550

\section{TABLE OF CONTENTS}

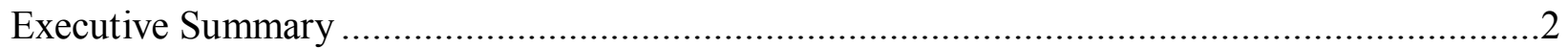

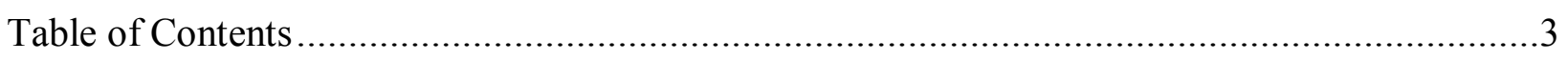

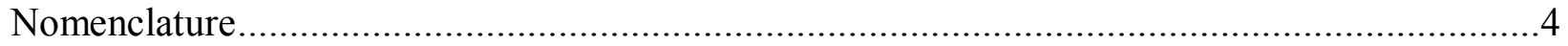

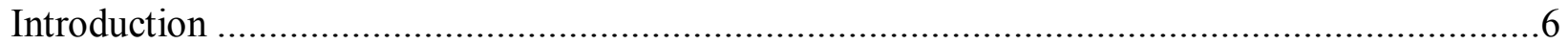

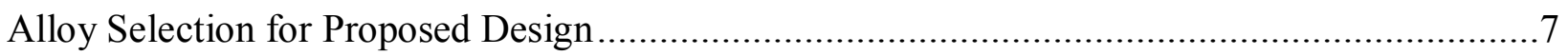

Foundational Relationships Between Stress \& Strain...........................................................

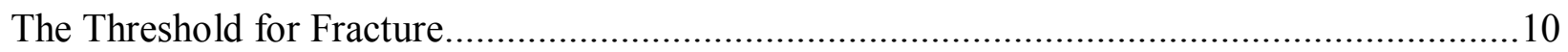

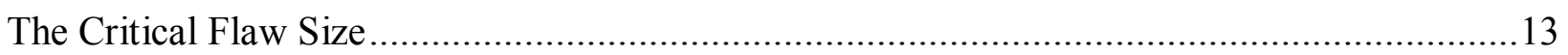

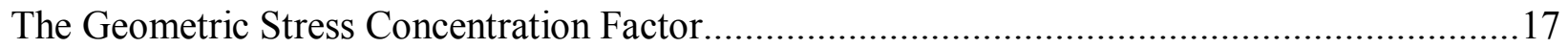

Mean and alternating Stresses Encountered during fatigue .......................................................19

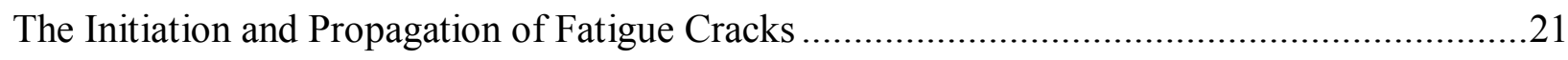

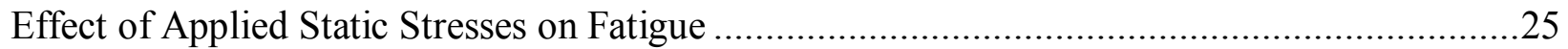

Formulae Used for the Superposition of Static and Alternating Stresses ...................................25

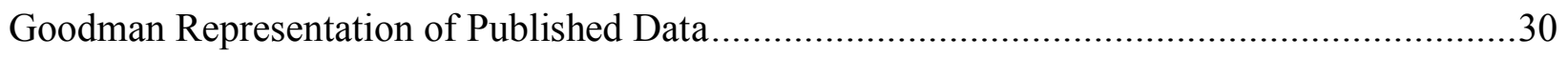

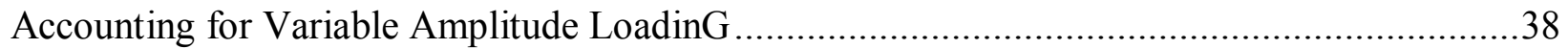

Effect of Radiation Damage on Mechanical Properties ..............................................................39

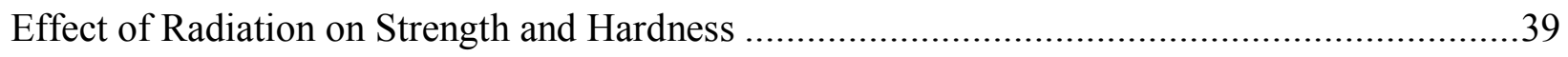

Effect of Radiation on Ductile Brittle Transition Temperature..................................................40

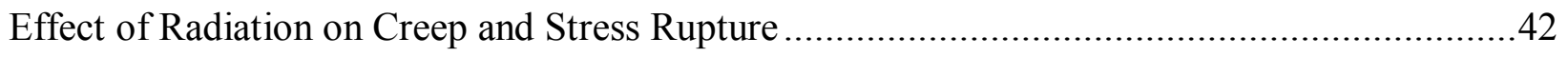

Effects of Radiation on Fatigue Life of FM Steels ..................................................................

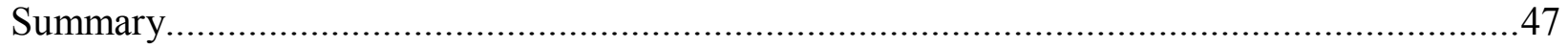

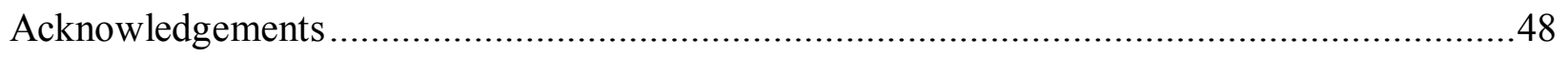

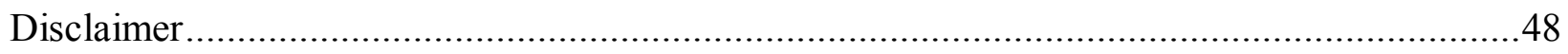

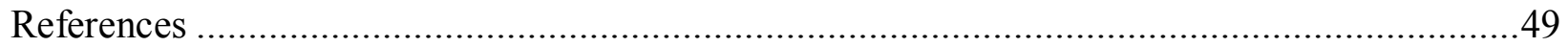

Appendix A - Mean Stress in the Walls of Cylindrical \& Spherical Vessels...............................52

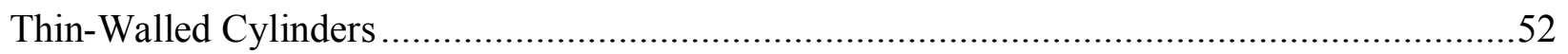

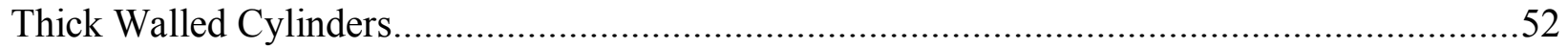

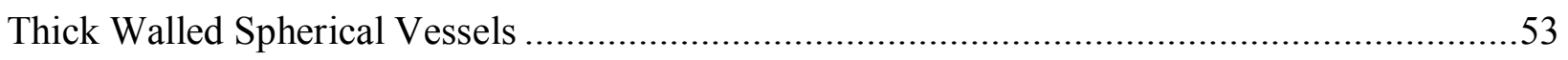

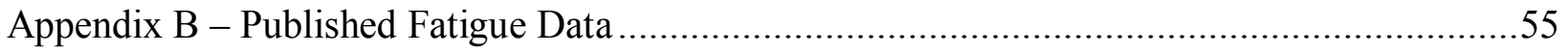




\section{NOMENCLATURE}

$\alpha$

$\varepsilon$

$\varepsilon_{e l}$

$\varepsilon_{p l}$

$\varepsilon_{\text {total }}$

$\gamma_{\text {eff }}$

$\gamma_{s}$

$\mu$

$\phi$

$\phi_{0}$

$\sigma_{a}$

$\sigma_{m}$

$\sigma_{\text {max }}$

$\sigma_{\min }$

$\sigma_{f a t}$

$\sigma_{C R}$

$\sigma_{U T S}$

$\sigma_{U T S}$

$\Delta \sigma$

$\Delta \sigma_{S}$

$a$

$a$

$a_{c}$

$a_{\text {critical }}$

$b$

$b$

$d$

$f\left(\varepsilon_{e l}\right)$

$t_{i}$

$t_{f}$

$q$

$B$

DBTT
Average obstacle strength

Strain

Elastic strain

Plastic strain

Total strain

Effective plastic energy absorbed around the crack tip during fracture

Area specific energy required for creating new surface inside crack

Shear modulus of steel

Irradiation dose

Scaling irradiation dose characteristic

Alternating stress

Mean stress

Maximum stress

Minimum stress

Fatigue limit or fatigue stress limit

Fatigue limit or fatigue stress limit

Yield strength

Ultimate tensile strength

Radiation hardening

Saturation value of radiation hardening

Weighting factor

Crack depth

Critical flaw size for crack initiation and propagation

Critical flaw size for crack initiation and propagation

Remaining wall thickness

Burgers vector of moving dislocation

Average obstacle diameter

Damage function, assumed linear with limited data

Creep time under stress $\sigma_{i}$

Creep rupture time

Notch sensitivity

Sample width

Change in ductile brittle transition temperature due to irradiation 
Farmer, Kramer \& Williams, Fatigue Life Prediction for Steels in Pulsating Irradiated Systems, LLNL-TR-554731,

Lawrence Livermore National Laboratory, Livermore, California 94550

$\begin{array}{ll}\triangle D B T T & \text { Change in ductile brittle transition temperature due to irradiation } \\ \triangle D B T T_{S} & \text { Saturation value of change in DBTT due to irradiation } \\ K_{t} & \text { Geometric stress concentration factor } \\ K_{f} & \text { Ratio of fatigue limit (unnotched) to fatigue limit (notched) } \\ K_{C} & \text { Critical value of stress concentration factor } \\ M & \text { Taylor factor } \\ N & \text { Volume density of obstacles } \\ N & \text { Volume density of defects } \\ N_{S} & \text { Saturation defect density } \\ N & \text { Number of fatigue cycles } \\ N_{f} & \text { Number of fatigue cycles at failure } \\ R & \text { The stress ratio } \\ T_{i r r} & \text { Irradiation temperature } \\ T_{t e s t} & \text { Test temperature } \\ U & \text { Plastic work per unit exposed area to advance fatigue crack } \\ U T S & \text { Ultimate tensile strength } \\ W & \text { Sample thickness } \\ Y S & \text { Yield strength }\end{array}$




\section{INTRODUCTION}

Continuous energy pulses at a repetition rate of $10 \mathrm{~Hz}$ and the use of ferritic-martensitic (FM) steel for construction are assumed for a hypothetical high-temperature neutron source under study. Initial analyses based upon published literature data and established fracture mechanics models indicate that the service life of such a system would be limited by fatigue, and that viability would require designers to limit the magnitude of the alternating stress, keeping it well below $10 \mathrm{MPa}$ in order to achieve a service life of 1 year with an assumed availability of 85 percent.

These standard analyses use analytical expressions from published sources such as Roark's Handbook. The applied static stress is either assumed, or taken from parallel predictions made with finite element model (FEM) codes. The alternating stress is predicted with formulae that account for (1) thermal stress pulses associated with isochoric heating of the structural material; and (2) pressure pulses from any working fluid in contact with the vessel wall. With published mechanical property data for the irradiated structural material, including the yield strength $\left(\sigma_{Y S}\right)$ and fracture toughness $\left(K_{C}\right)$, the critical flaw size for initiation of a fatigue crack $\left(\mathrm{a}_{\mathrm{c}}\right)$ can then be estimated. The calculated critical flaw size $\left(a_{c}\right)$, and the largest expected manufacturing defect in the surface $\left(a_{0}\right)$ are required to calculate the number fatigue cycles to failure $\left(N_{f}\right)$ as a function of applied stress $(\sigma)$. The fatigue limit $\left(\sigma_{C R}\right)$ can be estimated once the required number of fatigue cycles are specified, which in this case are in excess of 200 million $(268,056,000)$ cycles. This integrated approach for fatigue analysis is illustrated in Figure 1.

Given the fatigue limit and the yield stress, the Soderberg equation is used to establish the more conservative bounds for the mean and alternating stresses than the Goodman and Gerber equations, bounds that cannot be exceeded for safe operation. Less conservatively, and given the fatigue limit and ultimate tensile strength of the material, the Goodman equation can be used to establish these bounds. Even more optimistic estimates can be made with the Gerber equation. Of course, more complicated alternating stress waveforms can be accounted for using the damage accumulation model, with cycle counting based upon the rainfall criterion.

Model parameters were based experimental data for HT-9, MANET, and EUROFER97 from a number of published sources, and recently published data on the mechanical testing of EUROFER97 and EUROFER97 HT after irradiation to 71 dpa in the BOR-60 reactor in Russia. These data indicate that radiation-induced damage, strengthening and hardening, and ductile brittle transition temperature (DBTT) increases approach saturation levels after a damage level of 10 to 20 displacements per atom (dpa) is reached. 


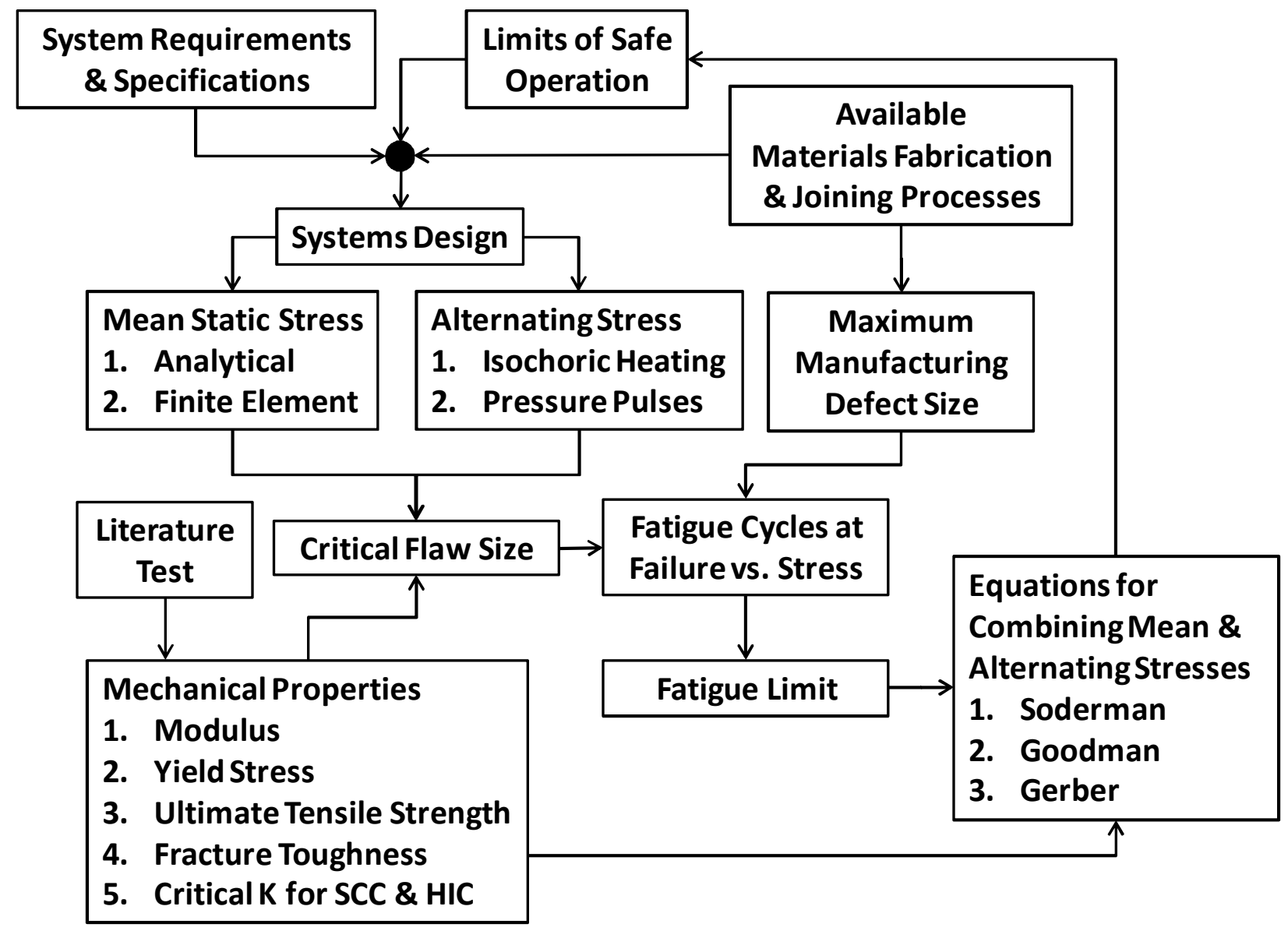

Figure 1 - Integrated approach for the systematic analysis of a hypothetical system subjected to cyclic fatigue. Such a system must satisfy operate safely within established limits.

\section{ALLOY SELECTION FOR PROPOSED DESIGN}

The proposed system will be subjected to high doses of fast neutrons. Based upon the published literature, appropriate proven alloys include EUROFER97, HT-9 and MANET steels. The composition of the EUROFER97 alloys obtained from FZK in Germany is approximately: 0.12 $\%$ C, $8.96 \%$ Cr, $<0.001 \%$ Mo, $1.1 \% \mathrm{~W},<0.001 \% \mathrm{Nb}, 0.13 \%$ Ta, $0.19 \% \mathrm{~V},<0.005 \% \mathrm{P}, 0.43 \%$ $\mathrm{Mn}, 0.007 \% \mathrm{Ni},<0.001 \% \mathrm{~B}, 0.016 \% \mathrm{~N}$, and $0.07 \% \mathrm{Si}$, with the balance being iron. The composition of HT-9 is approximately: $0.2 \% \mathrm{C}, 12 \% \mathrm{Cr}, 1 \% \mathrm{Mo}, 0.5 \% \mathrm{~W}, 0.6 \% \mathrm{Mn}, 0.3 \% \mathrm{~V}$, and $0.2 \% \mathrm{Si}$, with the balance being iron [Gelles 1987]. The yield and ultimate tensile strengths of neutron irradiated HT-9 are as a function of test temperature are shown in Table 1 and Figure 2 , and represented by the following correlation by the authors of this report:

$$
\begin{array}{ll}
\sigma_{Y S}=-0.0031 T^{2}+1.4299 T+568.85 & R^{2}=0.5211 \\
\sigma_{U T S}=-0.0032 T^{2}+1.2631 T+738.59 & R^{2}=0.6240
\end{array}
$$


Farmer, Kramer \& Williams, Fatigue Life Prediction for Steels in Pulsating Irradiated Systems, LLNL-TR-554731, Lawrence Livermore National Laboratory, Livermore, California 94550

Table 1 - Yield Strength (YS) and Ultimate Tensile Strength (UTS) for HT-9 Steel at Specified Test Temperature

\begin{tabular}{|c|c|c|c|c|c|c|c|}
\hline Material & $\Phi$ & $\mathrm{T}_{\text {irr }}$ & $\mathrm{T}_{\text {test }}$ & $\sigma_{\mathrm{YS}}$ & $\sigma_{\text {UTS }}$ & $\varepsilon_{\text {uniform }}$ & $\varepsilon_{\text {total }}$ \\
\hline Alloy & $10^{22} \mathrm{n} / \mathrm{cm}^{2}$ & ${ }^{\circ} \mathrm{C}$ & ${ }^{\circ} \mathrm{C}$ & $\mathrm{MPa}$ & $\mathrm{MPa}$ & $\%$ & $\%$ \\
\hline HT9 & 15 & 495 & 25 & 615 & 790 & 8.0 & 12.0 \\
\hline HT9 & 15 & 495 & 495 & 428 & 506 & 2.4 & 8.1 \\
\hline HT9 & 15 & 550 & 25 & 563 & 777 & 8.0 & 12.4 \\
\hline HT9 & 15 & 550 & 660 & 199 & 229 & 1.5 & 13.0 \\
\hline HT9 & 15 & 670 & 25 & 441 & 635 & 15.2 & 20.7 \\
\hline HT9 & 15 & 670 & 205 & 912 & 1125 & 9.5 & 12.9 \\
\hline HT9 & 15 & 750 & 25 & 337 & 500 & 16.2 & 22.6 \\
\hline HT9 & 31 & 410 & 25 & 814 & 943 & 3.9 & 6.5 \\
\hline HT9 & 31 & 410 & 205 & 649 & 790 & 3.5 & 6.0 \\
\hline HT9 & 31 & 410 & 410 & 621 & 694 & 3.0 & 6.2 \\
\hline HT9 & 36 & 410 & 25 & 810 & 916 & 4.8 & 7.7 \\
\hline HT9 & 36 & 410 & 205 & 714 & 790 & 3.2 & 5.6 \\
\hline HT9 & 36 & 410 & 410 & 645 & 711 & 2.6 & 4.9 \\
\hline
\end{tabular}

HT-9 YS \& UTS

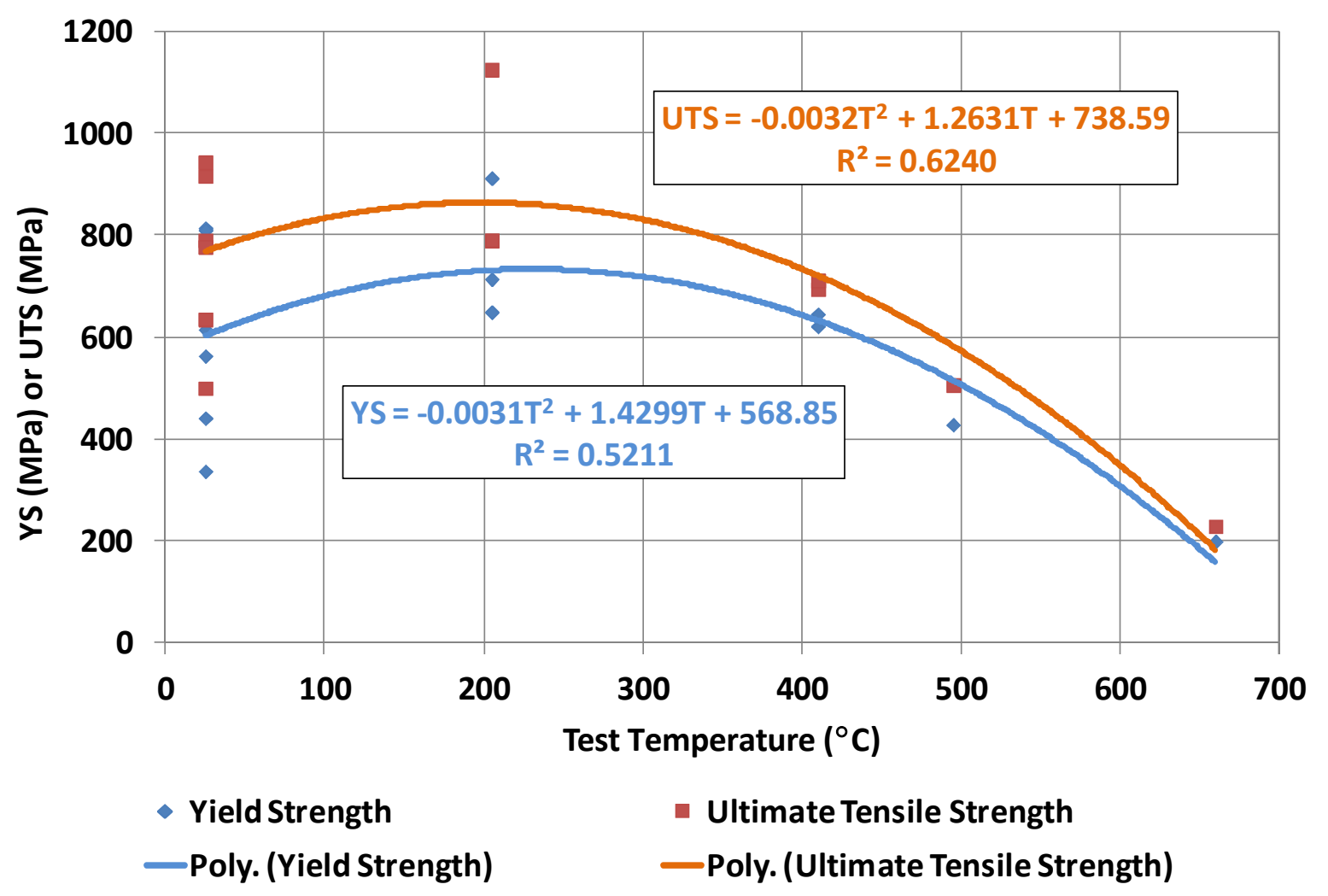

Figure 2 - The yield strength (YS) and ultimate tensile strength (UTS) for HT-9 steel as a function of test temperature are shown with regression equations. 
Farmer, Kramer \& Williams, Fatigue Life Prediction for Steels in Pulsating Irradiated Systems, LLNL-TR-554731, Lawrence Livermore National Laboratory, Livermore, California 94550

\section{FOUNDATIONAL RELATIONSHIPS BETWEEN STRESS \& STRAIN}

Before discussing methods for combining the effects of mean and variable-amplitude alternating stresses encountered during fatigue, the foundational relationships between stress and strain are reviewed. When a material such as a ferritic-martensitic steel is subjected a level of stress below its yield stress, is will experience simple elastic strain in accordance with Hooke's Law:

$$
\varepsilon_{e l}=\frac{\sigma}{E} \quad \sigma<\sigma_{Y S}
$$

As the stress is increased above the yield stress, the material becomes plastically deformed, with the total strain in the material consisting of elastic and plastic contributions:

$$
\varepsilon_{\text {total }}=\varepsilon_{e l}+\varepsilon_{p l} \quad \sigma_{Y S}<\sigma<\sigma_{U T S}
$$

The plastic strain can be calculated from the total stress and strain, which are both measured, and Young's modulus, which is usually known or found through measurement.

$\varepsilon_{p l}=\varepsilon-\frac{\sigma}{E}$ 


\section{THE THRESHOLD FOR FRACTURE}

As discussed in the literature, the Griffith Criterion was developed in the 1920s [Griffith 1921], and is one of the foundation stones of modern fracture mechanics [Bowles 1997]. Griffith developed an energy release rate criterion for the fracture of brittle materials. His development begins with an expression for the elastic strain energy per unit volume contained in an elastic material:

$U_{0}=\frac{\sigma}{2 E}$

When a crack is formed, the energy is assumed to be released into an elliptical region surrounding the crack, with the volume of that region defined as:

$V=2 \pi a^{2} B$

The length of the elliptical crack is assumed to be $(2 a)$ and the thickness of the material undergoing fracture is assumed to be $(B)$. The total energy released is therefore the product of the volume and the strain energy per unit volume:

$U=2 \pi a^{2} B \frac{\sigma}{2 E}=\frac{\pi a^{2} B \sigma}{E}$

Griffith's criterion simply states that when the amount of elastic strain energy released during crack advancement exceeds the energy required to initiate crack growth, crack growth will occur, which is expressed mathematically as:

$$
\frac{d U}{d a} \geq \frac{d W}{d a}
$$

Note that $d W / d t$ is also known as $R$, the crack resistance. Integration leads to the classic Griffith Criterion, where $\sigma$ is the applied stress, $a$ is the crack length, $E$ is Young's Modulus, and $\gamma_{s}$ is the specific surface energy for a given material, or the area-specific energy required for creating new surface inside crack:

$\sigma \sqrt{\pi a}=\sqrt{2 E \gamma_{s}}$

For the elastic case, the energy release rate required for crack growth is $\left(G_{C}\right)$ can be expressed in terms of the effective plastic energy absorbed around the crack tip during fracture $\left(\gamma_{\text {eff }}\right)$ :

$G_{C}=2 \gamma_{\text {eff }}$

The well-known critical stress intensity factor for crack initiation can therefore be written as: 
Farmer, Kramer \& Williams, Fatigue Life Prediction for Steels in Pulsating Irradiated Systems, LLNL-TR-554731, Lawrence Livermore National Laboratory, Livermore, California 94550

$K_{C}=\sqrt{E G_{C}}=\sigma \sqrt{\pi a}$

This is for a small elliptical crack of length $(2 a)$ in an in a plate much larger than the crack and subjected to tension normal to the crack, as shown in Figure 3. As will be discussed subsequently, the critical flaw size can be defined in terms of this expression. The energy release rate required for crack growth $\left(G_{C}\right)$ can be modified to account for both elastic and plastic deformation during fracture:

$G_{C}=2 \gamma+\Gamma \sigma_{y} \delta_{c}$

Note that the parameter $\gamma$ represents the surface energy associated with creation of the crack. The corresponding expression for the critical stress intensity factor for crack initiation can then be written as:

$K_{C}=\sqrt{2 E \gamma+\Gamma E \sigma_{y} \delta_{c}}$

In essence, the fracture toughness is the energy absorbed per unit of crack area exposed per crack extension event. The Charpy Impact Test as prescribed by ASTM E23 actually measures the energy release rate required for crack growth, assuming plain strain $\left(G_{I C}\right)$ :

$G_{I C}=\frac{K_{I C}^{2}}{E}$

The corresponding plane strain fracture toughness is:

$K_{I C}=n \sqrt{E \sigma_{Y S} \varepsilon_{f}}$

Note that $\varepsilon_{f}$ is the fracture strain. The impact energy that can be withstood by irradiated HT- 9 , up to a damage of $26 \mathrm{dpa}$ has been determined by performing Charpy impact tests on mechanical test specimens, as shown in Figure 4 [Gelles 1987]. This source of data indicates that the impact energy drops from approximately $375 \mathrm{~J} / \mathrm{cm}^{2}$ prior to irradiation, to approximately $150 \mathrm{~J} / \mathrm{cm}^{2}$ after irradiation to $26 \mathrm{dpa}$, due to radiation strengthening (hardening). 
Farmer, Kramer \& Williams, Fatigue Life Prediction for Steels in Pulsating Irradiated Systems, LLNL-TR-554731, Lawrence Livermore National Laboratory, Livermore, California 94550

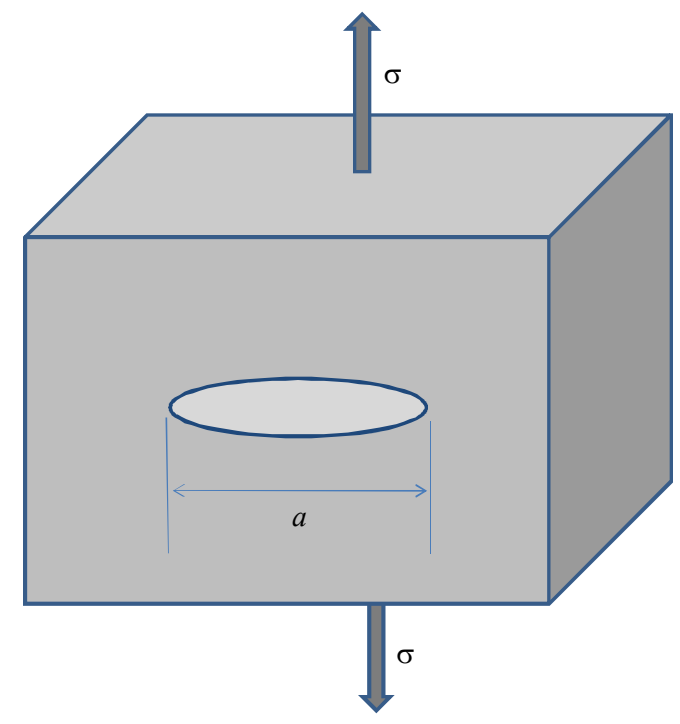

Figure 3 - Illustration showing small elliptical crack of length $(2 a)$ in an in a plate much larger than the crack and subjected to tension normal to the crack.

HT-9 Charpy Impact

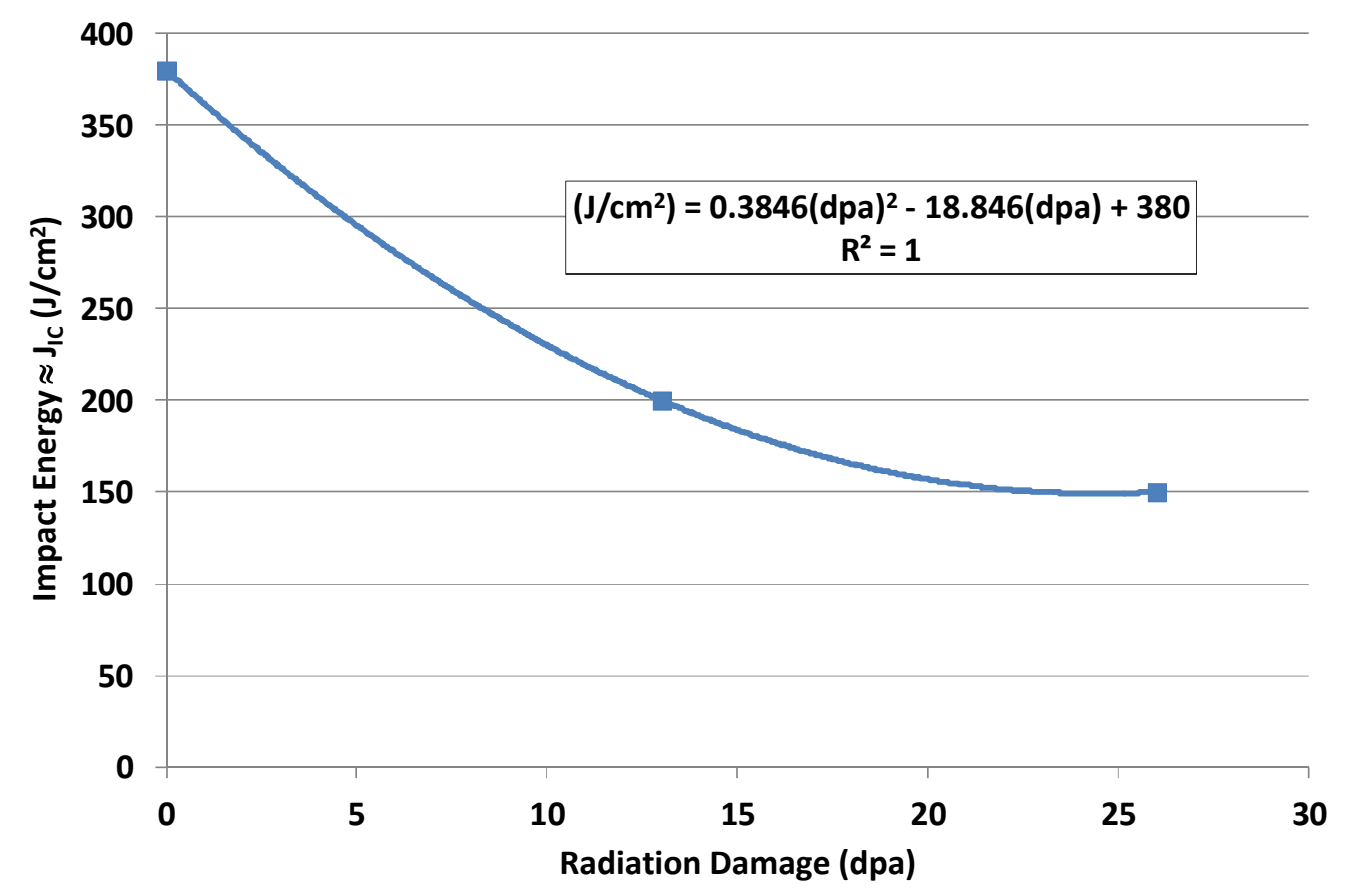

Figure 4 - Effect of irradiation and radiation damage on the impact energy of HT-9 determined with the Charpy Impact Test. These data are for a temperature of $250^{\circ} \mathrm{C}$ [D. S. Gelles, Journal of Nuclear Materials 149 (1987) 192-199]. 


\section{THE CRITICAL FLAW SIZE}

The value of the initial flaw size $\left(a_{0}\right)$ is usually determined from non-destructive evaluation (NDE) of the finished part, and for the sake of the calculations shown here, is assumed to be approximately 100 microns, comparable to abrasive grit and debris found in industrial plants. A value of the critical flaw size $\left(a_{c}\right)$ must then be estimated, and requires knowledge of the critical stress intensity factor $\left(K_{C}\right)$. If the stress intensity factor $(K)$ exceeds this critical value $\left(K_{C}\right)$, a brittle crack will initiate and grow:

\section{$K \geq K_{C}$}

Representative values of the stress intensity factors in plane strain are given in Table 1, with a value of 50 (close to average of values in table) assumed in calculations to be discussed subsequently. The formula for the stress intensity factor can then be used as the basis of calculating a critical flaw size required for crack initiation and propagation, by substituting the yield stress $\left(\sigma_{Y S}\right)$ for the applied stress.

$a_{c} \leq \frac{1}{\pi}\left(\frac{K_{C}}{\sigma_{Y S} f(a / W)}\right)^{2}$

Representative values of the yield stress and fracture toughness required for estimating the critical flaw size for a range of common steels at ambient conditions and without irradiation are summarized in Table 2 [Thornton \& Colangelo 1985]. The effects of irradiation on the impact energy and fracture toughness of HT-9 are summarized in Table 3 [Huang 1997]. Rough estimates of the critical flaw size based upon available properties, or assumed properties based upon published data for similar alloys, are given in Table 4.

The critical stress intensity factor may reflect any one of several types of environmental fracture, including stress corrosion cracking (SCC), hydrogen induced cracking (HIC), and liquid metal embrittlement (LME). In advanced high-temperature nuclear systems, liquid metal or molten salt coolants, the presence of hydrogen, deuterium and tritium at significant concentrations, and the exposure of various components to flowing liquid metals. Liquid metal embrittlement (LME) of ferritic-martensitic steels in molten lead alloys, including EUROFER97 and T91 which have been studied at $150-450^{\circ}$ and at strain rates from $1 \times 10^{-3}$ to $1 \times 10^{-6} \mathrm{~s}^{-1}$, are discussed in the literature [Van den Bosch et al. 2008]. While there was relatively little sensitivity to the liquid metals in very smooth samples, samples with stress concentrators in the surface (notched specimens), and samples that had already been exposed and corroded by these liquid metals exhibited a substantial decrease in the total elongation at failure. A substantial reduction in the yield stress was also observed after liquid metal exposure. 
Farmer, Kramer \& Williams, Fatigue Life Prediction for Steels in Pulsating Irradiated Systems, LLNL-TR-554731, Lawrence Livermore National Laboratory, Livermore, California 94550

Table 2 - Representative Values of the Critical Stress Intensity Factor

\begin{tabular}{|l|r|r|}
\hline Steel & \multicolumn{1}{|l|}{ YS } & \multicolumn{1}{l|}{$\mathrm{K}_{\mathrm{IC}}$} \\
\hline & $\mathrm{MPa}$ & $\mathrm{MPa} \sqrt{\mathrm{m}}$ \\
\hline 4340 Steel & 860 & 99 \\
\hline 4340 Steel & 1515 & 60 \\
\hline 4335 Steel Plus V & 1340 & 72 \\
\hline 4335 Steel Plus V & 1035 & 132 \\
\hline 17-7 pH Stainless & 1435 & 77 \\
\hline 15-7 Mo Stainless & 1415 & 50 \\
\hline H-11 Tool Steel & 1790 & 38 \\
\hline 350 Maraging Steel & 1550 & 55 \\
\hline 350 Maraging Steel & 2240 & 38 \\
\hline 52100 Ball Bearing & 2070 & 14 \\
\hline
\end{tabular}

Source: Peter A. Thornton, Vito J. Colangelo, Typical Plane Strain Fracture Toughness Values for Certain Alloys, Table 9-1, Fundamentals of Engineering Materials, Prentice-Hall, Englewood Cliffs, New Jersey, 1985, p. 268. 
Farmer, Kramer \& Williams, Fatigue Life Prediction for Steels in Pulsating Irradiated Systems, LLNL-TR-554731, Lawrence Livermore National Laboratory, Livermore, California 94550

Table 3 - Effect of Irradiation on Impact Energy \& Fracture Toughness of HT-9

\begin{tabular}{|c|c|c|c|c|c|c|c|c|}
\hline Reactor & Material & Damage & $\mathrm{T}_{\text {irr }}$ & $\Phi \mathrm{t}$ & $\mathrm{T}_{\text {test }}$ & $\begin{array}{c}\text { Tearing } \\
\text { Modulus }\end{array}$ & $\mathrm{J}_{\mathrm{C}}$ & $\mathrm{K}_{\mathrm{C}}$ \\
\hline ID & ID & $\mathrm{dpa}$ & ${ }^{\circ} \mathrm{C}$ & $10^{22} \mathrm{n} / \mathrm{cm}^{2}$ & ${ }^{\circ} \mathrm{C}$ & & $\mathrm{kJ} / \mathrm{m}^{2}$ & $\mathrm{MPa} \sqrt{\mathrm{m}}$ \\
\hline EBR-II & HT-9 Modfied & & 400 & 6.0 & 93 & 80 & 99.0 & \\
\hline EBR-II & HT-9 Modfied & & 400 & 6.0 & 205 & 73 & 58.8 & \\
\hline EBR-II & HT-9 Modfied & & 450 & 6.0 & 205 & 172 & 53.4 & \\
\hline EBR-II & HT-9 Modfied & & 550 & 6.0 & 205 & 195 & 54.4 & \\
\hline EBR-II & HT-9 Duct (91354) & & 383 & 9.0 & 57 & 55 & & 106.3 \\
\hline EBR-II & HT-9 Duct (91354) & & 383 & 9.0 & 205 & 61 & & 100.9 \\
\hline EBR-II & HT-9 Duct (91354) & & 383 & 9.0 & 316 & 81 & & 91.7 \\
\hline EBR-II & HT-9 Duct (91354) & & 383 & 9.0 & 427 & 88 & & 81.1 \\
\hline EBR-II & HT-9 Plate (91354) & & 393 & 9.0 & 62 & 60 & & 115.2 \\
\hline EBR-II & HT-9 Plate (91354) & & 393 & 9.0 & 205 & 81 & & 106.7 \\
\hline EBR-II & HT-9 Plate (91354) & & 393 & 9.0 & 316 & 73 & & 101.3 \\
\hline EBR-II & HT-9 Plate (91354) & & 393 & 9.0 & 427 & 93 & & 95.9 \\
\hline EBR-II & HT-9 MOTA (91353) & & 410 & 36.0 & 32 & 78 & 51.8 & 102.9 \\
\hline EBR-II & HT-9 MOTA (91353) & & 410 & 36.0 & 205 & 70 & 48.0 & 96.4 \\
\hline EBR-II & HT-9 MOTA (91353) & & 410 & 36.0 & 410 & 55 & 48.8 & 93.7 \\
\hline EBR-II & HT-9 MOTA (91353) & & 405 & 17.5 & 25 & 79 & 59.2 & 110.0 \\
\hline EBR-II & HT-9 MOTA (91353) & & 405 & 17.5 & 205 & 80 & 61.3 & 108.9 \\
\hline EBR-II & HT-9 MOTA (91353) & & 550 & 13.0 & 32 & 211 & 81.9 & 129.4 \\
\hline EBR-II & HT-9 MOTA (91353) & & 550 & 13.0 & 205 & 146 & 53.4 & 101.6 \\
\hline EBR-II & HT-9 MOTA (84425) & & 410 & 31.0 & 32 & 58 & 72.5 & 121.8 \\
\hline EBR-II & HT-9 MOTA (84425) & & 410 & 31.0 & 205 & 79 & 63.2 & 110.6 \\
\hline EBR-II & HT-9 MOTA (84425) & & 410 & 31.0 & 410 & 39 & 56.0 & 100.3 \\
\hline EBR-II & HT-9 MOTA (84425) & & 550 & 14.0 & 205 & 105 & 77.2 & 122.1 \\
\hline EBR-II & HT-9 MOTA (84425) & & 550 & 14.0 & 410 & 137 & 52.7 & 97.4 \\
\hline EBR-II & HT-9 MOTA (84425) & & 405 & 13.7 & 25 & 71 & 55.3 & 106.4 \\
\hline EBR-II & HT-9 MOTA (84425) & & 405 & 13.7 & 205 & 95 & 53.2 & 101.6 \\
\hline HFIR & HT-9 MOTA & 10 & 50 & 2.35 & 25 & & 63.3 & \\
\hline HFIR & HT-9 MOTA & 10 & 50 & 2.35 & 93 & & 52.0 & \\
\hline HFIR & HT-9 MOTA & 10 & 50 & 2.35 & 205 & & 56.7 & \\
\hline HFIR & HT-9 Weld Metal & & 390 & 2.35 & 93 & 38 & 102.2 & \\
\hline HFIR & HT-9 Weld Metal & & 390 & 2.35 & 205 & 42 & 98.9 & \\
\hline HFIR & HT-9 Weld Metal & & 390 & 2.35 & 316 & 45 & 95.7 & \\
\hline HFIR & HT-9 Weld Metal & & 390 & 2.35 & 427 & 48 & 76.0 & \\
\hline FFTF & HT-9 ACO-1 Duct & & 411 & 15.9 & 32 & 75 & & 109.7 \\
\hline FFTF & HT-9 ACO-1 Duct & & 360 & 5.5 & 32 & & & 31.9 \\
\hline FFTF & HT-9 ACO-1 Duct & & 360 & 5.5 & 32 & & & 28.2 \\
\hline FFTF & HT-9 ACO-1 Duct & & 360 & 5.5 & 205 & 26 & & 126.0 \\
\hline
\end{tabular}

Source: F. H. Huang, Mechanical Properties of Ferritic Alloys, Chapter 13, Fracture Properties of Irradiated HT-9 Modified and 9Cr-1Mo, Table 13.5, Fracture Toughness Results for HT-9 Irradiated in the EBR-II to $9 \times 10^{22} \mathrm{n} / \mathrm{cm}^{2}$, Table 13.6, Fracture Toughness Test Results of HT-9 Irradiated at FFTF, Table 13.7, Fracture Properties of Ferritic Alloys Irradiated at $50^{\circ} \mathrm{C}$ to a Dose of 10 dpa in HFIR, Table 13.8, Fracture Properties of Irradiated Alloys, Avante Publishing, P. O. Box 183, Richland, Washington, 1997, pp. 261-284. 
Farmer, Kramer \& Williams, Fatigue Life Prediction for Steels in Pulsating Irradiated Systems, LLNL-TR-554731, Lawrence Livermore National Laboratory, Livermore, California 94550

Table 4 - Assumed Material Properties and Corresponding Estimates of Critical Flaw Size for EUROFER97 \& HT-9 Steels

\begin{tabular}{|l|l|r|r|r|r|l|}
\hline & Symbol & EUROFER97 & $\begin{array}{r}\text { EUROFER97 } \\
\text { Post-BOR60 }\end{array}$ & MANET & HT-9 & Units \\
\hline Parameter & $\mathrm{T}$ & 550.0000 & 550.0000 & 660.0000 & 660.0000 & ${ }^{\circ} \mathrm{C}$ \\
\hline Wall $(\mathrm{W})$ & $\mathrm{W}$ & 10.0000 & 10.0000 & 10.0000 & 10.0000 & $\mathrm{~cm}$ \\
\hline Mean Static Stress $\left(\sigma_{\mathrm{m}}\right)$ & $\sigma_{\mathrm{m}}$ & 75.0000 & 75.0000 & 75.0000 & 75.0000 & $\mathrm{MPa}$ \\
\hline Max Alternating Stress $\left(\sigma_{\max }\right)$ & $\sigma_{\max }$ & 115.0000 & 115.0000 & 115.0000 & 115.0000 & $\mathrm{MPa}$ \\
\hline Min Alternating Stress $\left(\sigma_{\min }\right)$ & $\sigma_{\min }$ & 115.0000 & 115.0000 & 115.0000 & 115.0000 & $\mathrm{MPa}$ \\
\hline Alternating Stress $\left(\sigma_{\text {alt }}\right)$ & $\sigma_{\text {alt }}$ & 0.0000 & 0.0000 & 0.0000 & 0.0000 & $\mathrm{MPa}$ \\
\hline Max Total Stress $\left(\sigma_{\mathrm{m}}+\sigma_{\max }\right)$ & $\sigma_{\mathrm{m}}+\sigma_{\max }$ & 190.0000 & 190.0000 & 190.0000 & 190.0000 & $\mathrm{MPa}$ \\
\hline Min Total Stress $\left(\sigma_{\mathrm{m}}-\sigma_{\min }\right)$ & $\sigma_{\mathrm{m}}-\sigma_{\min }$ & -40.0000 & -40.0000 & -40.0000 & -40.0000 & $\mathrm{MPa}$ \\
\hline Yield Stress $\left(\sigma_{\mathrm{YS}}\right)$ & $\sigma_{\mathrm{YS}}$ & 360.0000 & 360.0000 & 199.0000 & 199.0000 & $\mathrm{MPa}$ \\
\hline Ultimate Tensile Strength $\left(\sigma_{\mathrm{UTS}}\right)$ & $\sigma_{\mathrm{UTS}}$ & 440.0000 & 440.0000 & 229.0000 & 229.0000 & $\mathrm{MPa}$ \\
\hline Threshold $\left(\mathrm{K}_{\text {critrical }}\right)$ & $\mathrm{K}_{\text {critrical }}$ & 93.7000 & 93.7000 & 93.7000 & 93.7000 & $\mathrm{MPa} \sqrt{\mathrm{m}}$ \\
\hline Assumed Crack/Wall Ratio & $a / \mathrm{W}$ & 0.0000 & 0.0000 & 0.0000 & 0.0000 & $\mathrm{none}$ \\
\hline Corresponding Geometric Factor & $\mathrm{f}(a / \mathrm{W})$ & $<<1.0000$ & $<<1.0000$ & $<<1.0000$ & $<<1.0000$ & $\mathrm{none}$ \\
\hline Critical Flaw Size & $a_{\text {critical }}$ & 2.1564 & 2.1564 & 7.0570 & 7.0570 & $\mathrm{~cm}$ \\
\hline
\end{tabular}




\section{THE GEOMETRIC STRESS CONCENTRATION FACTOR}

The stress intensity factor is equivalent to the product of the applied stress $(\sigma)$, the thickness of the material $(\mathrm{W})$, and the geometric stress concentration factor:

$$
K=\sigma W^{1 / 2} f(a / W)
$$

Geometric stress concentration factors for three common flat-plate geometries with throughthickness cracks, including the (1) three-point bend specimen, (2) compact tension specimen, and (3) arc-shaped specimen, are given below [Thornton \& Colangelo 1985, Figures 9-6, 9-8, Equations 9-11, p. 272-275].

Three-point bend specimen (Figure 5a):

$$
f(a / W)=\frac{3(a / W)^{1 / 2}\left\{1.99-(a / W)(1-(a / W))\left(2.15-3.93(a / W)+2.7(a / W)^{2}\right)\right\}}{2(1+2(a / W))(1-(a / W))^{3 / 2}}
$$

Compact tension specimen (Figure 5b):

$$
f(a / W)=\frac{(2+(a / W))\left\{0.866+4.64(a / W)-13.32(a / W)^{2}+14.72(a / W)^{3}-5.6(a / W)^{4}\right\}}{(1-(a / W))^{3 / 2}}
$$

Arc-shaped specimen (Figure 5c):

$$
f(a / W)=\frac{(a / W)^{1 / 2}\left\{3.74-6.30(a / W)+6.32(a / W)^{2}-2.43(a / W)^{3}\right\}}{(1-(a / W))^{3 / 2}}
$$

In regard to the three-point bend specimen, there are several "bend specimens" that are commonly used in testing. The three-point bend specimen is the most common and is represented by the formulation given above, multiplied by the factor $(\mathrm{S} / \mathrm{W})$, which is the span between the applied forces, divided by the sample thickness. Applicability of these simple fracture mechanics models requires that the crack length $(a)$, ligament of specimen $(W-a)$, and specimen thickness $(B)$, satisfy the following criteria:

$$
\begin{aligned}
& a \geq 2.5\left(\frac{K_{I C}}{\sigma_{Y S}}\right)^{2} \\
& b \geq 2.5\left(\frac{K_{I C}}{\sigma_{Y S}}\right)^{2} \\
& B \geq 2.5\left(\frac{K_{I C}}{\sigma_{Y S}}\right)^{2}
\end{aligned}
$$


Farmer, Kramer \& Williams, Fatigue Life Prediction for Steels in Pulsating Irradiated Systems, LLNL-TR-554731, Lawrence Livermore National Laboratory, Livermore, California 94550
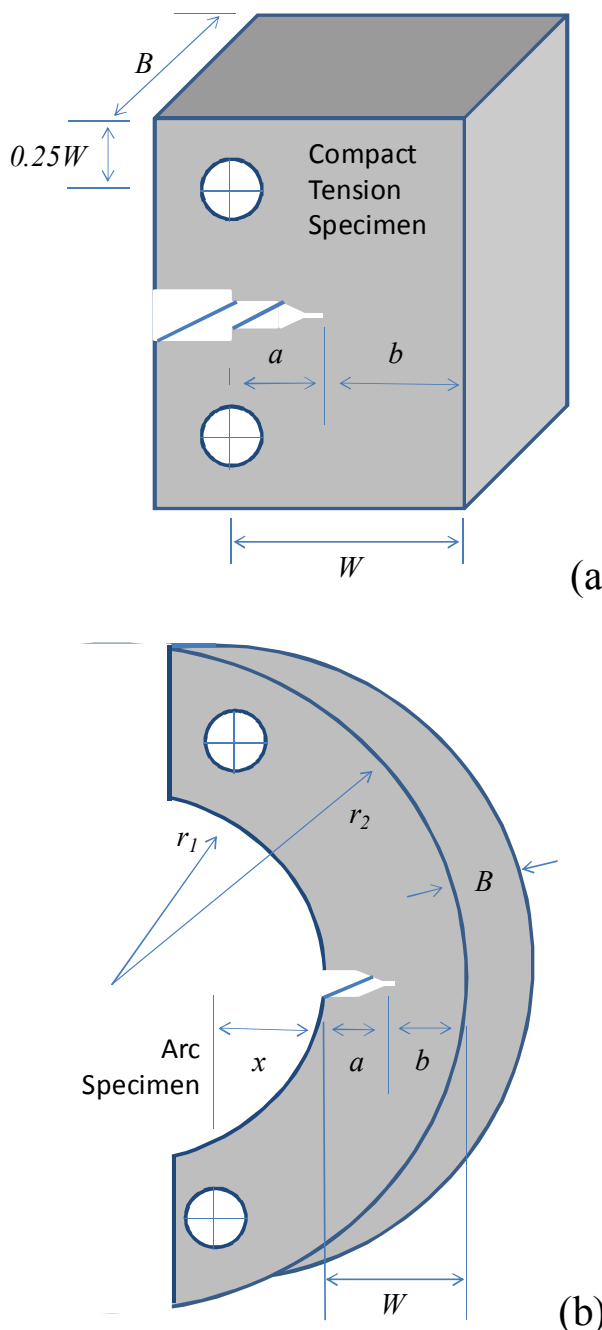

(a)

(b)

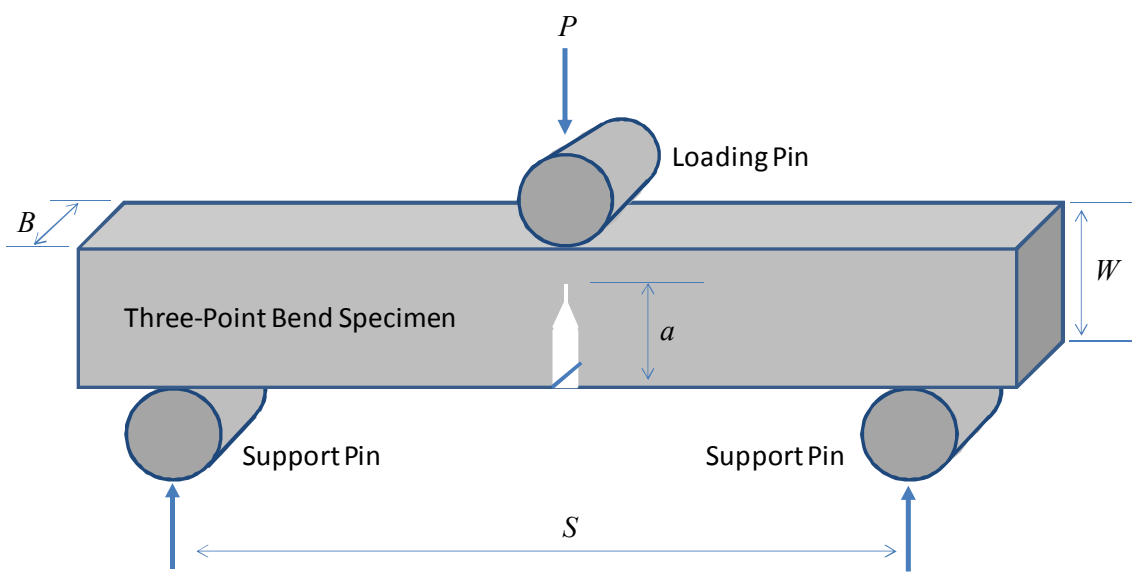

(c)

Figure 5 - Three common sample geometries used as the basis for calculating stress concentration factors, including the (a) three-point bend specimen, (b) compact tension specimen and (c) arc-shaped specimen, 


\section{MEAN AND ALTERNATING STRESSES ENCOUNTERED DURING FATIGUE}

Fatigue is a failure mode whereby cracks form during the application of repeated cyclic stresses [Thornton \& Colangelo 1985, p. 295]. The strain range $(\Delta \varepsilon)$ is defined in terms of the minimum and maximum strains ( $\varepsilon_{\min }$ and $\varepsilon_{\max }$ ) during a fatigue cycle, and the stress range $(\Delta \sigma)$ is defined in terms of the corresponding minimum and maximum stresses $\left(\sigma_{\min }\right.$ and $\left.\sigma_{\max }\right)$.

$$
\begin{aligned}
& \Delta \varepsilon=\varepsilon_{\max }-\varepsilon_{\min } \\
& \Delta \sigma=\sigma_{\max }-\sigma_{\min }
\end{aligned}
$$

Usually, as the strain and stress amplitudes are increased, the number of fatigue cycles to failure decreases, as shown in Figures 6a and 6b [Gaganidze et al. 2011]. Fitting a simple power law expression to this data:

$$
N_{f}=2648 \times(\Delta \varepsilon)^{-3.206}
$$

The mean and alternating strain and stress that are useful quantities in fatigue analysis are also defined in terms of the maximum and minimum applied stress.

$$
\begin{gathered}
\varepsilon_{m}=\frac{\varepsilon_{\max }+\varepsilon_{\min }}{2} \\
\varepsilon_{a}=\frac{\varepsilon_{\max }-\varepsilon_{\min }}{2}
\end{gathered}
$$

The alternating and mean stresses, and the stress ratio, are defined as the respective maximum and minimum levels:

$$
\begin{aligned}
& \sigma_{m}=\frac{\sigma_{\text {max }}+\sigma_{\min }}{2} \\
& \sigma_{a}=\frac{\sigma_{\max }-\sigma_{\min }}{2} \\
& R=\frac{\sigma_{\min }}{\sigma_{\max }}
\end{aligned}
$$


Farmer, Kramer \& Williams, Fatigue Life Prediction for Steels in Pulsating Irradiated Systems, LLNL-TR-554731, Lawrence Livermore National Laboratory, Livermore, California 94550

\section{Fatigue Cycles to Failure vs. Strain Range EUROFER97 at $550^{\circ} \mathrm{C}$}

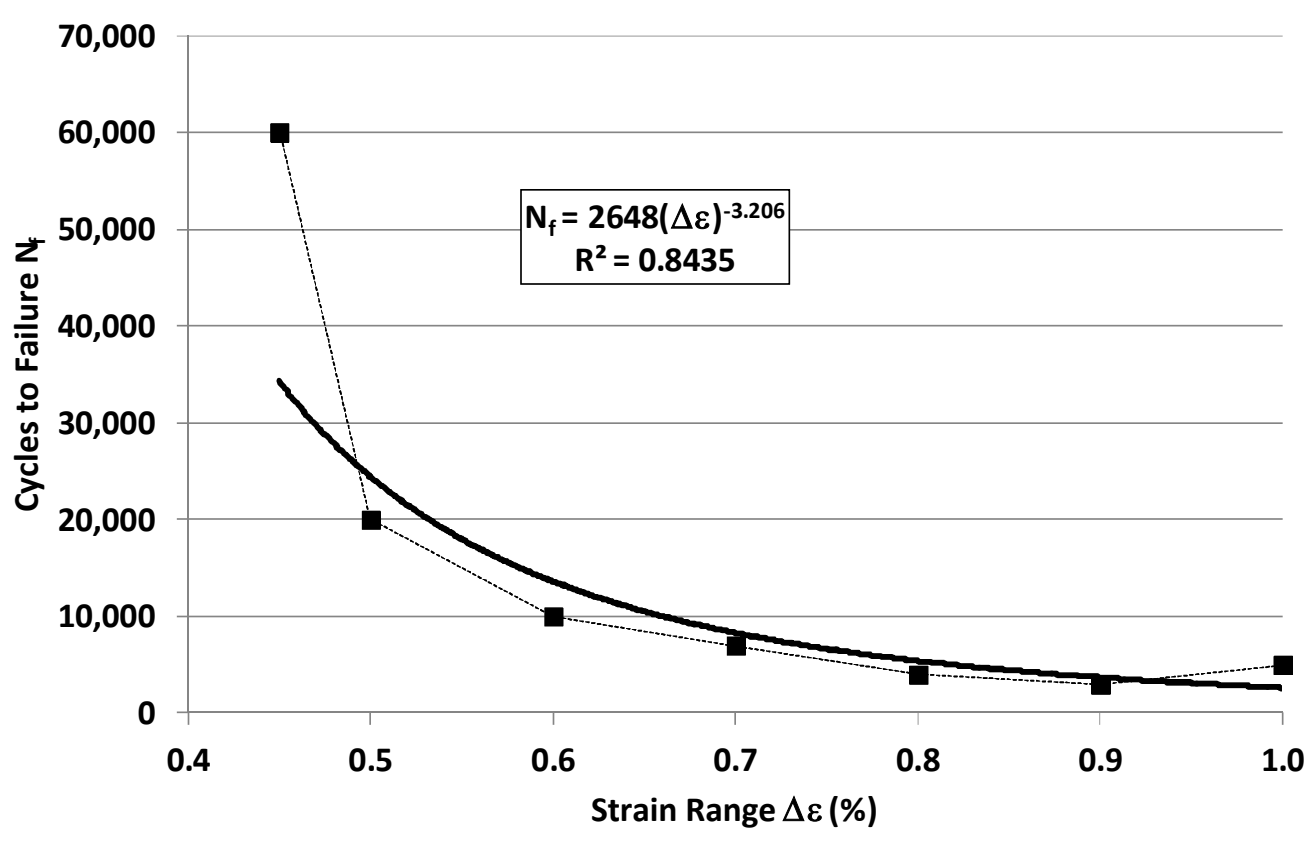

\section{Fatigue Cycles to Failure vs. Strain Range} EUROFER97 at $550^{\circ} \mathrm{C}$

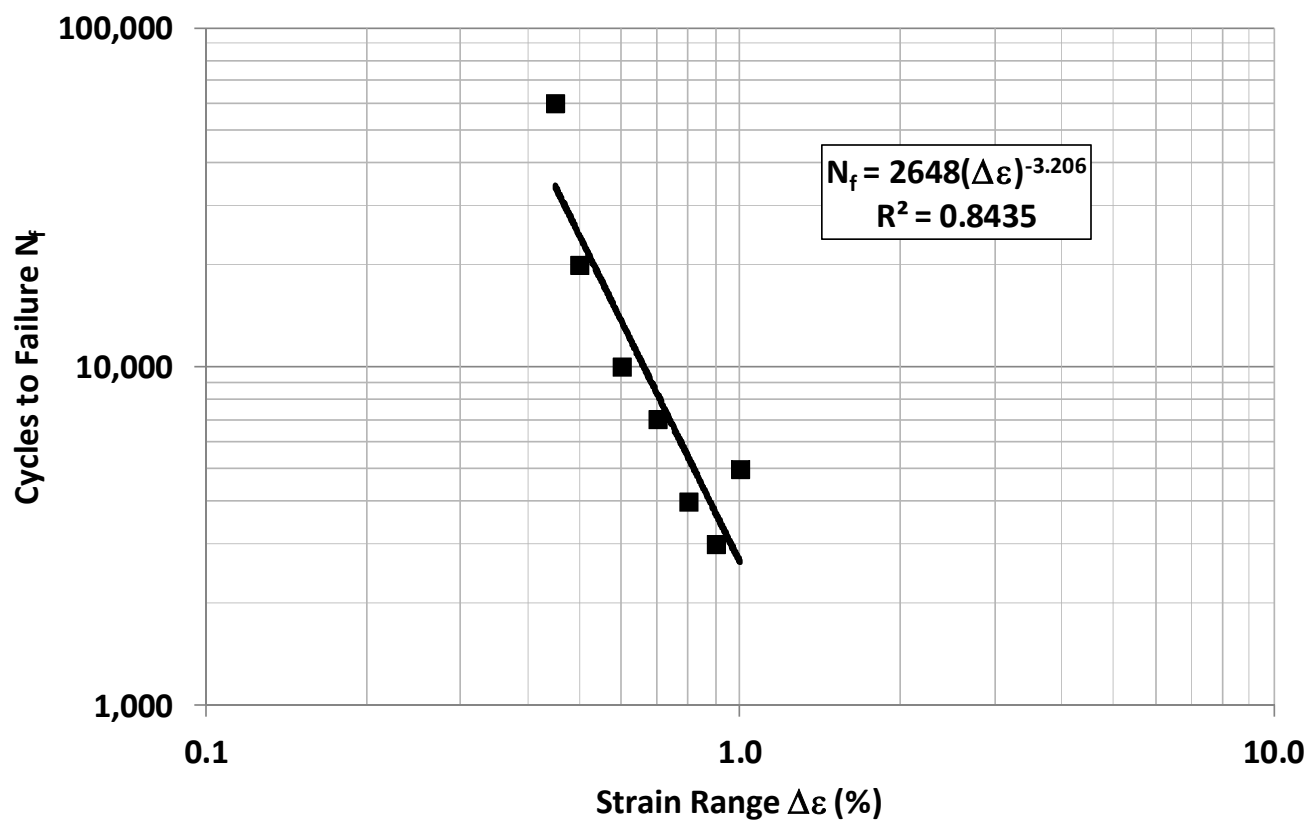

Figure 6 - Fatigue cycles to failure as a function of the strain range, for un-irradiated EUROFER97 at $550^{\circ} \mathrm{C}$ [Gaganidze et al. 2011]. Note that this curve is for the low-cycle fatigue regime. 


\section{THE INITIATION AND PROPAGATION OF FATIGUE CRACKS}

The initiation and propagation of fatigue cracks progress through three distinct phases or regions Region I, Region II and Region III [Fine et al. 1997]:

Region I: The initiation region, where the fatigue crack initiates at the threshold stress intensity factor range $\left(\Delta K_{t h}\right)$, with a rapid increase in crack propagation rate with relatively small increments in the stress intensity range $(\Delta K)$, eventually entering Region II where the Paris relationship is obeyed. This region is dominated by "non-continuum mechanisms" with large influence of microstructure, mean stress and environment.

Region II: The mid-region where the cracks propagate in accordance with the classical Paris relationship, which predicts that $\log (d a / d N)$ is proportional to $\log (\Delta K)$. This region is dominated by "continuum mechanisms" with relatively little influence of microstructure, mean stress, dilute environments, and thickness.

Region III: A region where propagating cracks begin accelerating rapidly to failure, at a value of the stress intensity factor range corresponding to the critical stress intensity factor $\left(K_{C}\right)$.

These three regions (initiation, propagation, and failure) can be modeled with the empirical McEvily-Foreman Equation [Fine et al. 1997]:

$$
\frac{d a}{d N}=C^{\prime}\left(\Delta K^{2}-\Delta K_{0}^{2}\right) \frac{1+\Delta K}{K_{C}-K_{\max }}
$$

While this expression appears in ASM publications, the authors were unable to find this in ASTM E647, ASTM E739, nor ASTM E1823. The fatigue crack propagation rate $(d a / d N)$ is proportional to the stress intensity factor range $(\Delta \mathrm{K})$, which is the difference in the maximum and minimum stress intensity factors, raised to the (n) power [Thornton \& Colangelo 1985, p. 308; Mitchell, 1997, 227-249]:

$$
\frac{d a}{d N}=C(\Delta K)^{n}
$$

The stress intensity factor range $(\Delta K)$ used in fatigue crack propagation models is defined as the difference between the maximum and minimum applied stress, during the fatigue cycle:

$$
\Delta K=K_{\max }-K_{\min }
$$

The maximum and minimum stress intensity factors are calculated from the maximum and minimum stress, respectively.

$$
K_{\text {max }}=\sigma_{\text {max }} W^{1 / 2} f(a / W)
$$


$K_{\min }=\sigma_{\min } W^{1 / 2} f(a / W)$

It should be noted that the classical Paris relationship can be derived theoretically, with the constant $(C)$ being shown to be proportional to yet another constant, the shear modulus $(\mu)$, the yield stress $\left(\sigma_{Y S}\right)$, and the energy release during crack propagation $(U)$ :

$\frac{d a}{d N}=A \frac{(\Delta K)^{n}}{\mu \sigma_{Y S}^{2} U}$

The Weertman theory predicts two limits for the value $\mathrm{n}(2<n<4)$. Within this limit $(n<4)$, the relationship between the plastic work per unit area required to advance a fatigue crack $(U)$ and the stress intensity factor range $(\Delta K)$ is:

$U=\beta(\Delta K)^{4-n}$

Experimentally, the value of the parameter $(n)$ has been determined to lie between 2 and 8 . More specifically, based upon the work of Izumi $(n \approx 3.7)$ and based upon the work of Frest $(n \approx 3.94)$.

The number of fatigue cycles at failure is calculated by rearranging the Paris expression crack propagation rate and integrating:

$$
N_{f}=\int_{0}^{N_{f}} d N=\int_{a_{0}}^{a_{c}} \frac{d a}{C(\Delta K)^{n}}
$$

As discussed in the literature [Thornton \& Colangelo 1985, p. 310], the stress intensity factor for a shallow edge crack in many types of specimens is given by the formula:

$$
K_{I}=1.12 \sigma(\pi a)^{1 / 2} f(a / W)
$$

Note that $(f(a / W))$ is a generalized function of the independent dimensionless variable $(a / W)$.

Please see equation 9-24 on page 310 of the cited reference. Integration of the expression for the number of fatigue cycles at failure $\left(N_{f}\right)$ with this form of the stress intensity factor yields:

$$
N_{f}=\frac{2}{(n-2) C(1.12)^{n}(\sigma)^{n} f(a / W)^{n}(\pi)^{n}}\left[\frac{1}{a_{0}^{(n-2) / 2}}-\frac{1}{a_{c}^{(n-2) / 2}}\right]
$$

The differences are probably due to inconsistencies in nomenclature used by different authors in the published literature. I double checked this equation, which is found on page 311 of the cited reference. I changed the parameter " $m$ " to " $n$ " and " $Y=f(a / W)$ " simply to " $f(a / W)$ ", but will cite it exactly as it appears in the published text: 
This expression for the fatigue life has the obvious constraint on the material constant $m(m \neq 2)$. Reasonable values of the materials constants $(m)$ and $(C)$ are needed for evaluation of $\left(N_{f}\right)$, and can be estimated from published experimental data. These parameters are determined by fitting experimental data to the following linear equation.

From further inspection of the integrated expression for the fatigue cycles at failure $\left(N_{f}\right)$, it is clear that values for the initial flaw size $\left(a_{0}\right)$, the critical flaw size $\left(a_{c}\right)$, and the geometric stress concentration factor must also be known, or estimated. As previously discussed, the value of the initial flaw size $\left(a_{0}\right)$ is usually determined from non-destructive evaluation (NDE) of the finished part, and for the sake of the calculations shown here, is assumed to be 100 microns. A value of the critical flaw size $\left(a_{c}\right)$ must then be estimated, which requires knowledge of the critical stress intensity factor $\left(K_{C}\right)$ and the yield stress $\left(\sigma_{Y S}\right)$. Recall that the plane stress fracture toughness is defined as [Thornton \& Colangelo 1985, Equation 9-9, p. 268] as:

$K_{C}=\sigma_{c} \sqrt{\pi a_{c}} f(a / W)$

Note that for the case for very small crack lengths in comparison to the specimen thickness, $\mathrm{f}(\mathrm{a} / \mathrm{w})$ is unity, and this expression is identical to that derived from Griffith critera, for a small elliptical crack in a very large (infinite plate). By rearranging this expression, and substituting the yield stress for the critical stress, the following well known expression for the critical flaw size is derived.

$a_{c} \leq \frac{1}{\pi}\left(\frac{K_{C}}{\sigma_{Y S} f(a / W)}\right)^{2}$

There is a crack tip plastic zone that is beyond yield. It should be further noted that for relatively small values of the dimensionless geometric parameter $(a / W \rightarrow 0)$, the geometric correction factor approaches unity $(f(a / W) \rightarrow 1)$. A nice compilation of experimental data useful for this purpose can be found in the primary and original references on fatigue [Thornton \& Colangelo 1985, Figure 9-39, p. 311; P. C. Paris 1964, p. 107].

$\log \left(\frac{d a}{d N}\right)=n \log (\Delta K)+\log C$

Parameter values for steel at modest temperature can be deduced from experimental determinations of the growth rate $(d a / d N)$ as a function of stress intensity factor range $(\Delta K)$ :

$n=4$

$C=5.9704 \times 10^{-10}$ 
Subsequent studies over the past three decades, however, have shown that $\mathrm{n}$ can range from 2 to 4 for most metals in the absence of a corrosive environment. The aforementioned empirical expression is functionally similar to the damage accumulation model:

$$
\frac{d a}{d N}=\frac{C}{\left(\sigma_{Y S} \varepsilon_{f} E\right)^{1 / \beta}(l)^{1 /(1-\beta)}(\Delta K)^{2 / \beta}}
$$

Note that the parameter $(\beta)$ is the Coffin-Manson exponent for low cycle fatigue. The integrated expression for the fatigue cycles to failure $\left(N_{f}\right)$ as a function of applied stress $(\sigma)$ was evaluated with model parameters believed to be representative of those for steels such as EUROFER97 and HT-9, over a wide range of applied stress. The results are shown in Figure 7, and clearly illustrate the rapid drop in fatigue life with increasing stress level. The operation of an irradiated system for 1 year with $85 \%$ availability, and a repetition rate of $10 \mathrm{~Hz}$, will subject materials to $268,056,000$ cycles, which may be possible with a maximum cyclic stress of $2 \mathrm{MPa}$.

\section{Parameters Values in Model Representative of EUROFER97 \& HT-9 Steels}

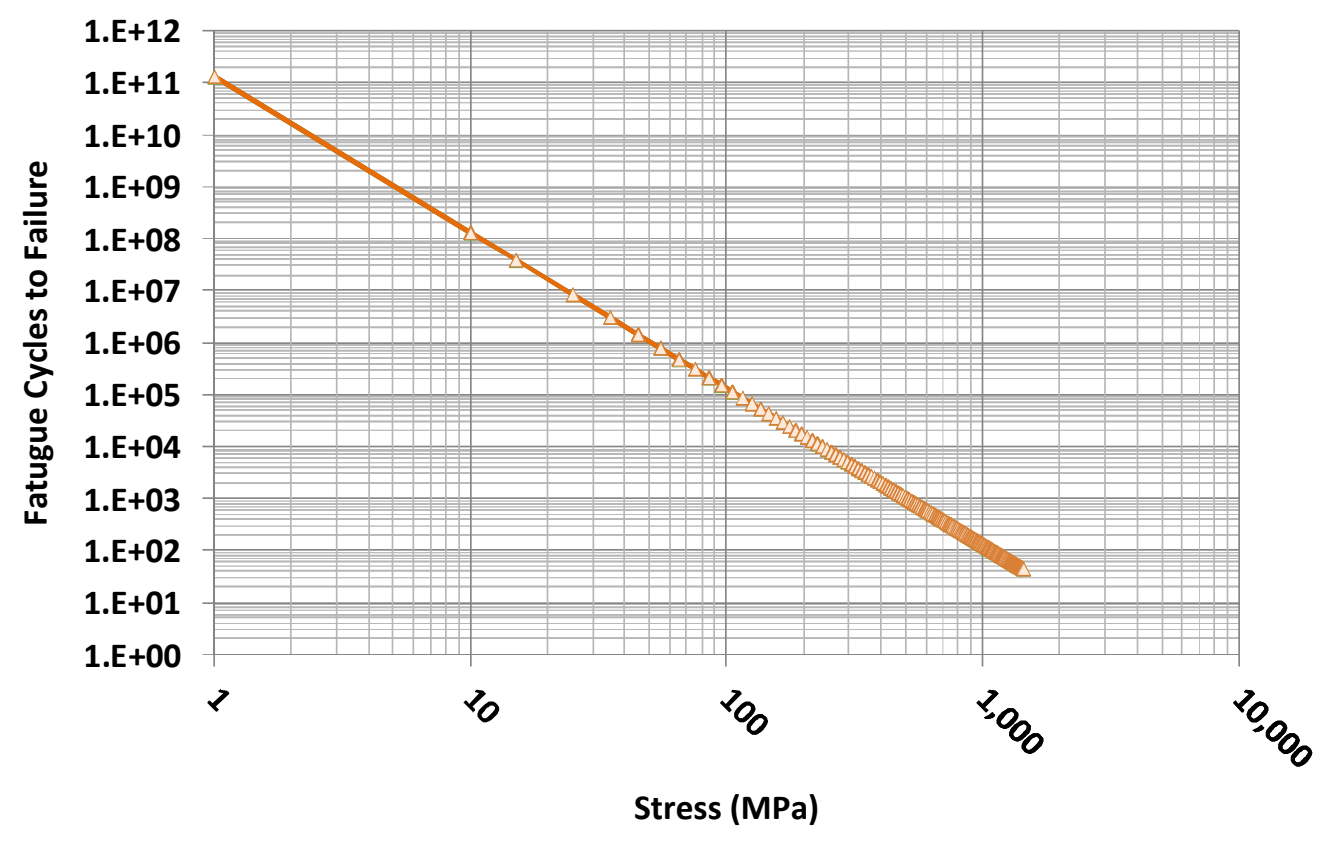

Figure 7 - Predicted fatigue cycles to failure $\left(N_{f}\right)$ as a function of applied stress $(\sigma)$, with model parameters believed to be representative of those for steels such as EUROFER97 and HT-9.

In regard to Figure 7, the data has been extrapolated well beyond low cycle fatigue regime. Note that the Coffin-Manson exponent is for low cycle fatigue. The authors do not believe that this extrapolation should be used for quantitative prediction, but can be used to illustrate qualitatively how few cycles can be endured as the alternating stress amplitude is increased. 
In general, the ASME Boiler and Pressure Vessel Code derives fatigue curves as follows: the fatigue curves are obtained from uniaxial strain cycling data in which the imposed strain amplitude (half range) is multiplied by the elastic modulus to put the values in stress units. A best fit to the experimental data is obtained by applying the method of least squares to the logarithms of the stress values. The curves are adjusted where necessary to include the maximum effect of mean stress. The design stress intensity values are obtained from the best fit curve by applying a factor of 2 on stress or a factor of 20 on cycles, whichever is more conservative at each point.

The effects of surface flaws on fatigue are reflected in other commonly used parameters. For example, the fatigue notch sensitivity $(q)$ is defined in ASTM E1823 as a measure of the degree of agreement between the fatigue notch factor $\left(K_{f}\right)$ and the theoretical stress concentration factor $\left(K_{t}\right)$, as shown below:

$$
q=\frac{K_{f}-1}{K_{t}-1}
$$

\section{EFFECT OF APPLIED STATIC STRESSES ON FATIGUE}

\section{Formulae Used for the Superposition of Static and Alternating Stresses}

In many engineering systems, the combined effects of applied static stresses, and cyclic stresses on fatigue must be accounted for. One accepted engineering approach that has evolved for treating such problems involves application of the well-known Goodman equation [Goodman 1899; Collins 1993; ASM Metals Handbook 1997; Wikipedia 2012; and other sources]:

$$
\sigma_{a}=\sigma_{C R} \times\left(1-\frac{\sigma_{m}}{\sigma_{U T S}}\right)
$$

In this expression $\left(\sigma_{a}\right)$ is the alternating stress, $\left(\sigma_{C R}\right)$ is the fatigue limit for the material, $\left(\sigma_{m}\right)$ is the mean stress, and $\sigma_{U T S}$ is the ultimate tensile strength. It appears simply be a method of weighting the static and dynamic stresses of a system, realizing that at zero static stress, failure is dominated by the fatigue limit, and at zero dynamic (differential, alternating, etc.) stress, failure is dominated by the ultimate tensile strength. A straight line is drawn between the two, with the hypothesis that as a system moves between the two limits, it does so along the straight line defined with the Goodman equation. In addition to the Goodman equation, other conventions including the Soderberg and Gerber equation have also been employed, and are summarized below 
Soderberg - conservative for most cases

$$
\frac{\sigma_{a}}{\sigma_{C R}}+\frac{\sigma_{m}}{\sigma_{Y S}}=1
$$

Goodman - conservative for ductile metals - good for brittle metals

$$
\frac{\sigma_{a}}{\sigma_{C R}}+\frac{\sigma_{m}}{\sigma_{U T S}}=1
$$

Gerber-good for ductile metals

$$
\frac{\sigma_{a}}{\sigma_{C R}}+\left(\frac{\sigma_{m}}{\sigma_{U T S}}\right)^{2}=1
$$

The Soderberg, Goodman and Gerber equations illustrated graphically in Figure 8. The fatigue limit plotted on the alternating stress axis $\left(\sigma_{C R}\right)$ and corresponds to the number of fatigue cycles at failure $\left(N_{f}\right)$. The area underneath these curves is a quantification of the ranges of mean and alternating stress where a material can be operated without fatigue failure. The larger the area, the greater the operating margin. Figure 8 shows very clearly that based upon this criterion, the most conservative predictions are made with the Soderberg equation, and that the least conservative predictions are made with the Gerber equation. The Goodman equation, or a modified form of it, is considered a reasonable compromise between the two extremes.

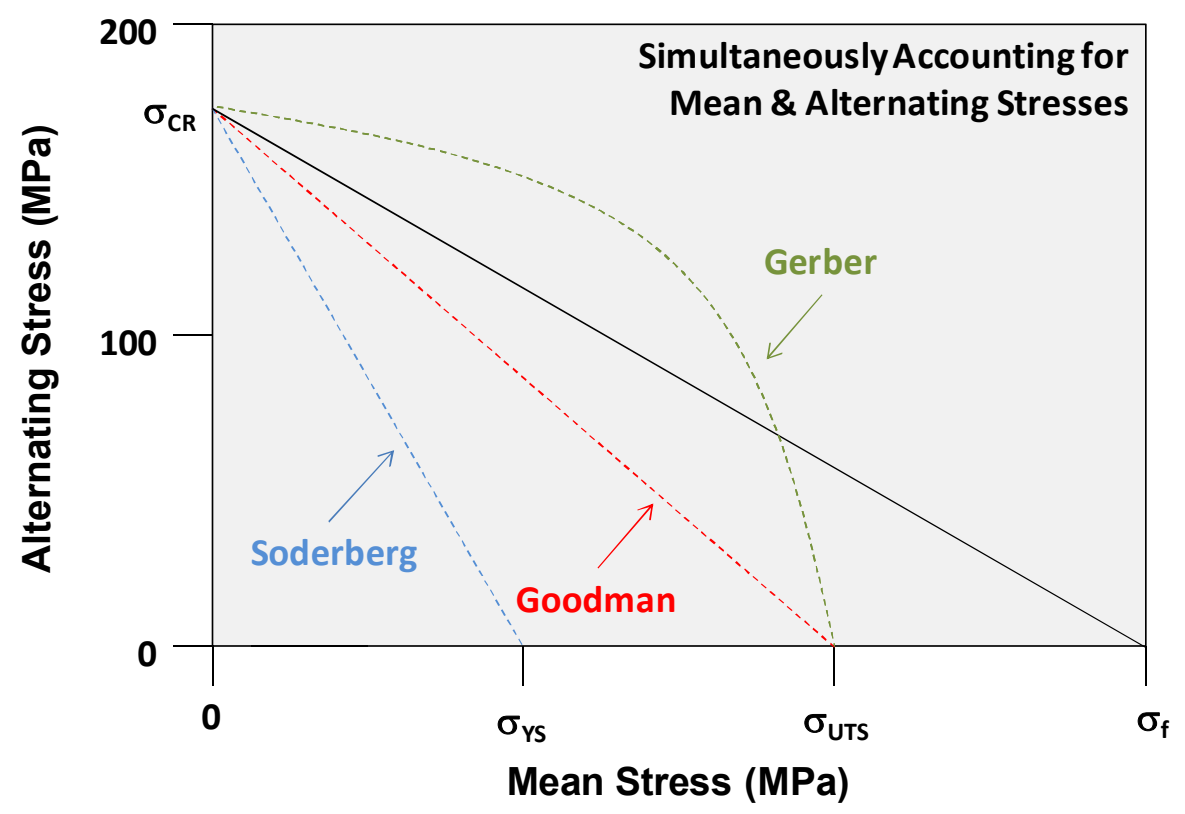

Figure 8 - Graphical comparison of the Soderberg, Goodman and Gerber equations for the combination of mean and alternating stresses. 
The generic pulsating stress anticipated in one particular design of the hypothetical, pulsating, irradiated system under consideration is shown in Figure 9, where the frequency $(f)$ is the frequency of the applied cyclic stress, and expected to be somewhere between 10 and $20 \mathrm{~Hz}$. In this case, the constant stress in the absence of the pulsation $\left(\sigma_{\text {static }}\right)$ is approximately $70 \mathrm{MPa}$. The stress pulse is assumed to have a width of approximately 8 nanoseconds, and a height of approximately $300 \mathrm{MPa}\left(\sigma_{\text {pulse }}\right)$. This asymmetric pulse train can be decomposed into an alternating stress $\left(\sigma_{a l}\right)$ of amplitude of $\pm 115 \mathrm{MPa}$ centered at the mean stress $\left(\sigma_{m l}\right)$, with a magnitude of approximately $185 \mathrm{MPa}$. If most of the fatigue damage is done during the transition from one stress state to the other, the approximation shown in Figure 10 is reasonable. The underlying static stress is illustrated in Figure 11.

The alternating stresses for the hypothetical system can be represented on the relatively conservative Goodman chart, as shown in Figure 12. The alternating stresses for the proposed system can be represented on a classical Goodman chart. In principle, if the mean and alternating stress for the operating system fall below the boundary for safe operation, it should be possible to achieve the number of fatigue cycles corresponding to the fatigue limit used to establish the boundary line. The pulsed stresses under consideration probably result in some fairly extreme strain rates that may in fact render estimates with the Goodman equation non-conservative. In discussions found on Wikipedia and elsewhere describe the alternating stress as being for complete load reversal it is unclear as to whether or not this approach can be used for cyclic loading without symmetrical wave forms for the applied load, and without complete reversal. 


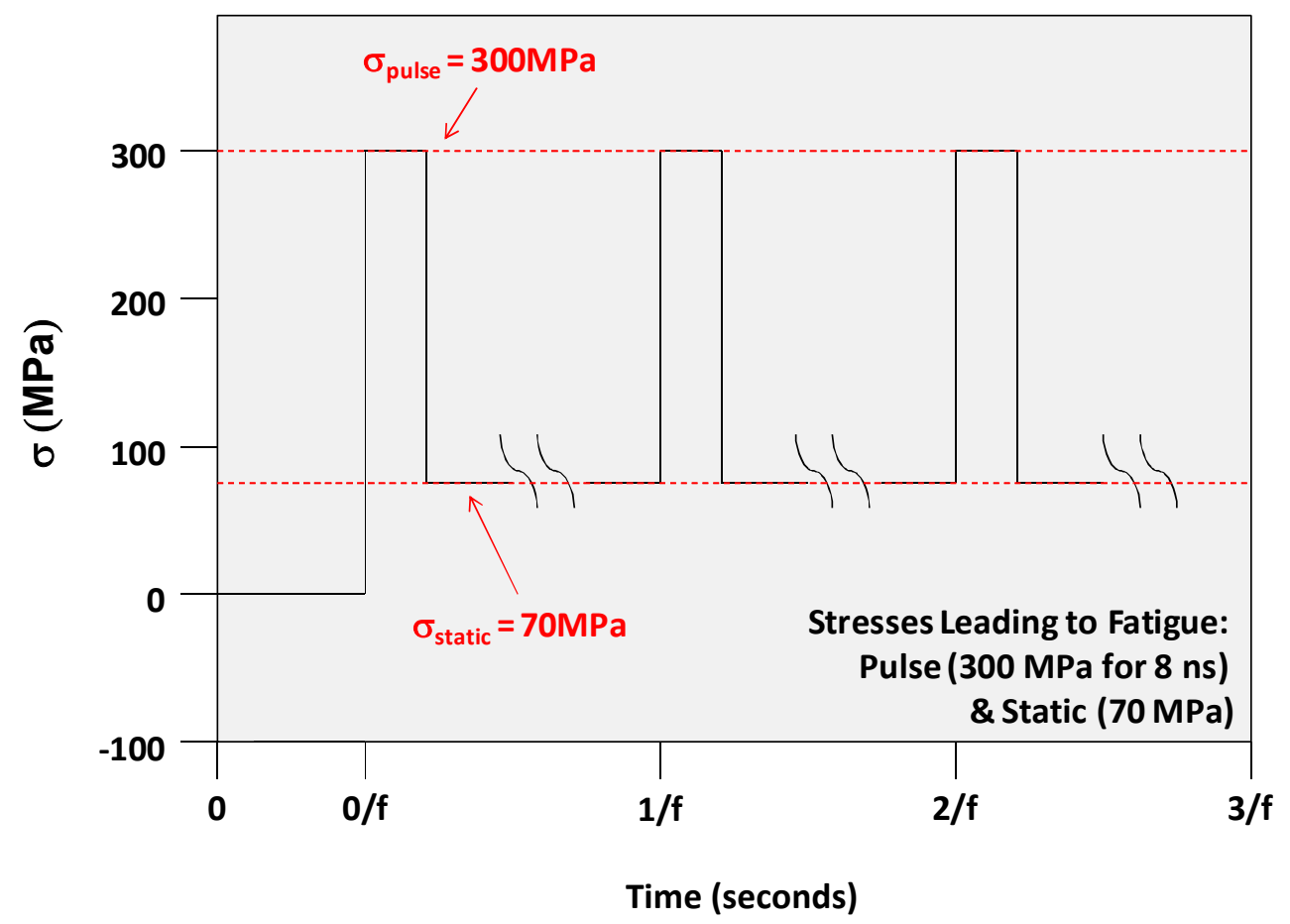

Figure 9 - The pulsating stress anticipated in the design under consideration, where the alternating stress has a frequency (f).

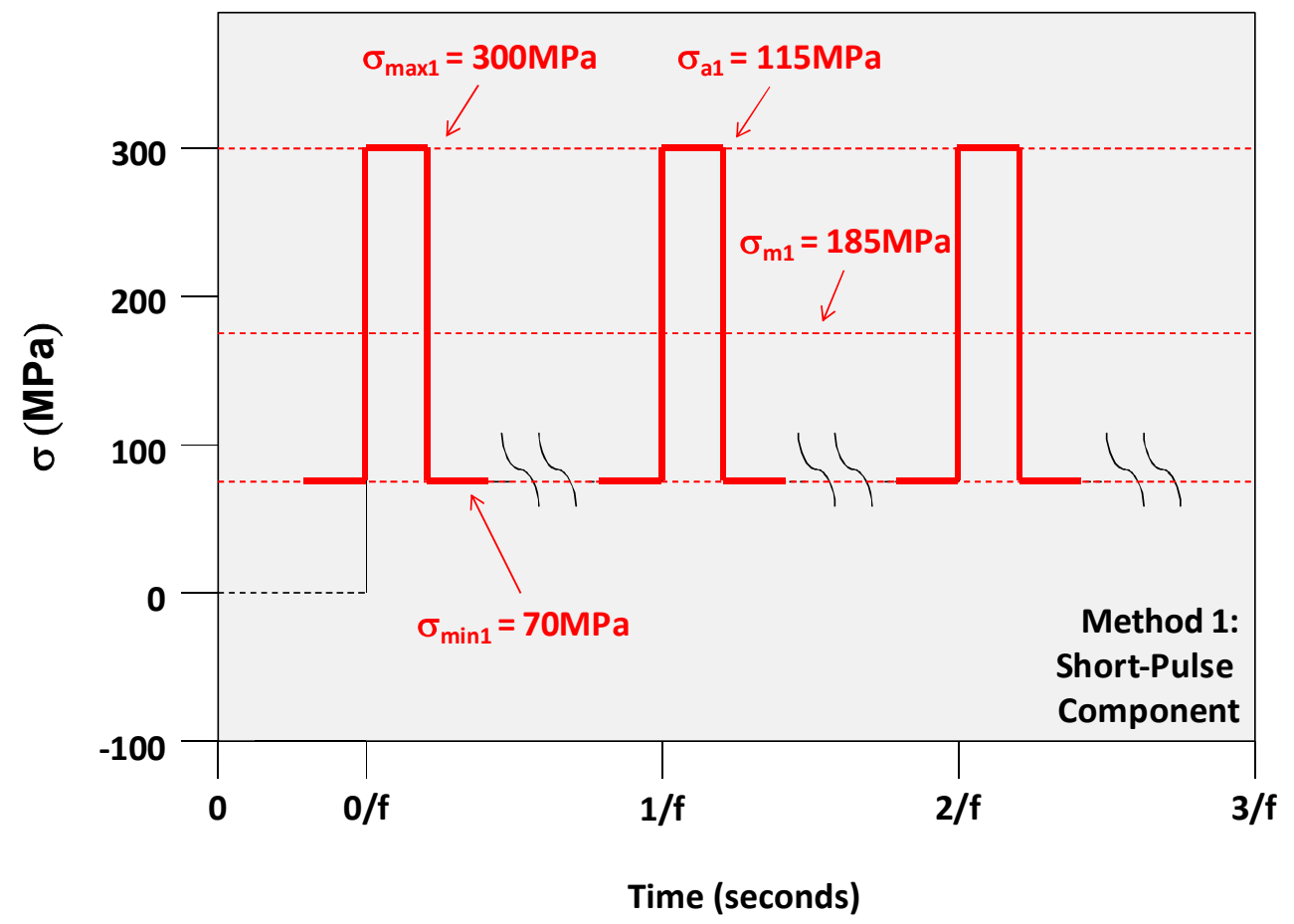

Figure 10 - This asymmetric pulse train can be decomposed into an alternating stress $\left(\sigma_{\mathrm{a} 1}\right)$ with an amplitude of $\pm 115 \mathrm{MPa}$ centered at a mean stress $\left(\sigma_{\mathrm{m} 1}\right)$ of approximately $185 \mathrm{MPa}$. Assuming that most of the fatigue damage is done during the transition from one stress state to the other, such an approximation is considered reasonable. 
Farmer, Kramer \& Williams, Fatigue Life Prediction for Steels in Pulsating Irradiated Systems, LLNL-TR-554731, Lawrence Livermore National Laboratory, Livermore, California 94550

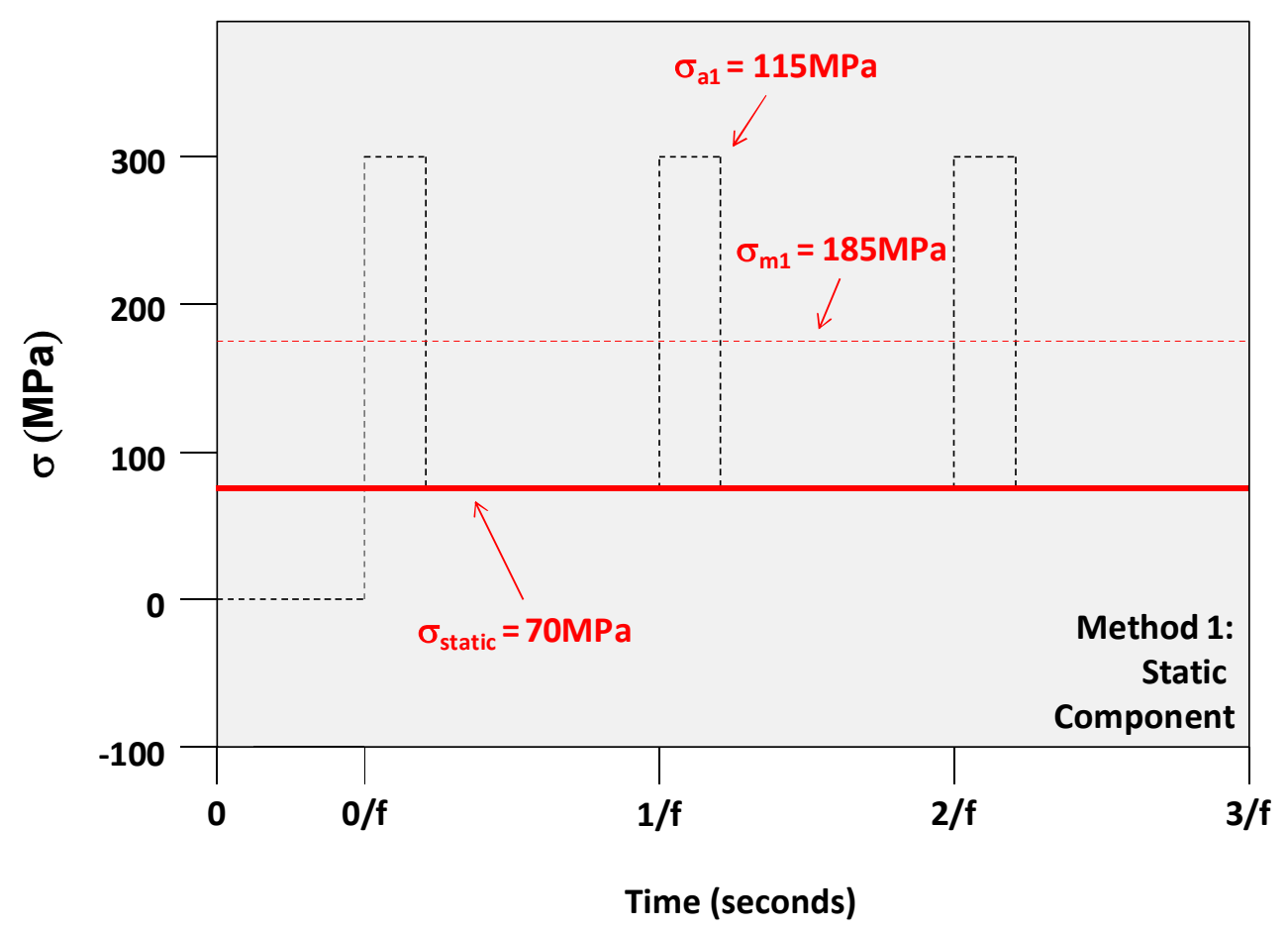

Figure 11 - Static stress in the absence of pulsating stress shown in the previous figure.

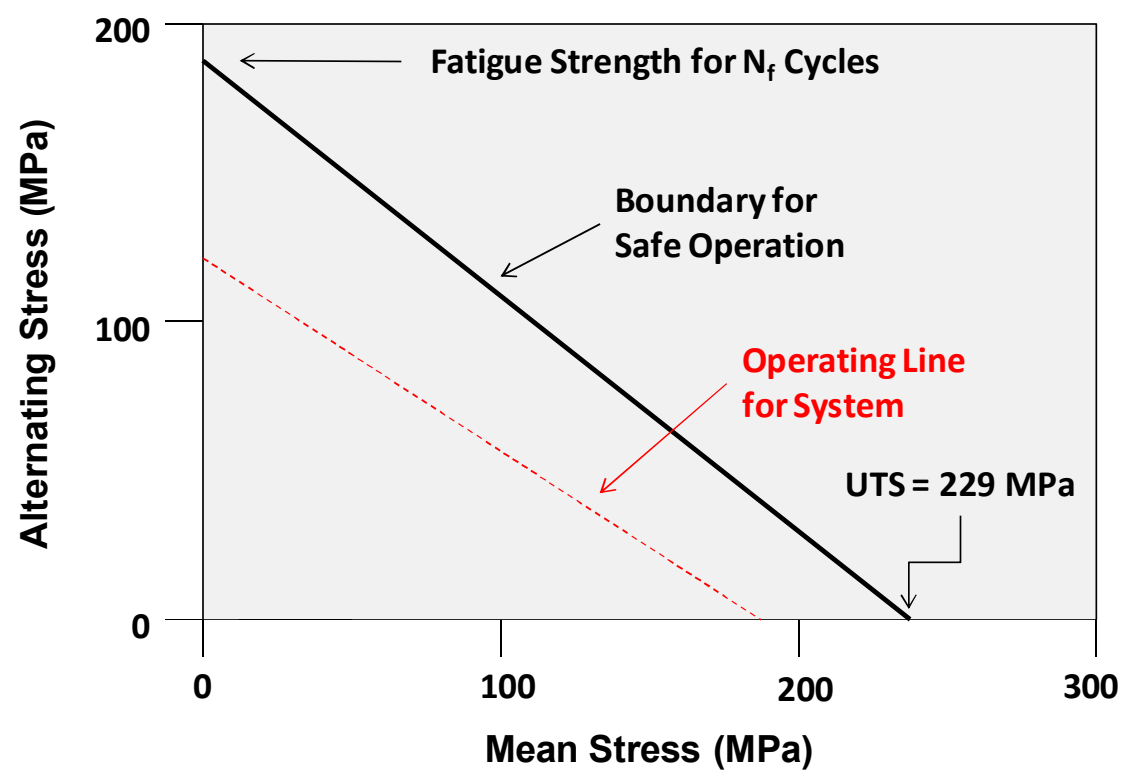

Figure 12 - The alternating stresses for the proposed system can be represented on a classical Goodman chart. In principle, if the mean and alternating stress for the operating system fall below the boundary for safe operation, it should be possible to achieve the number of fatigue cycles corresponding to the fatigue limit used to establish the boundary line. 


\section{GOODMAN REPRESENTATION OF PUBLISHED DATA}

Experimentally, the number of cycles at failure is found to be dependent on the alternating stress. More fatigue cycles can be tolerated at lower levels of alternating stress, as expected. Practically, this can be treated as a cycle-dependent fatigue life, and shown on a Goodman-type diagram as a family of lines, with each line corresponding to a different number of fatigue cycles, or hours of operation. It is noted that for high cycle fatigue, the modified Goodman diagram is preferred, as discussed in the ASME Boiler and Pressure Vessel Code, Section III, Appendix XIV, paragraph XIV-1221.3. As previously discussed, the operation of the hypothetical, pulsating, irradiated system for 1 year with $85 \%$ availability, and a pulse frequency of $10 \mathrm{~Hz}$, will subject materials to $268,056,000$ cycles. The objective of this application of the Goodman approach is to determine the combination of mean static stress, and alternating stress that will enable the system being designed to achieve nearly one-half billion fatigue cycles before failure.

The Goodman equation has been used to evaluate the susceptibility of three FM steels, HT-9, MANET, and EUROFER97, to fatigue in the system under consideration, with the analysis summarized in Figures 13 through 19. These charts show predicted regions of operation where fatigue failure can be avoidable. Each chart shows a family of curves, with each curve representing the limiting combination of mean and alternating stress for fatigue-free operation for the specified period of time (given in hours). As expected, lower alternating stress increases fatigue life. The upper chart is the classical Goodman chart with linear scales, and the lower chart uses logarithmic scales.

The Goodman chart for HT-9 steel at room temperature with irradiation of 15 dpa is shown in Figure 15. Similarly, Figures 16, 17, 18 and 19 represent: MANET at $420^{\circ} \mathrm{C}$ with irradiation of $1.6 \mathrm{dpa}$; EUROFER97 at $300^{\circ} \mathrm{C}$ with irradiation of $2.5 \mathrm{dpa}$; EUROFER97 at $330^{\circ} \mathrm{C}$ with irradiation of $71 \mathrm{dpa}$; and un-irradiated EUROFER97 at $550^{\circ} \mathrm{C}$. Graphical representations of Goodman equation using a more theoretically based equating to estimate the fatigue limit used for the assumed material are shown in Figure 20.

In several of these cases, published "strain range data" has been converted to an "alternating stress amplitude" through multiplication by an effective modulus, which ranges from 193,200 to $207,000 \mathrm{MPa}$ for steels of the type discussed here [Thornton and Colangelo 1985]. Recent publications on fatigue cycling of EUROFER97 within the apparent elastic limits of the material indicate an elastic modulus of approximately 200,000 MPa [Luzginova et al. 2011, Figure 5]. This material was irradiated to a damage level of approximately $2.5 \mathrm{dpa}$. As previously discussed, this is consistent with the ASME Boiler and Pressure Vessel Code, which derives fatigue curves as follows: the fatigue curves are obtained from uniaxial strain cycling data in

which the imposed strain amplitude (half range) is multiplied by the elastic modulus to put the values in stress units. 
Farmer, Kramer \& Williams, Fatigue Life Prediction for Steels in Pulsating Irradiated Systems, LLNL-TR-554731, Lawrence Livermore National Laboratory, Livermore, California 94550

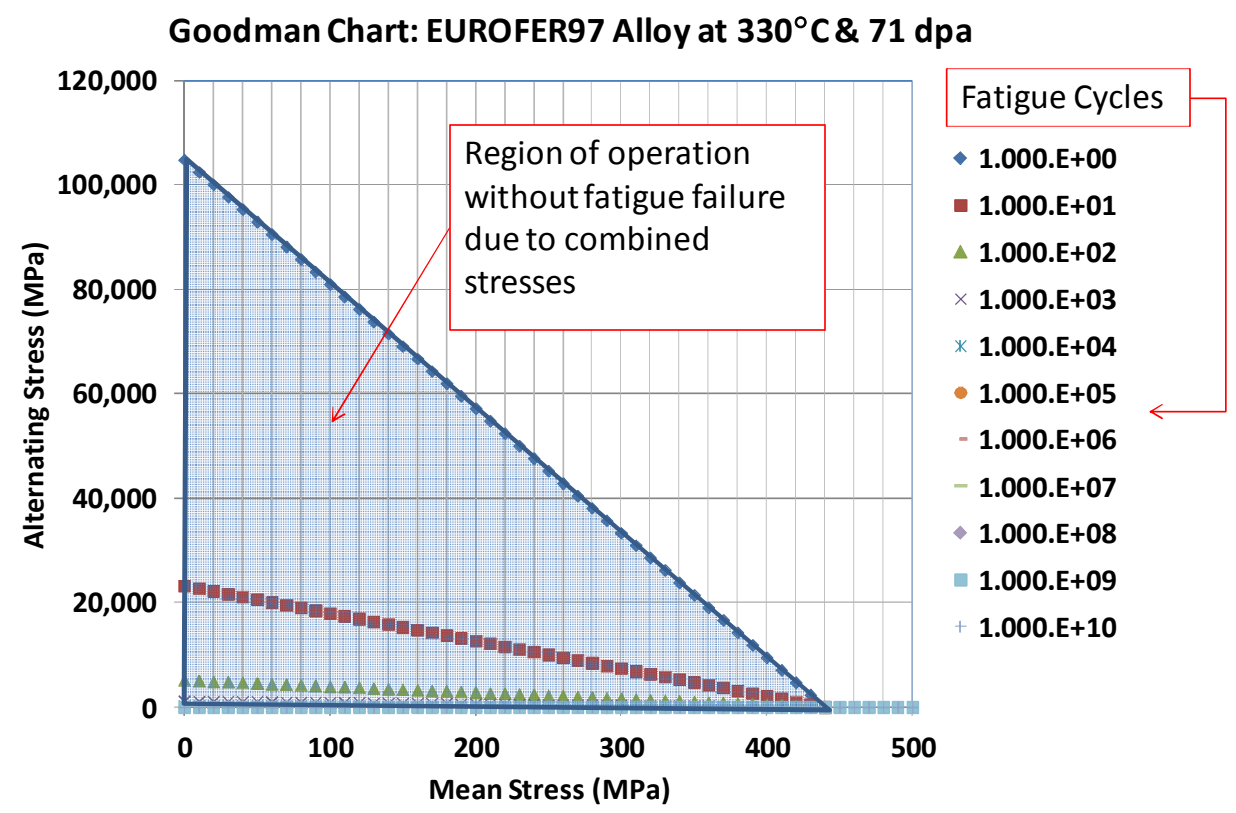

Figure 13 - Classical representation of Goodman chart showing the combined effects of a mean static stress, and an alternating stress, with the shaded region showing a region of operation where, at least conceptually, operation without fatigue failure should be possible.

\section{Goodman Chart: EUROFER97 Alloy at $330^{\circ} \mathrm{C} \& 71 \mathrm{dpa}$}

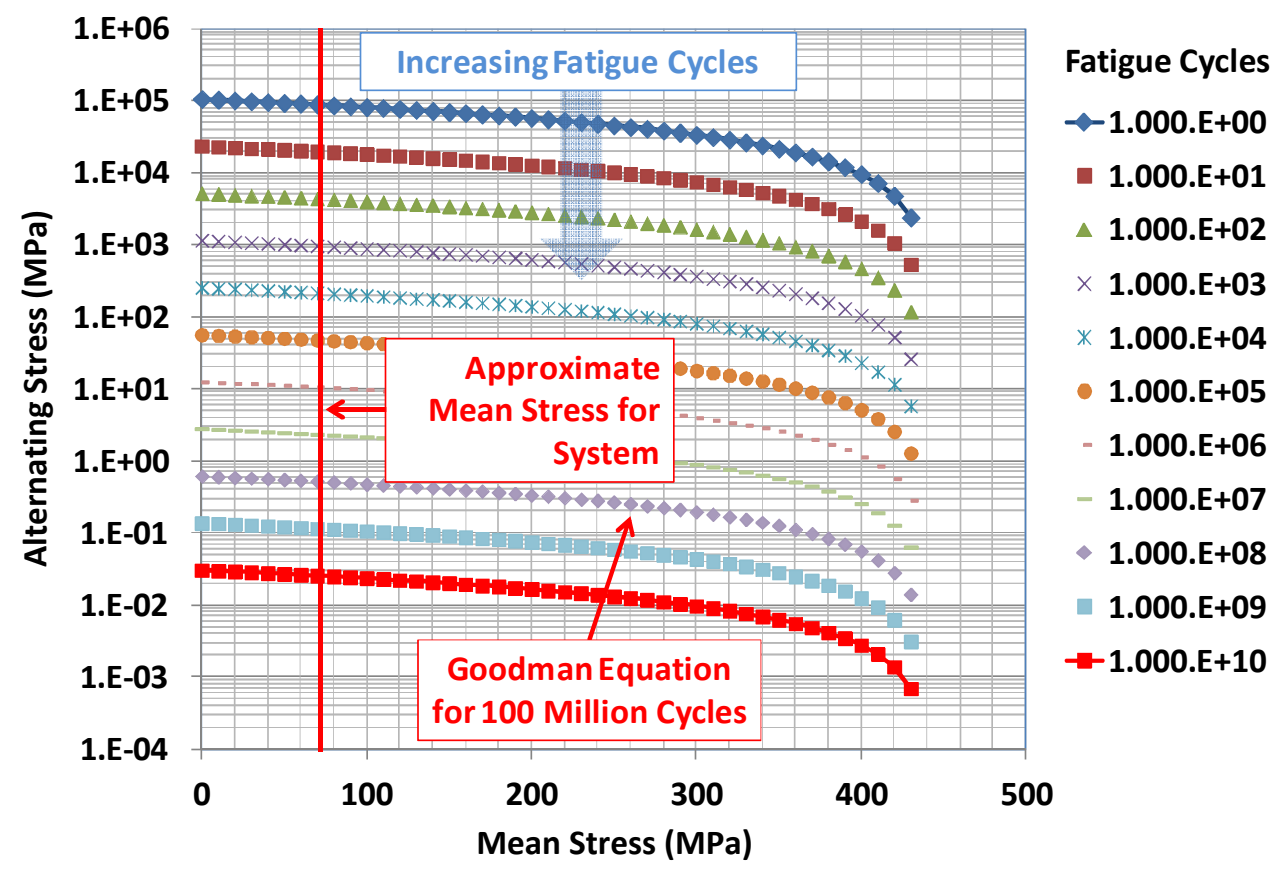

Figure 14 - Goodman chart with logarithmic scales, with assumed $75 \mathrm{MPa}$ static stress shown. The Goodman equation based upon the fatigue limit allowing operation to 100 million cycles is also shown. The allowable alternating stress must be decreased to achieve a long operation periods without fatigue failure. 


\section{Goodman Chart: HT-9 Alloy at Room Temperature \& $15 \mathrm{dpa}$}

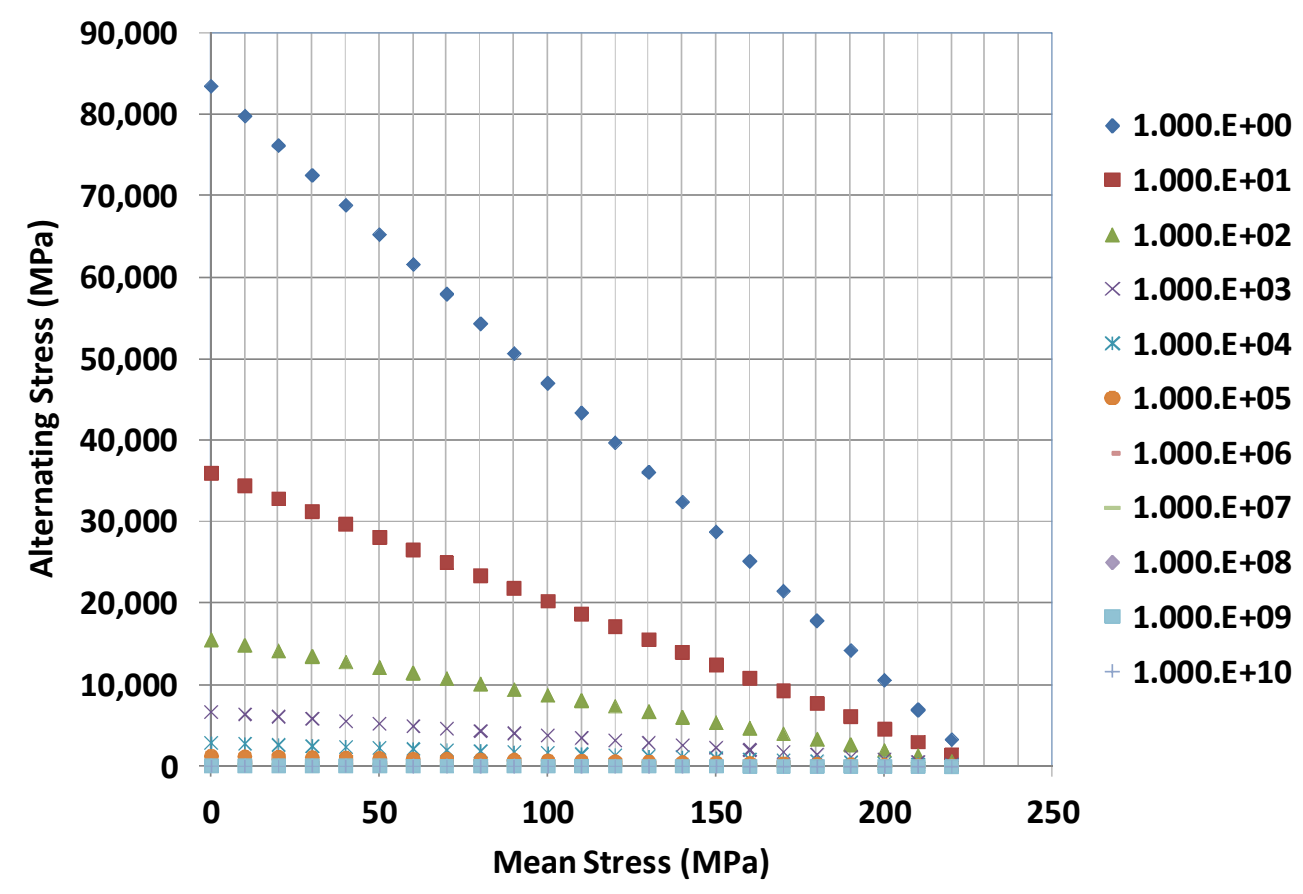

\section{Goodman Chart: HT-9 Alloy at Room Temperature \& 15 dpa}

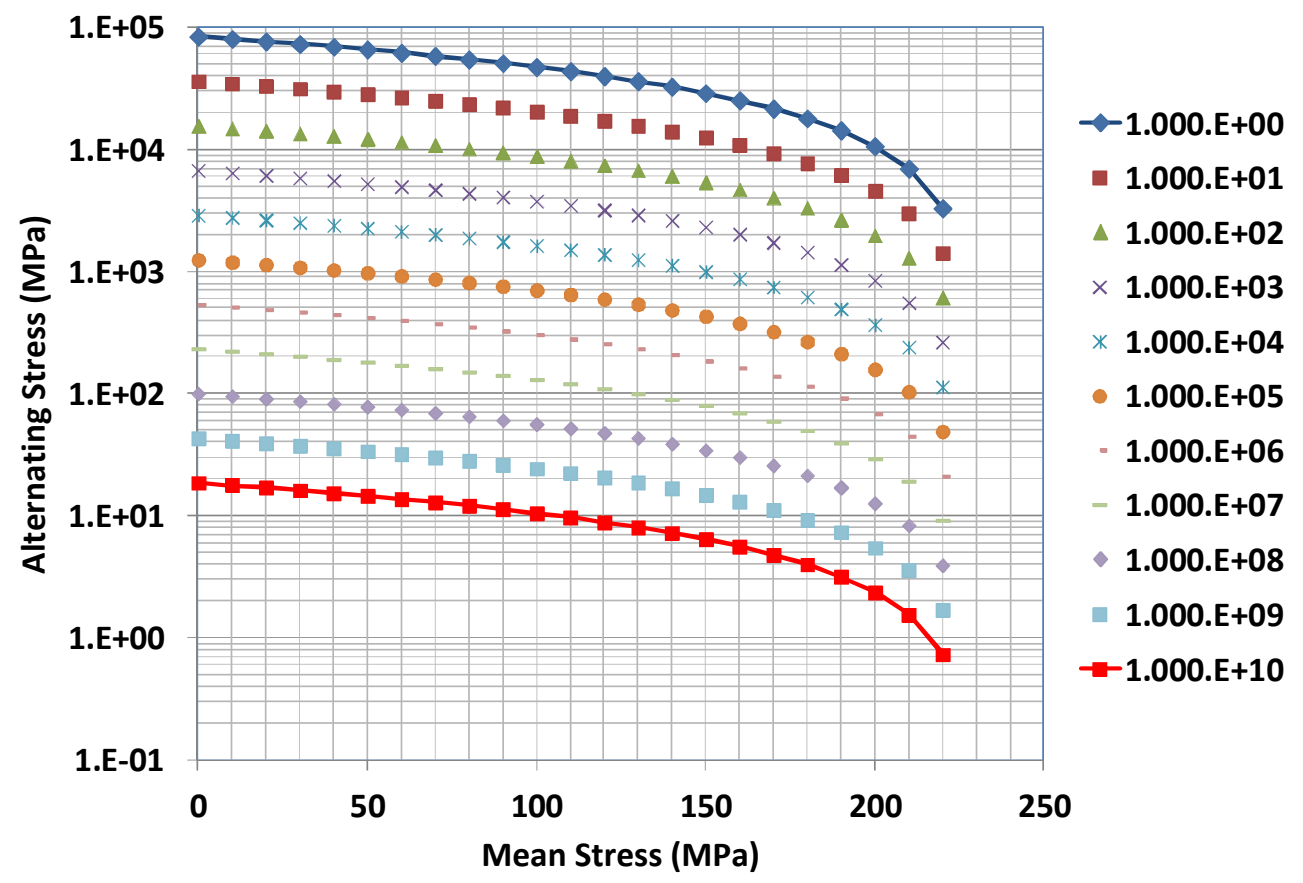

Figure 15 - Graphical representations of Goodman equation for HT-9 steel at room temperature with irradiation of $15 \mathrm{dpa}$, based upon the fatigue limit (altenrating stress at which failure occurs) for various hours of operation with fatigue cycling. As expected, lower alternating stress increases fatigue life. The upper chart is the classical Goodman chart with linear scales, and the lower chart uses logarithmic scales. 
Farmer, Kramer \& Williams, Fatigue Life Prediction for Steels in Pulsating Irradiated Systems, LLNL-TR-554731, Lawrence Livermore National Laboratory, Livermore, California 94550
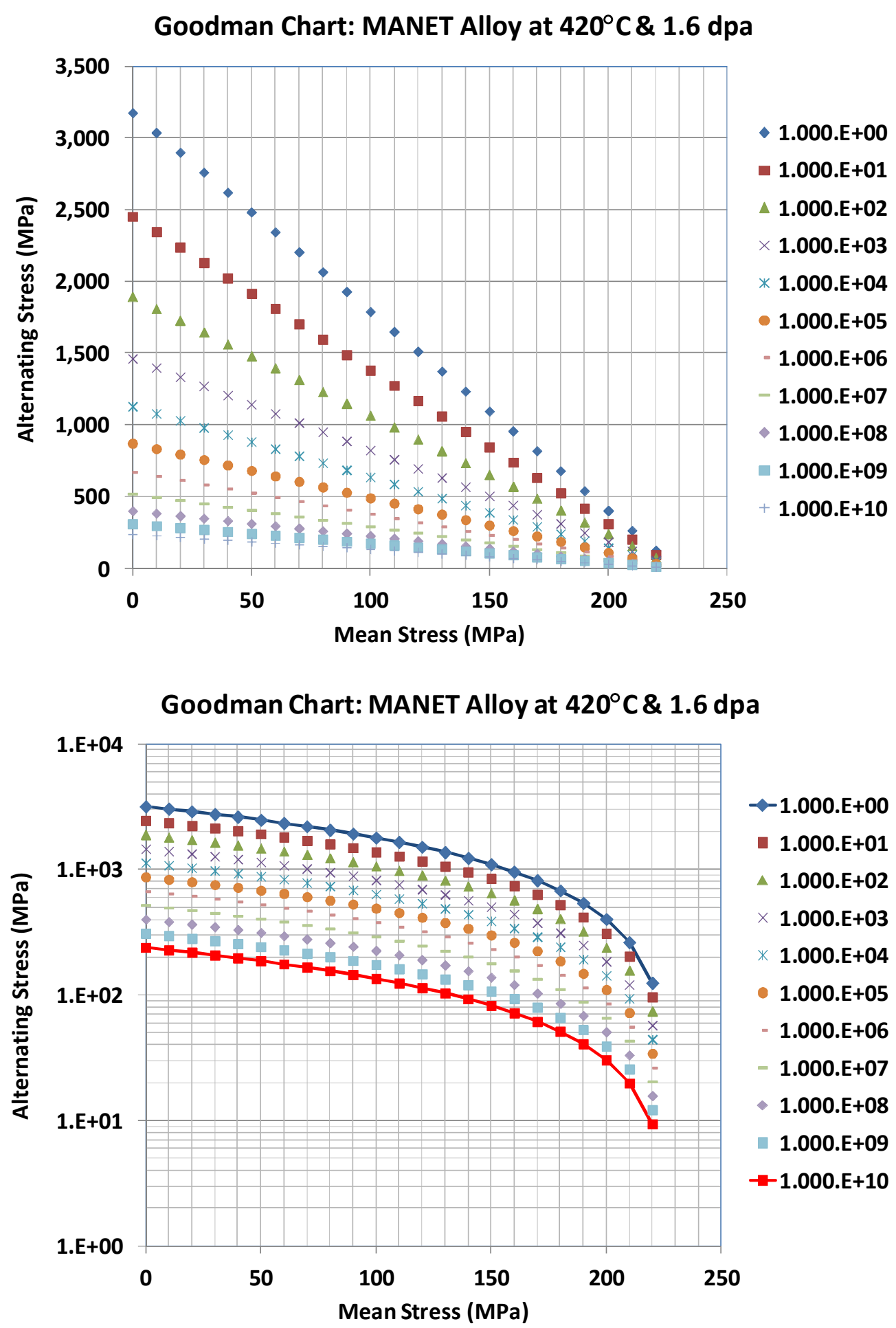

Figure 16 - Graphical representations of Goodman equation for MANET steel at $420^{\circ} \mathrm{C}$ with irradiation of $1.6 \mathrm{dpa}$, based upon the fatigue limit (altenrating stress at which failure occurs) for various hours of operation with fatigue cycling. As expected, lower alternating stress increases fatigue life. The upper chart is the classical Goodman chart with linear scales, and the lower chart uses logarithmic scales. 
Farmer, Kramer \& Williams, Fatigue Life Prediction for Steels in Pulsating Irradiated Systems, LLNL-TR-554731, Lawrence Livermore National Laboratory, Livermore, California 94550

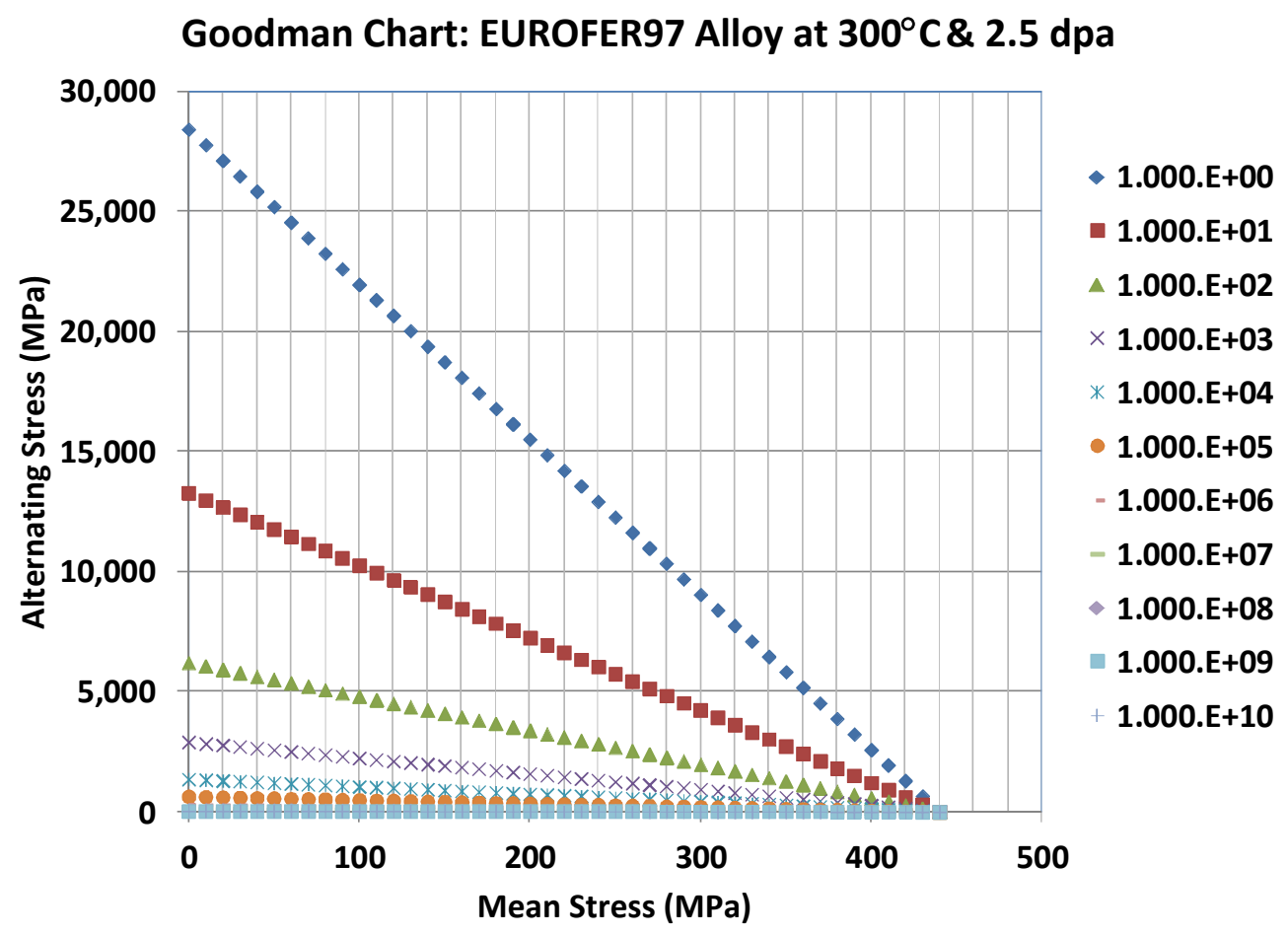

Goodman Chart: EUROFER97 Alloy at $300^{\circ} \mathrm{C} \& 2.5 \mathrm{dpa}$

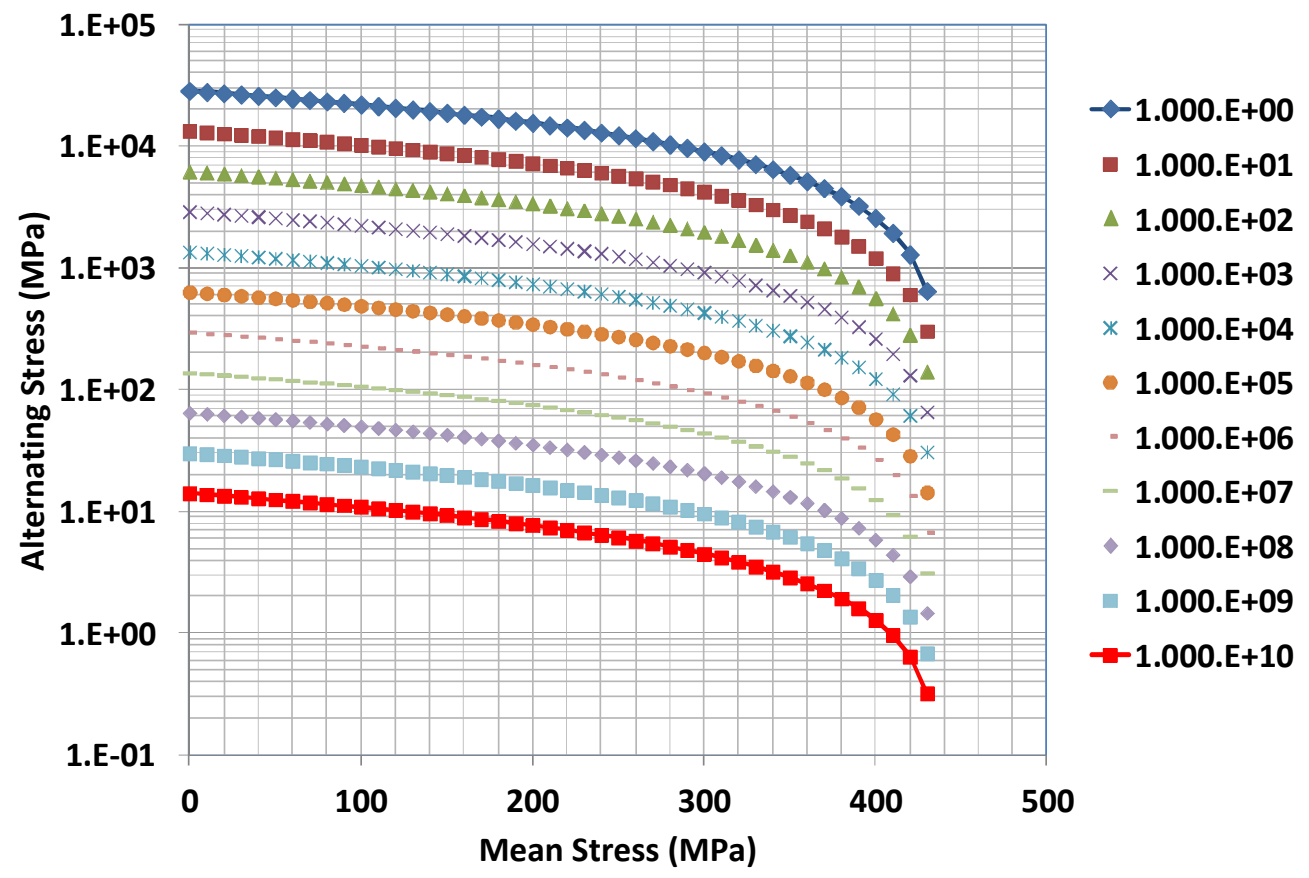

Figure 17 - Graphical representations of Goodman equation for EUROFER97 steel at $300^{\circ} \mathrm{C}$ with irradiation of $2.5 \mathrm{dpa}$, based upon the fatigue limit (altenrating stress at which failure occurs) for various hours of operation with fatigue cycling. As expected, lower alternating stress increases fatigue life. The upper chart is the classical Goodman chart with linear scales, and the lower chart uses logarithmic scales. UPDATE 
Farmer, Kramer \& Williams, Fatigue Life Prediction for Steels in Pulsating Irradiated Systems, LLNL-TR-554731, Lawrence Livermore National Laboratory, Livermore, California 94550

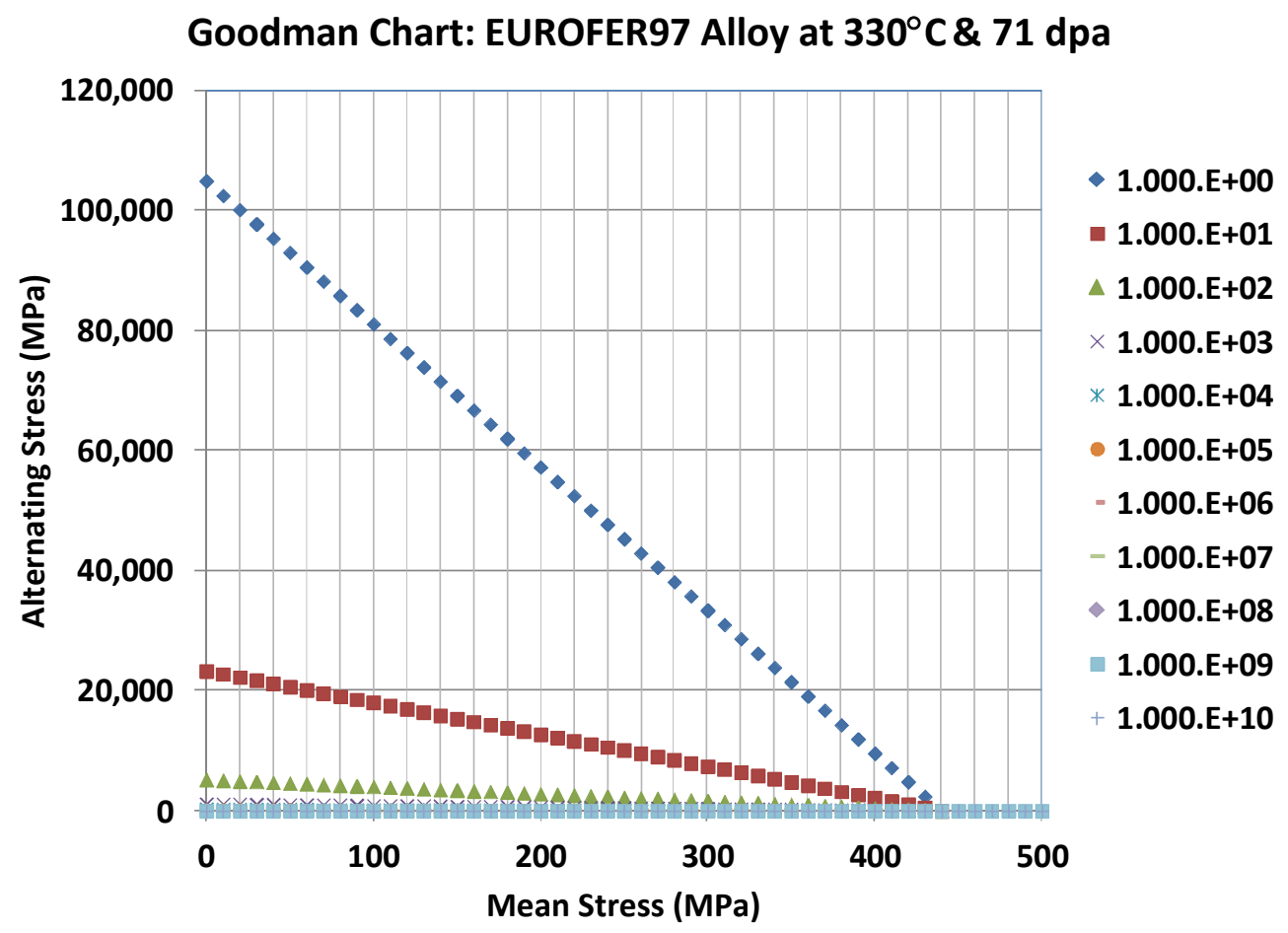

Goodman Chart: EUROFER97 Alloy at $330^{\circ} \mathrm{C} \& 71 \mathrm{dpa}$

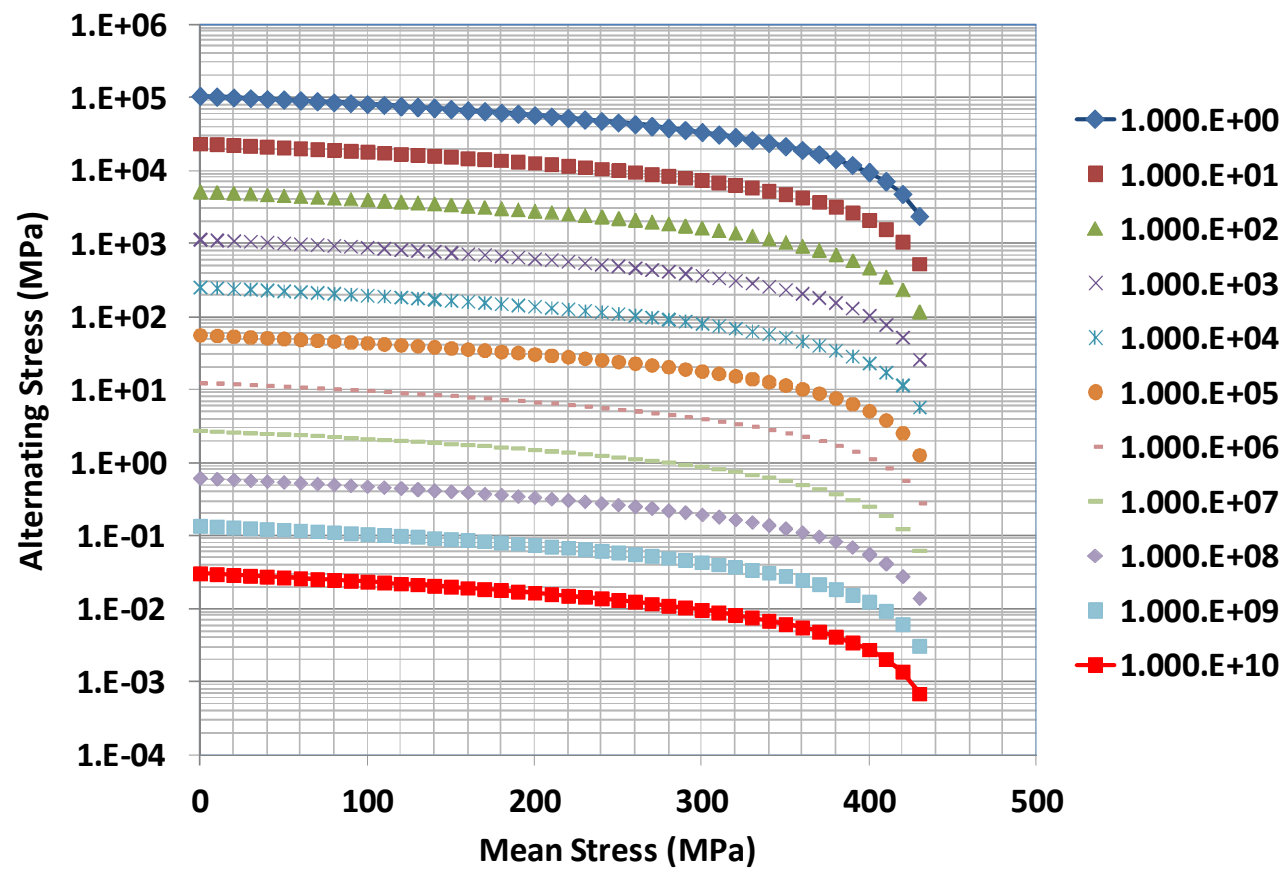

Figure 18 - Graphical representations of Goodman equation for EUROFER97 steel at $330^{\circ} \mathrm{C}$ with irradiation of $71 \mathrm{dpa}$, based upon the fatigue limit (altenrating stress at which failure occurs) for various hours of operation with fatigue cycling. As expected, lower alternating stress increases fatigue life. The upper chart is the classical Goodman chart with linear scales, and the lower chart uses logarithmic scales. 

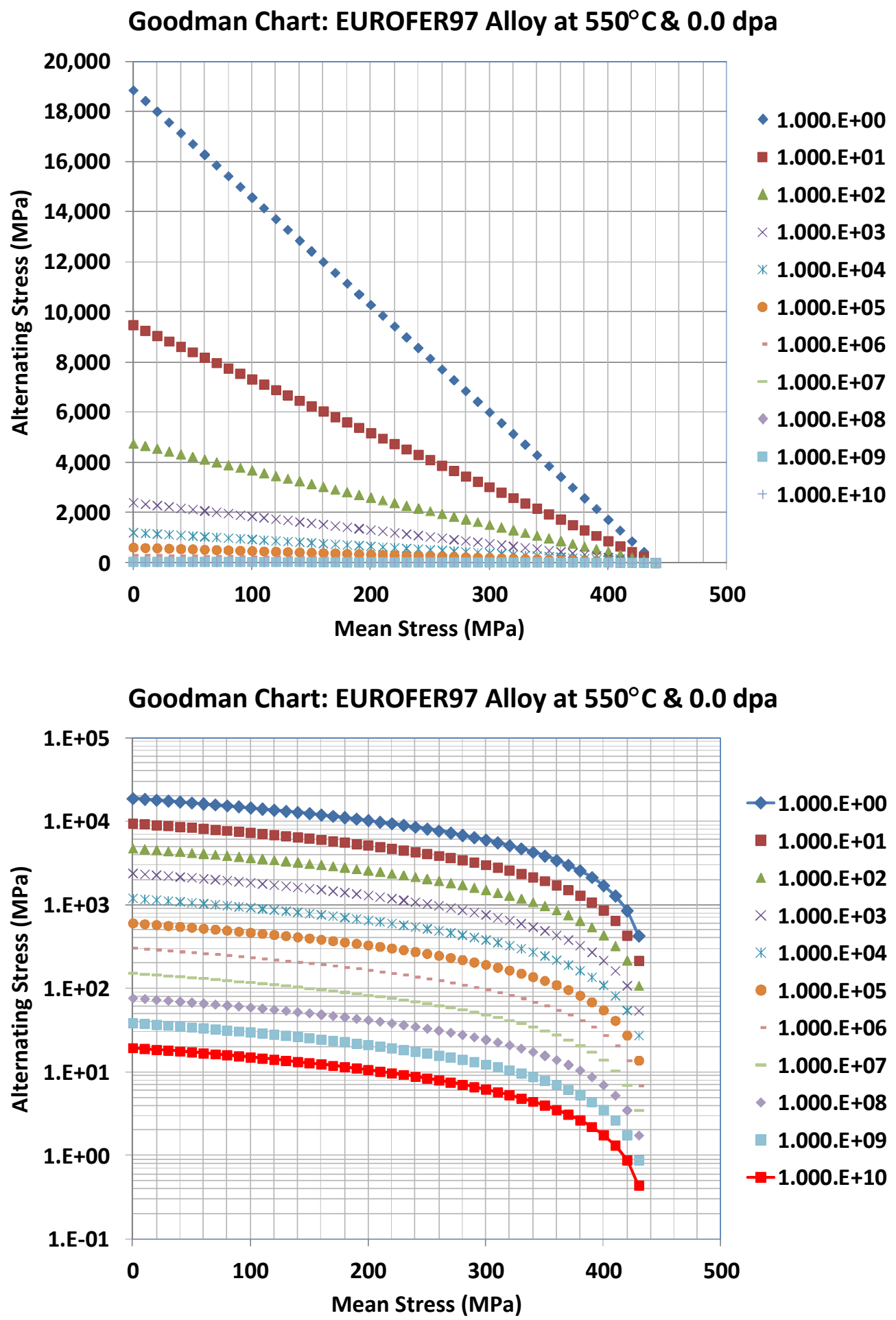

Figure 19 - Graphical representations of Goodman equation for un-irradiated EUROFER97 steel at $550^{\circ} \mathrm{C}$, based upon the fatigue limit (alternating stress at which failure occurs) for various hours of operation with fatigue cycling. As expected, lower alternating stress increases fatigue life. The upper chart is the classical Goodman chart with linear scales, and the lower chart uses logarithmic scales. 

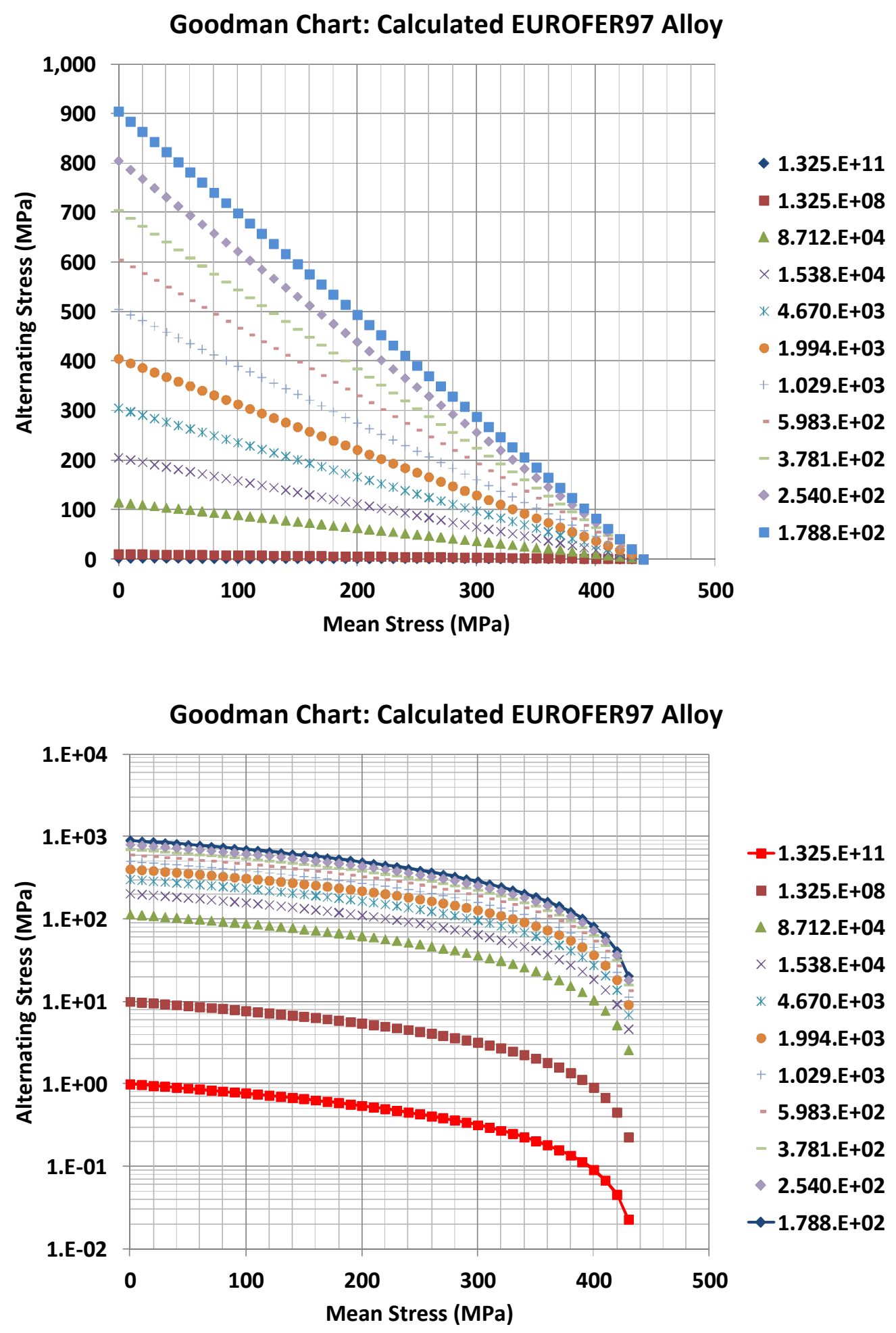

Figure 20 - Graphical representations of Goodman equation using a more theoretically based equating to estimate the fatigue limit used for the assumed material. 


\section{ACCOUNTING FOR VARIABLE AMPLITUDE LOADING}

In many engineered systems, including aircraft, ships, bridges, and piping systems, the fatigue cycles may be due to the superposition of several different fluctuating loads, each with a characteristic frequency and amplitude. The damage accumulation model was developed to account for fatigue due to such variable amplitude loading [Schijve 1997]. It is assumed that each component comprising the total fluctuating load contributes individually to the eventual fatigue failure. The development begins with the assumption that the $\mathrm{j}$-th fatigue cycle $\left(N_{j}\right)$ is applied at the $\mathrm{j}$-th stress level $\left(\sigma_{j}\right)$. The contribution of the $\mathrm{j}$-th stress level to the overall fatigue damage is $\left(d_{j}\right)$ :

$d_{j}=\frac{2 N_{j}}{2 N_{f j}}=\frac{N_{j}}{N_{f j}}$

The fraction of the fatigue life exhausted at stress level $\sigma_{j}$ is then equivalent to $d_{j}$

$d_{j}=\frac{N_{j}}{N_{f j}}$

The well-known Palmgren-Miner (PM) Rule is based upon the concept of cumulative fatigue damage for multiple (m) levels of loading:

$D=\sum_{j}^{m} d_{j}=\sum_{j}^{m} \frac{N_{j}}{N_{f j}}=1$

If typical variable loading is known for one aircraft flight, one machine operating cycle, or other time interfacial, for one repetition cycle:

$1=B_{f}\left[\sum_{j}^{m} \frac{N_{j}}{N_{f j}}\right]_{\text {onerepetitioncycle }}$ 
Farmer, Kramer \& Williams, Fatigue Life Prediction for Steels in Pulsating Irradiated Systems, LLNL-TR-554731, Lawrence Livermore National Laboratory, Livermore, California 94550

\section{EFFECT OF RADIATION DAMAGE ON MECHANICAL PROPERTIES}

\section{Effect of Radiation on Strength and Hardness}

Irradiation changes a material's mechanical properties, and therefore also changes the materials response to fatigue. The effects of radiation-induced hardening can be understood in terms of the evolution of radiation-induced defect density within the material being irradiated [Gaganidze et al. 2011]. These radiation-induced defects serve as obstacles impeding glide dislocation. The change in strength is proportional to the obstacle size, number density, and average strength, the shear modulus of the material, and the Burgers vector of the moving dislocation:

$\Delta \sigma=M \alpha \mu b \sqrt{N d}$

Parameters in this expression are defined as follows:

$M=$ Taylor factor

$N=$ obstacle number density

$d=$ average obstacle diameter

$\alpha=$ obstacle average strength

$\mu=$ shear modulus of material, assumed to be steel

$b=$ Burgers vector of moving dislocation

The evolution of radiation-induced defect density in ferritic alloys is given by the WhapmanMakin equation [Whapman \& M. J. Makin 1960]:

$$
N=N_{S}\left[1-\exp \left(\phi / \phi_{0}\right)\right]
$$

Substitution of this dose-dependent expression for the defect number density into the expression for radiation-induced hardening yields:

$$
\Delta \sigma=\Delta \sigma_{S} \sqrt{1-\exp \left(\phi / \phi_{0}\right)}
$$

Parameters in the Whapman-Makin equation, and the radiation hardening formula based upon it, are defined as follows:

$$
\begin{aligned}
& N=\text { defect density } \\
& N_{S}=\text { saturation defect density } \\
& \phi=\text { irradiation dose }
\end{aligned}
$$


Farmer, Kramer \& Williams, Fatigue Life Prediction for Steels in Pulsating Irradiated Systems, LLNL-TR-554731, Lawrence Livermore National Laboratory, Livermore, California 94550

$\phi_{0}=$ scaling irradiation dose characteristic

$\Delta \sigma=$ radiation hardening

$\Delta \sigma_{S}=$ saturation value of radiation hardening

Parameter values for predicting radiation-induced hardening of EUROFER97 are as follow:

$T_{i r r}=300-335^{\circ} \mathrm{C}$

$T_{\text {test }}=300-350^{\circ} \mathrm{C}$

$\Delta \sigma_{S}=492 M P a$

$\phi_{0}=7.3 \mathrm{dpa}$

\section{Effect of Radiation on Ductile Brittle Transition Temperature}

A similar approach can be used to predict the effect of radiation on the ductile brittle transition temperature (DBTT):

$\triangle D B T T=\triangle D B T T_{S} \sqrt{1-\exp \left(\phi / \phi_{0}\right)}$

$\triangle D B T T=$ change in ductile brittle transition temperature due to irradiation

$\triangle D B T T_{S}=$ saturation value of change in ductile brittle transition temperature due to irradiation

Parameter values for predicting radiation-induced changes in the DBTT of EUROFER97 are as follows:

$\triangle D B T T_{S}=238^{\circ} \mathrm{C}$

$\phi_{0}=16.7 \mathrm{dpa}$

The ingrowth of helium also impacts the DBTT for this material. The change in DBTT at 400 appm helium is approximately $200^{\circ} \mathrm{C}$ :

$\triangle D B T T_{400 \text { appm He }}=200^{\circ} \mathrm{C}$

Figure 21 shows curves based upon recently published data for the irradiation of EUROFER97 and EUROFER97 HT in the BOR-60 reactor. These data indicate that damage and the resultant hardening saturate between 10-20 dpa, which indicate that engine materials may be able to operate longer than now assumed. Furthermore, operation at temperatures above the temperature of $330^{\circ} \mathrm{C}$ where these published data were collected should enable damage to anneal. 
Farmer, Kramer \& Williams, Fatigue Life Prediction for Steels in Pulsating Irradiated Systems, LLNL-TR-554731, Lawrence Livermore National Laboratory, Livermore, California 94550

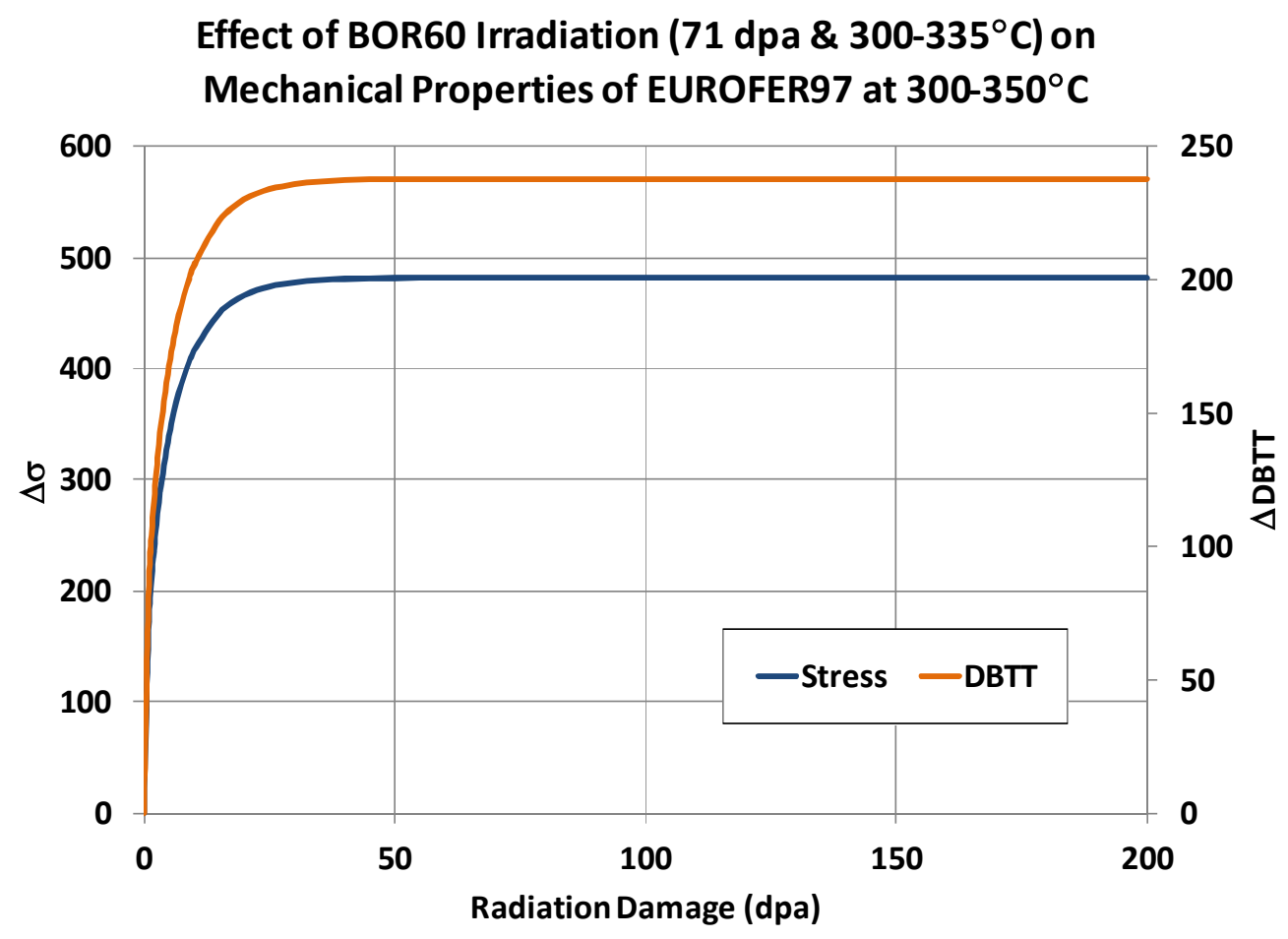

Figure 21 - From recently published data for the irradiation of EUROFER97 and EUROFER97 HT in the BOR-60 reactor, with relatively high radiation-induced damage, it appears that damage and the resultant hardening saturates between 10-20 dpa. 


\section{Effect of Radiation on Creep and Stress Rupture}

Studies of the combined effects of creep and fatigue on the failure of EUROFER97 at $500^{\circ} \mathrm{C}$ have been published very recently, and require additional review and analysis: C. Vorpahl, A. Möslang, M. Rieth, Creep-fatigue interaction and related structure property correlations of EUROFER97 steel at $550^{\circ} \mathrm{C}$ by decoupling creep and fatigue load [Vorpahl et al. 2011].

Data capturing the effects of radiation on creep and stress rupture are taken from two primary sources: (1) D. S. Gelles, Effects of Irradiation on Ferritic Alloys and Implications for Fusion Reactor Applications, Journal of Nuclear Materials, 149 (1987) 192-199; (2) F. H. Huang, Stress Rupture Data for HT9 Irradiated in the EBR-II, Table 7.1, Fracture Properties of Irradiated Alloys, Avante Publishing, P. O. Box 183, Richland, Washington, 1997, pp. 111. These data are summarized in the following tables and figures.

Predictions of creep in HT-9 based upon data from EBR-II and FFTF are summarized in Table 5 and Figure 22. As expected, the lattice damage, along with the accumulation of hydrogen and helium in the matrix, cause an increase in strain with neutron dose. These predictions were made with the following published correlation [Gelles 1987]:

$$
\varepsilon=B(\Phi t) \sigma^{n}
$$

As shown in Table 5, parameters for the correlation were found to be approximately:

Low Value of Pre-Exponential Factor: $\quad B=3 \times 10^{-28} \mathrm{MPa}^{1.5} \mathrm{~cm}^{2} \mathrm{n}^{-1}$

High Value of Pre-Exponential Factor: $\quad B=6 \times 10^{-27} \mathrm{MPa}^{1.5} \mathrm{~cm}^{2} \mathrm{n}^{-1}$

$$
\text { Exponent: } \quad n=1.3
$$

Creep rupture data for HT-9 irradiated in EBR-II, and published by Huang is presented in Table 6, and shown graphically in Figure 23 [Huang 1997]. This data has been found to fit the following empirical relationship:

$$
\log \left(t_{R}\right)=A+\frac{B}{T}+\frac{C}{T} \log (\sigma)
$$

This equation can also be rewritten as the well-known Larson-Miller relationship for thermally activated creep:

$$
L M P=T\left[A+\log \left(t_{R}\right)\right]=1 \times 10^{-3} T\left[34.14+\log \left(t_{R}\right)\right]
$$

The time required for rupture is $\left(t_{R}\right)$ in hours, the absolute temperature is $(T)$ in Kelvin, and the hoop stress in the test sample is $(\sigma)$ in megapascals. 
Farmer, Kramer \& Williams, Fatigue Life Prediction for Steels in Pulsating Irradiated Systems, LLNL-TR-554731, Lawrence Livermore National Laboratory, Livermore, California 94550

Table 5 - Predictions of Irradiation Creep in HT-9 Based Upon Published Data [Gelles 1987]

\begin{tabular}{|l|c|c|c|c|}
\hline$\sigma(\mathrm{MPa})$ & 75 & 75 & 75 & 75 \\
\hline $\mathrm{n}$ & 1.3 & 1.3 & 1.3 & 1.3 \\
\hline $\mathrm{B}\left(\mathrm{MPa}^{-1.5} \mathrm{~cm}^{2} / \mathrm{n}\right)$ & $3.00 \mathrm{E}-28$ & $4.00 \mathrm{E}-28$ & $6.00 \mathrm{E}-28$ & $6.00 \mathrm{E}-27$ \\
\hline $\mathrm{T}\left({ }^{\circ} \mathrm{C}\right)$ & 500 & 570 & 580 & 660 \\
\hline$\Phi \mathrm{t}\left(\mathrm{n} / \mathrm{cm}^{2}\right)$ & $\varepsilon$ & $\varepsilon$ & $\varepsilon$ & $\varepsilon$ \\
\hline $1.00 \mathrm{E}+14$ & $8.22 \mathrm{E}-12$ & $1.10 \mathrm{E}-11$ & $1.64 \mathrm{E}-11$ & $1.64 \mathrm{E}-10$ \\
\hline $1.00 \mathrm{E}+15$ & $8.22 \mathrm{E}-11$ & $1.10 \mathrm{E}-10$ & $1.64 \mathrm{E}-10$ & $1.64 \mathrm{E}-09$ \\
\hline $1.00 \mathrm{E}+16$ & $8.22 \mathrm{E}-10$ & $1.10 \mathrm{E}-09$ & $1.64 \mathrm{E}-09$ & $1.64 \mathrm{E}-08$ \\
\hline $1.00 \mathrm{E}+17$ & $8.22 \mathrm{E}-09$ & $1.10 \mathrm{E}-08$ & $1.64 \mathrm{E}-08$ & $1.64 \mathrm{E}-07$ \\
\hline $1.00 \mathrm{E}+18$ & $8.22 \mathrm{E}-08$ & $1.10 \mathrm{E}-07$ & $1.64 \mathrm{E}-07$ & $1.64 \mathrm{E}-06$ \\
\hline $1.00 \mathrm{E}+19$ & $8.22 \mathrm{E}-07$ & $1.10 \mathrm{E}-06$ & $1.64 \mathrm{E}-06$ & $1.64 \mathrm{E}-05$ \\
\hline $1.00 \mathrm{E}+20$ & $8.22 \mathrm{E}-06$ & $1.10 \mathrm{E}-05$ & $1.64 \mathrm{E}-05$ & $1.64 \mathrm{E}-04$ \\
\hline $1.00 \mathrm{E}+21$ & $8.22 \mathrm{E}-05$ & $1.10 \mathrm{E}-04$ & $1.64 \mathrm{E}-04$ & $1.64 \mathrm{E}-03$ \\
\hline $1.00 \mathrm{E}+22$ & $8.22 \mathrm{E}-04$ & $1.10 \mathrm{E}-03$ & $1.64 \mathrm{E}-03$ & $1.64 \mathrm{E}-02$ \\
\hline $1.00 \mathrm{E}+23$ & $8.22 \mathrm{E}-03$ & $1.10 \mathrm{E}-02$ & $1.64 \mathrm{E}-02$ & $1.64 \mathrm{E}-01$ \\
\hline $1.00 \mathrm{E}+24$ & $8.22 \mathrm{E}-02$ & $1.10 \mathrm{E}-01$ & $1.64 \mathrm{E}-01$ & \\
\hline $1.00 \mathrm{E}+25$ & $8.22 \mathrm{E}-01$ & & & \\
\hline $1.00 \mathrm{E}+26$ & & & & \\
\hline
\end{tabular}

Source: D. S. Gelles, Effects of Irradiation on Ferritic Alloys and Implications for Fusion Reactor Applications, Journal of Nuclear Materials, 149 (1987) 192-199.

HT-9 Irradiation Creep Predicted from EBR-II \& FFTF Data

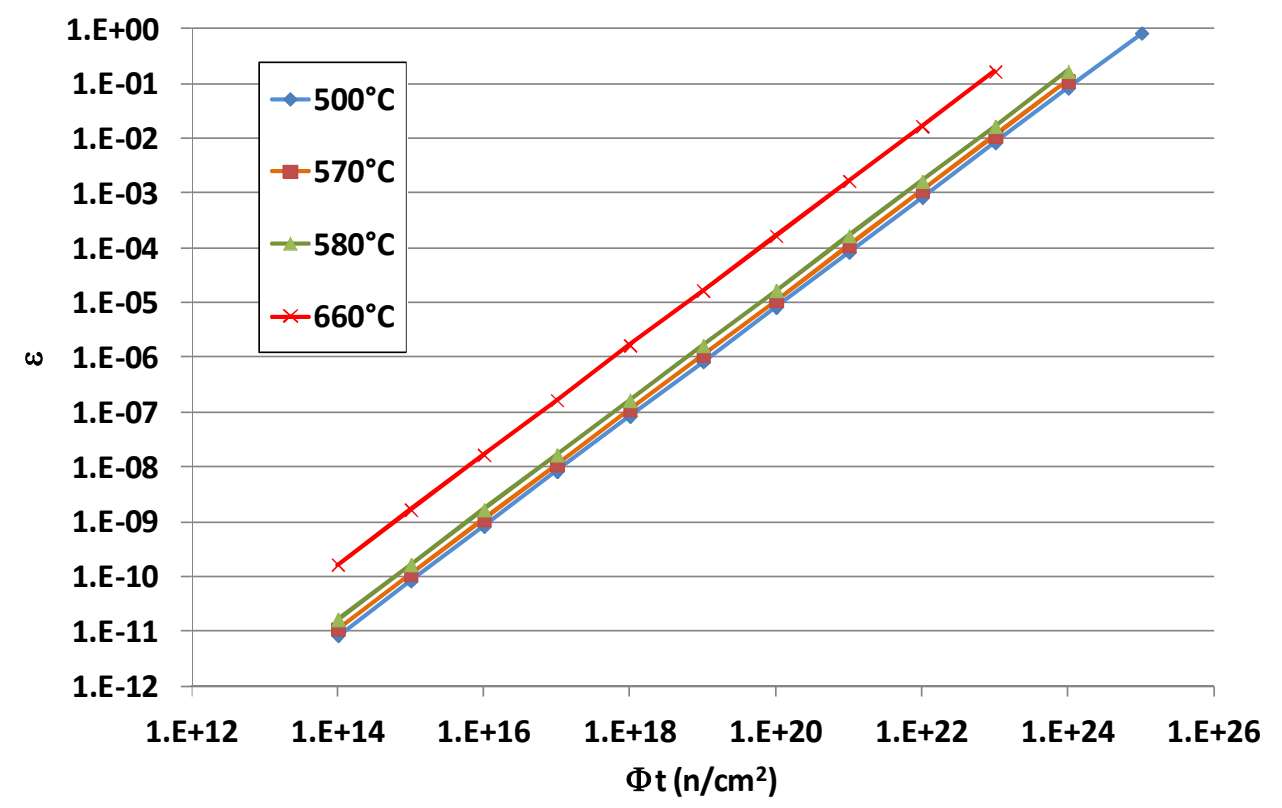

Figure 22 - Predictions of creep in HT-9 based upon data from EBR-II and FFTF [Gelles 1987]. 
Farmer, Kramer \& Williams, Fatigue Life Prediction for Steels in Pulsating Irradiated Systems, LLNL-TR-554731, Lawrence Livermore National Laboratory, Livermore, California 94550

Table 6 - Creep Rupture data for HT-9 Irradiated in EBR-II [Huang 1997]

\begin{tabular}{|c|c|c|c|c|c|}
\hline $\mathrm{T}$ & $\sigma$ & $\Phi \mathrm{t}$ & $\mathrm{t}_{\mathrm{R}}$ & $\varepsilon$ & $\varepsilon_{\max }$ \\
\hline${ }^{\circ} \mathrm{C}$ & $\mathrm{MPa}$ & $10^{22} \mathrm{n} / \mathrm{cm}^{2}$ & $\mathrm{~h}$ & $\%$ & $\%$ \\
\hline 593 & 170 & 1.18 & 1879 & 3.9 & 9.6 \\
\hline 593 & 187 & 1.1 & 1750 & 2.8 & 4.4 \\
\hline 593 & 215 & 0.153 & 243 & 3.8 & 8.7 \\
\hline 658 & 75 & 1.81 & 2873 & 3.4 & 6.5 \\
\hline 658 & 80 & 1.07 & 1694 & 3.7 & 8.3 \\
\hline 658 & 90 & 0.387 & 615 & 2.1 & 6.5 \\
\hline 704 & 34 & 0.354 & 503 & 20.7 & 39.0 \\
\hline 704 & 38 & 0.284 & 450 & 12.1 & 35.0 \\
\hline 704 & 48 & 0.166 & 264 & 4.9 & 23.0 \\
\hline
\end{tabular}

Source: F. H. Huang, Stress Rupture Data for HT9 Irradiated in the EBR-II, Table 7.1, Fracture Properties of Irradiated Alloys, Avante Publishing, P. O. Box 183, Richland, Wa, 1997, pp. 111.

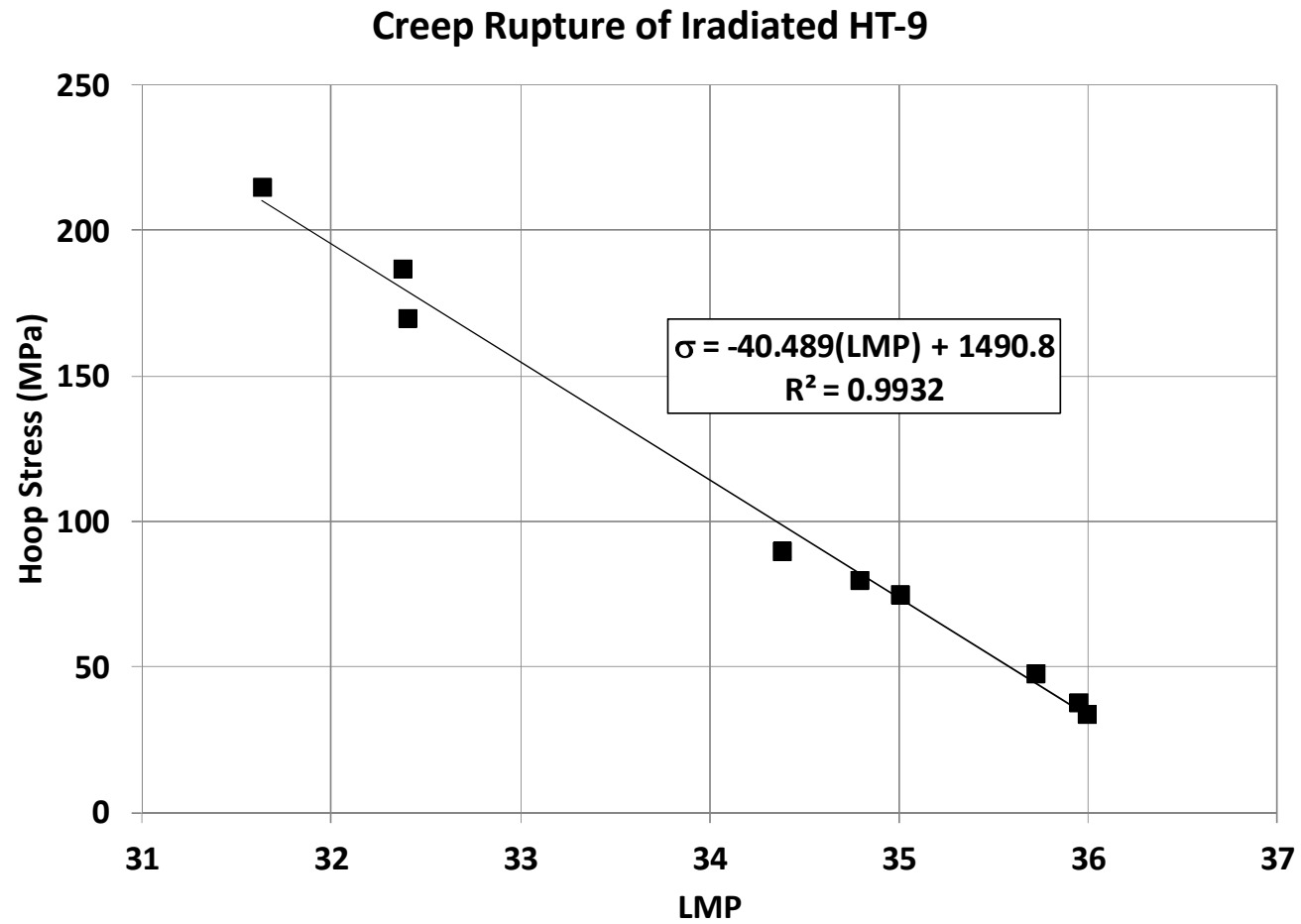

Figure 23 - Published creep rupture data for HT-9 irradiated in EBR-II [Huang 1997]. 


\section{Effects of Radiation on Fatigue Life of FM Steels}

Unfortunately, values of the materials constants $(m)$ and $(C)$ for irradiated steels have not been published, are not generally known. From reviewing the literature, it appears that many investigators studying fatigue of steels subjected to very high doses of radiation use the MansonCoffin equation, which relates the inelastic strain amplitude and the number of fatigue cycles at failure, as the basis of their experimental work:

$\Delta \varepsilon_{\text {inelastic }}=C N_{f}^{m}$

A comparison of the predictions for non-irradiated and irradiated EUROFER97, HT-9, and MANET steels, based upon correlations of published data (Figure 24), leads to the conclusion that the fatigue life of EUROFER97 is shortened by irradiation at a damage level of $71 \mathrm{dpa}$.

The effect of irradiation on low cycle fatigue (LCF) is reflected in published parameters for Manson-Coffin equation for both non-irradiated and irradiated samples. For example, such lowcycle fatigue data at a test temperature of $300-350^{\circ} \mathrm{C}$ has just appeared in the scientific literature for EUROFER97 and EUROFER07 HT, with irradiation to 0,31, 47 and $71 \mathrm{dpa}$, at an irradiation temperature of $300-335^{\circ} \mathrm{C}$ [Gaganidze et al. 2011]. The irradiation was done in the BOR-60 sodium-cooled fast reactor in Russia. These investigators plot the "strain range" as a function of the "number of cycles to failure" for both steels, and determine one of the parameters in the Manson-Coffin equation:

Parameter for EUROFER97: $\quad m=-0.68$

Parameter for EUROFER97 HT: $\quad m=-0.52$

In comparison with the curves in the ASME Boiler and Pressure Vessel Code, for the stated number of cycles $(268,056,000)$, the associated alternating stress is taken at approximately 100 $\mathrm{MPa}$ for temperatures not exceeding $425^{\circ} \mathrm{C}$. In general, it is recommended that the fatigue analysis be performed at least twice; once for the material in the unirradiated condition; and once at the damage level assumed at the end of life of the component. It is not evident which of these two conditions will eventually be that which produces the largest calculated cumulative usage factor. 


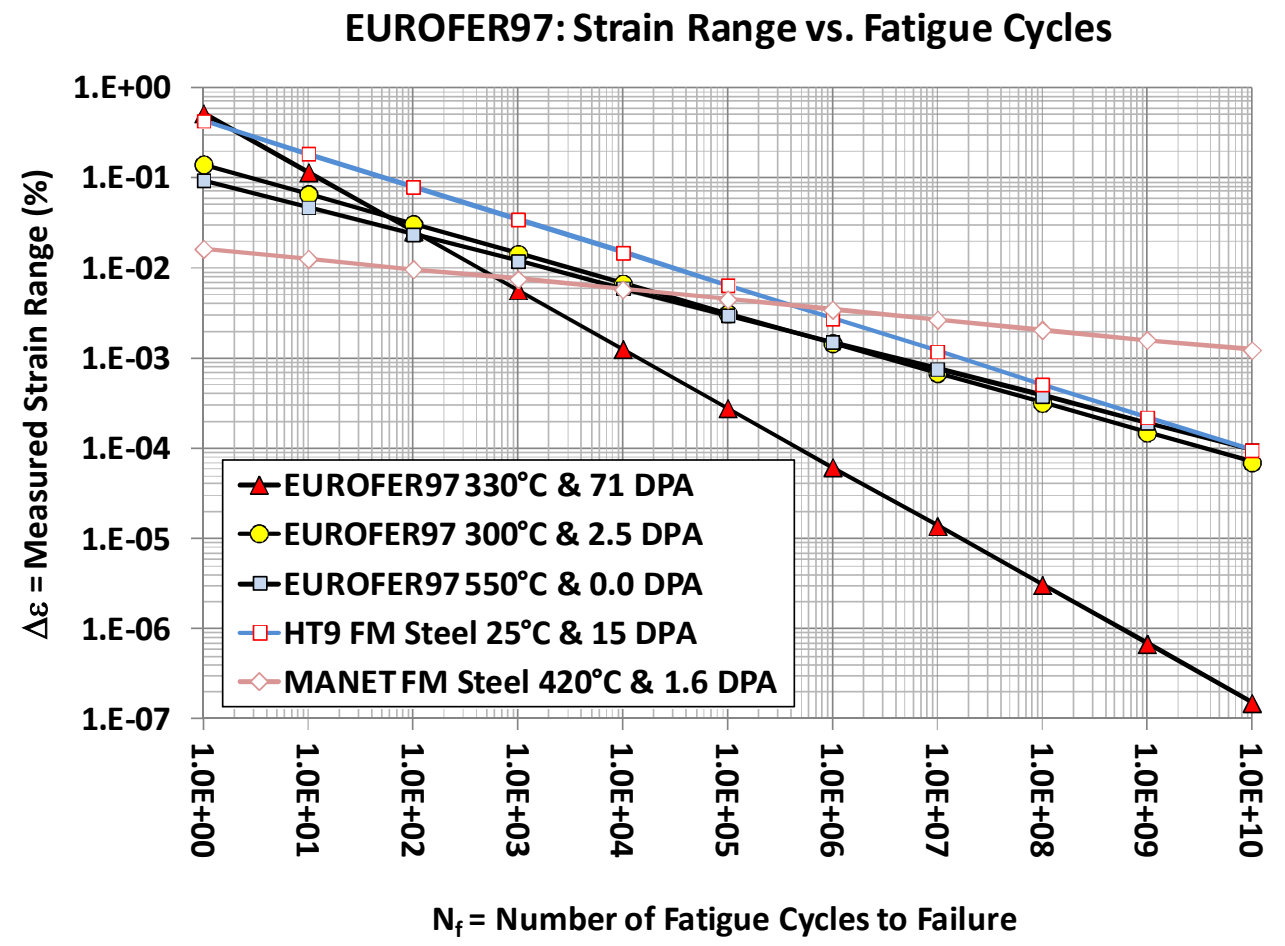

\section{EUROFER97: Estimated Alternating Stress vs. Fatigue Cycles}

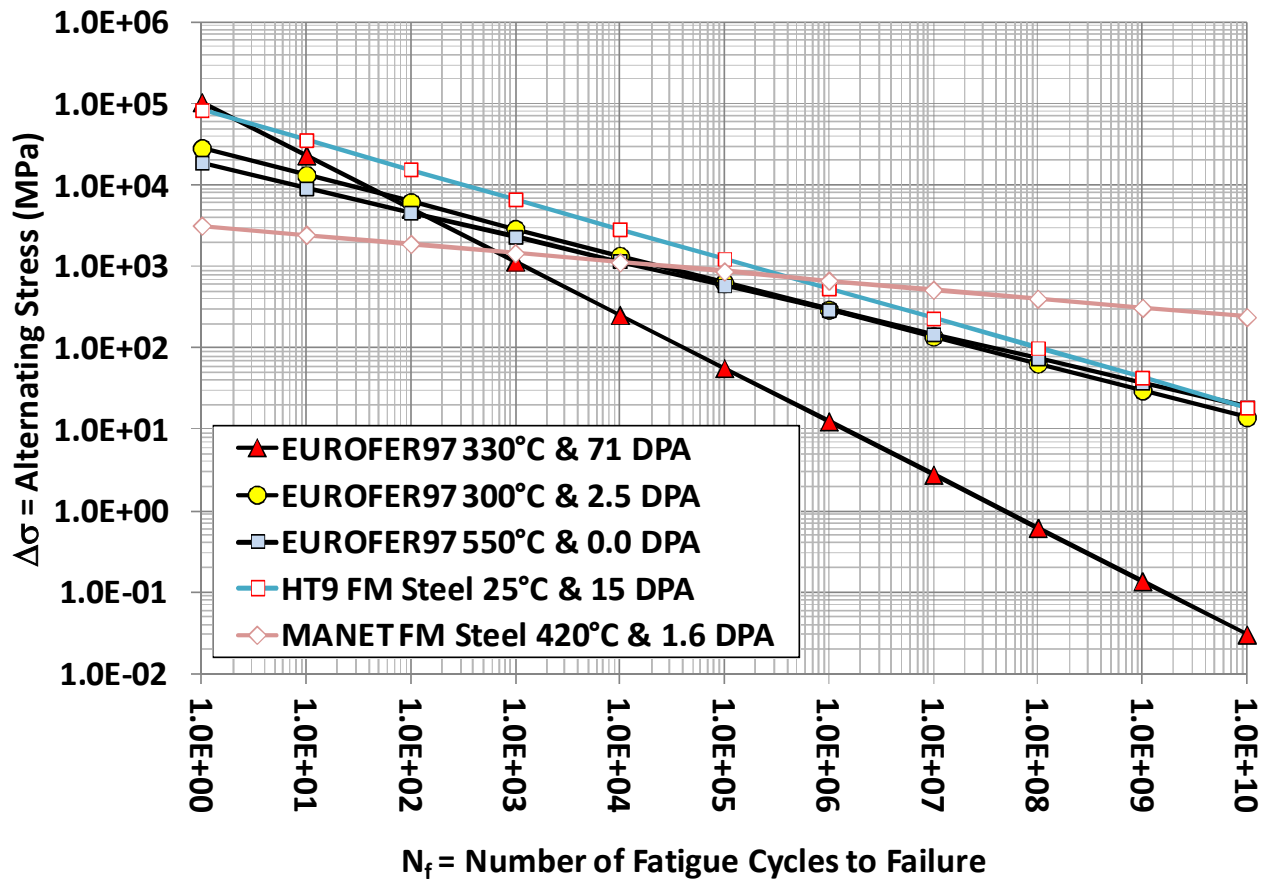

Figure 24 - By comparing data for non-irradiated and irradiated EUROFER97, HT-9, and MANET steels, it appears that the fatigue life of EUROFER97 may be shortened by irradiation with a corresponding damage level of $71 \mathrm{dpa}$. 


\section{SUMMARY}

Continuous stress pulses at a repetition rate of $10 \mathrm{~Hz}$ are assumed in the hypothetical, pulsed neutron source that is being evaluated and discussed in this report. A preliminary fatigue life assessment for ferritic-martensitic (FM) steels proposed for the construction this system has been done, with the results documented here. Initial predictions based upon published literature data and standard analytical fracture mechanics models indicate that the service life of the system under consideration will be severely limited by fatigue, and that viability will require designers to limit the magnitude of the alternating stress, keeping it well below $10 \mathrm{MPa}$ in order to achieve a service life of 1 year with an assumed availability of 85 percent. This appears to be consistent with other independent calculations which have been performed since the first draft of this report appeared.

The analysis of a proposed system design begins with an estimate of the mean static stress level in the system, using well known analytical expressions from published sources such as Roark's Handbook, or predictions from finite element codes (Figure 1). Then, the alternating stress is predicted with formulae that account for (1) thermal stress pulses associated with isochoric heating of the structural material; and (2) pressure pulses from any working fluid in contact with the vessel wall. With mechanical property data for the irradiated structural material, including the yield strength $\left(\sigma_{Y S}\right)$ and fracture toughness $\left(K_{C}\right)$, the critical flaw size for initiation of a fatigue crack $\left(\mathrm{a}_{\mathrm{c}}\right)$ can then be estimated. The calculated critical flaw size $\left(a_{c}\right)$, and the largest expected manufacturing defect in the surface $\left(a_{0}\right)$ are required to calculate the number fatigue cycles to failure $\left(N_{f}\right)$ as a function of applied stress $(\sigma)$. The fatigue limit $\left(\sigma_{C R}\right)$ can be estimated once the required number of fatigue cycles are specified, which in this case are in excess of 400 million $(268,056,000)$ cycles.

Given the fatigue limit and the yield stress, the Soderberg equation is used to establish the most conservative bounds for the mean and alternating stresses, levels that cannot be exceeded for safe operation. Less conservatively, and given the fatigue limit and ultimate tensile strength of the material, the Goodman equation can be used to establish these bounds. Even more optimistic estimates can be made with the Gerber equation. Of course, more complicated alternating stress waveforms can be accounted for using the damage accumulation model, with cycle counting based upon the rainfall criterion.

Model parameters were based experimental data for HT-9, MANET, and EUROFER97 from a number of published sources, and recently published data on the mechanical testing of EUROFER97 and EUROFER97 HT after irradiation to $71 \mathrm{dpa}$ in the BOR-60 reactor in Russia. These data indicate that radiation-induced damage, strengthening and hardening, and ductile brittle transition temperature (DBTT) increases approach saturation levels after a damage level of 10 to 20 displacements per atom (dpa) is reached. 
The relatively crude analysis provided here illustrates an expected rapid drop in fatigue life with increasing stress level. The operation of an irradiated system for 1 year with $85 \%$ availability, and a repetition rate of $10 \mathrm{~Hz}$, will subject materials to, which may be possible with a maximum cyclic stress below $10 \mathrm{MPa}$ and perhaps below $1 \mathrm{MPa}$ in some cases.

The critical stress intensity factor may reflect any one of several types of environmental fracture, including stress corrosion cracking (SCC), hydrogen induced cracking (HIC), and liquid metal embrittlement (LME). All of these failure modes may be encountered in the pulsating irradiated system under consideration due to the possible use of liquid metals or molten salts as coolants, as well as the presence of hydrogen isotopes, including deuterium and tritium, at significant concentrations. Liquid metal embrittlement (LME) of ferritic-martensitic (FM) steels in molten lead alloys, including EUROFER97 and T91, had been studies at $150-450^{\circ}$ at strain rates from $1 \times 10^{-3}$ to $1 \times 10^{-6} \mathrm{~s}^{-1}$, are discussed in the literature [Van den Bosch et al. 2008]. While there was relatively little sensitivity to the liquid metals in very smooth samples, samples with stress concentrators in the surface (notched specimens), and samples that had already been exposed and corroded by these liquid metals exhibited a substantial decrease in the total elongation at failure. A substantial reduction in the yield stress was also observed after liquid metal exposure. Thus, the presence of liquid lead alloys at the surface of the FM steels of interest here will exacerbate fatigue failure, with the impact worsening above $300^{\circ} \mathrm{C}$.

\section{ACKNOWLEDGEMENTS}

Lawrence Livermore National Laboratory is operated by Lawrence Livermore National Security, LLC, for the U.S. Department of Energy, National Nuclear Security Administration under Contract DE-AC52-07NA27344.

\section{DISCLAIMER}

This document was prepared as an account of work sponsored by an agency of the United States government. Neither the United States government, nor Lawrence Livermore National Security LLC, nor any of their employees make any warranty, expressed or implied, or assumes any legal liability or responsibility for the accuracy, completeness, or usefulness of any information, apparatus, product, or process disclosed, or represents that its use would not infringe privately owned rights. Reference herein to any specific commercial product, process, or service by trade name, trademark, manufacturer, or otherwise does not necessarily constitute or imply its endorsement, recommendation, or favoring by the United States government or Lawrence Livermore National Security, LLC. The views and opinions of authors expressed herein do not necessarily state or reflect those of the United States government or Lawrence Livermore National Security, LLC, and shall not be used for advertising or product endorsement purposes. 
Farmer, Kramer \& Williams, Fatigue Life Prediction for Steels in Pulsating Irradiated Systems, LLNL-TR-554731, Lawrence Livermore National Laboratory, Livermore, California 94550

\section{REFERENCES}

[ASME 2011] ASME Boiler and Pressure Vessel Code, Section III, Appendix XIV, paragraph XIV-1221.3, 2011.

[Collins 1993] Jack A. Collins, Failure of Materials in Mechanical Design: Analysis, Prediction, Prevention, $2^{\text {nd }}$ Edition, 1993.

[Duquette 1984] D. J. Duquette, Fundamentals of Corrosion Fatigue of Metals and Alloys, Hydrogen Embrittlement and Stress Corrosion Cracking, American Society for Metals, Metal Parks, Ohio 44073, 1984 (Fifth Printing, March 1995), ISBN 0-87170-185-5, 1984, 257-258.

[Fine et al. 1997] M. E. Fine, Y. W. Chung, Fatigue Failure in Metals, Fatigue and Fracture, Volume 19, ASM Handbook, S. R. Lampman, Technical Editor, ASM International, Materials Park, Ohio (1997) pp. 63-72.

[Gaganidze et al. 2011] E. Gaganidze, C. Petersen, E. Materna-Morris, C. Dethloff, O. J. Wei $\beta$, J. Aktaa, A Povstyanko, A. Fedoseev, O. Makarov, V. Prokhorov, Mechanical properties and TEM examination of RAFM steels irradiated up to 70 dpa in BOR-60, Journal of Nuclear Materials, xxx (2011) xxx-xxx. [doi:10.1016/j.jnucmat.2010.12.047].

[Gelles 1987] D. S. Gelles (Westinghouse Hanford Company, Richland, Washington), Effects of Irradiation on Ferritic Alloys and Implications for Fusion Reactor Applications, Journal of Nuclear Materials, 149 (1987) 192-199.

[Gelles 2011] D. S. Gelles (Pacific Northwest National Laboratory, Hanford, Washington), A Review of Recent Work on Fatigue Response in Ferritic/Martensitic Steels, 2011, pp. 16-21.

[Goodman 1899] J. Goodman, Mechanics Applied to Engineering, Longman, Green \& Company, London, 1899.

[Hertzberg 1996] R. W. Hertzberg, Deformation and Fracture Mechanics and Engineering Materials, Fourth Edition, John Wiley and Sons Inc., Hoboken, New Jersey, 1996.

[Huang 1995] F. H. Huang (Fluor-Daniel, Richland, Washington), Stress Rupture Data for HT9 Irradiated in the EBR-II, Table 7.1, Small Specimen Test Techniques, Chapter 7, Table 13.5, Fracture Toughness Results for HT-9 Irradiated in the EBR-II to $9 \times 10^{22} \mathrm{n} / \mathrm{cm}^{2}$, Table 13.6, Fracture Toughness Test Results of HT-9 Irradiated at FFTF, Table 13.7, Fracture Properties of Ferritic Alloys Irradiated at $50^{\circ} \mathrm{C}$ to a Dose of $10 \mathrm{dpa}$ in HFIR, Table 13.8, Fracture Properties of Irradiated Alloys, Mechanical Properties of Ferritic Alloys, Chapter 13, Fracture of Ferritic Alloys, Chapter 14, Failure of Fuel Cladding, Chapter 15, Fracture Properties of Irradiated Alloys, Avante Publishing, P. O. Box 183, Richland, Washington 99352, ISBN-0-9646655-8-1, 1995 (Second Printing, August 1997) pp. 110-112, 261-284, 285-310, 311-314. 
Farmer, Kramer \& Williams, Fatigue Life Prediction for Steels in Pulsating Irradiated Systems, LLNL-TR-554731, Lawrence Livermore National Laboratory, Livermore, California 94550

[Larson and Miller 1955] R. R. Larson, J. Miller, A Time-Temperature Relationship for Rupture and Creep Stresses, Transactions of the Americaon Society of Mechanical Engineers, 74 (1955) 765-775.

[Luzginova et al. 2011] N. V. Luzginova, J. Rensman, P. ten Pierick, J. B. J. Hegeman, Low cycle fatigue of irradiated and unirradiated Eurofer97 steel at $300^{\circ} \mathrm{C}$, Journal of Nuclear Materials, 409 (2011) 153-155. [doi:10.1016/j.jnucmat.2010.09.017].

[Whapman \& Makin 1960] D. Whapman, M. J. Makin, Philos. Mag. 5, 51 (1960) 237-250.

[Materna et al. 2009] E. Materna-Morris, A. Möslang, R. Rolli b, H.-C. Schneider, Effect of helium on tensile properties and microstructure in $9 \% \mathrm{Cr}-\mathrm{WVTa}-$ steel after neutron irradiation up to 15 dpa between 250 and $450^{\circ} \mathrm{C}$, Journal of Nuclear Materials, 386-388 (2009) 422-425. [doi:10.1016/j.jnucmat.2008.12.157].

[Mitchell 1997] M. R. Mitchell, Fundamentals of Modern Fatigue Analysis, Fatigue and Fracture, Volume 19, ASM Handbook, S. R. Lampman, Technical Editor, ASM International, Materials Park, Ohio (1997) pp. 227-249.

[Mueller et al. 2009] Pablo Mueller, P. Spätig, R. Bonadé, G. R. Odette, D. Gragg, Fracture toughness master-curve analysis of the tempered martensitic steel Eurofer97, Journal of Nuclear Materials, 386-388 (2009) 323-327. [doi:10.1016/j.jnucmat.2008.12.122].

[Schivje 1997] J. Schijve, Fatigue Crack Growth Under Variable Amplitude Loading, Fatigue and Fracture, Volume 19, ASM Handbook, S. R. Lampman, Technical Editor, ASM International, Materials Park, Ohio (1997) pp. 110-133.

[Thornton \& Colangelo 1985] Peter A. Thornton, Vito J. Colangelo, Elastic Properties for Selected Engineering Materials at Room Temperature, Table 6-1, Strengthening Mechanisms and Response to Thermal Treatement, Chapter Six, Mechanical Testing and Selection of Engineering Materials, Chapter 8, Typical Plane Strain Fracture Toughness Values for Certain Alloys, Table 9-1, Fracture Toughness and Fatigue of Engineering Materials, Chapter 9, Fundamentals of Engineering Materials, Prentice-Hall, Englewood Cliffs, New Jersey, ISBN 013-338401-2, 1985, pp. 144, 232, 268, 272, 295, 308-314.

[Van den Bosch et al. 2008] J. Van den Bosch, R. W. Bosch, D. Sapundjiev, A. Almazouzi, Liquid metal embrittlement of ferritic-martensitic steel of liquid lead alloys, Journal of Nuclear Materials, 376 (2008) 322-329. [doi:10.1016/j.jnucmat.2008.02.008].

[Vorpahl et al. 2011] C. Vorpahl, A. Möslang, M. Rieth, Creep-fatigue interaction and related structure property correlations of EUROFER 97 steel at $550^{\circ} \mathrm{C}$ by decoupling creep and fatigue load, Journal of Nuclear Materials, xxx (2011) xxx-xxx. [doi:10.1016/j.jnucmat.2010.12.262]. 
Farmer, Kramer \& Williams, Fatigue Life Prediction for Steels in Pulsating Irradiated Systems, LLNL-TR-554731, Lawrence Livermore National Laboratory, Livermore, California 94550

[Young 1989] Roarks Formulas for Stress \& Strain $6^{\text {th }}$ Edition, Chapter 12, Shells of Revolution, Pressure, Vessels \& Pipes, Table 28, Table 32, pp. 618, 638, 639. 


\section{APPENDIX A - MEAN STRESS IN THE WALLS OF CYLINDRICAL \& SPHERICAL VESSELS}

The mean stress for an assessment of fatigue failure is usually obtained from a classical analysis of stress, which can be performed with elegant finite element (FEM) models, or performed with simpler analytical expressions. Fortunately, a number of very useful analytical expressions have been developed for engineering design over the years, and can be used to make reasonable estimates on a timely basis. For example, two consider applied static stresses for three classically shaped bodies, thin and thick walled cylinders, and the thick-walled sphere.

\section{Thin-Walled Cylinders}

Analytical solutions exist for calculating the stress in thin-walled cylinder, with capped ends (Roarks Formulas for Stress \& Strain 6th Edition, Chapter 12, Shells of Revolution, Pressure, Vessels \& Pipes, Table 28 and Page 618) [Young 1989]. In this case, a thin-walled vessel is defined as one with a radius-to-wall thickness ratio greater than 10 . The equations for stress and strain are:

$$
\begin{aligned}
& \sigma_{1}=\frac{P R}{2 t} \\
& \sigma_{2}=\frac{P R}{t} \\
& \Delta R=\frac{P R^{2}}{E t}\left(1-\frac{v}{2}\right) \\
& \Delta y=\frac{P R y}{E t}\left(\frac{1}{2}-v\right)
\end{aligned}
$$

In these formulae, $\mathrm{P}$ is the uniform internal pressure, $\mathrm{R}$ is the radius of the cylinder, $\mathrm{t}$ is the wall thickness, $\sigma_{1}$ is the longitudinal stress in the cylinder, $\sigma_{2}$ is the circumferential stess in the wall, E is Young's modulus, and $v$ is Poisson's ratio.

\section{Thick Walled Cylinders}

Solutions also exist for calculating the stress in a thick-walled cylinder with the characteristic dimensions shown in the figure below (Roarks Formulas for Stress \& Strain 6th Edition, Chapter 12, Shells of Revolution, Pressure, Vessels \& Pipes, Table 32 and Page 638) [Young 1989]. In this case, a thick-walled vessel is defined as one with a radius-to-wall thickness ratio less than 10. The equations for stress and strain are:

$$
\begin{aligned}
& \sigma_{1}=0 \\
& \sigma_{2}=\frac{P b^{2}\left(a^{2}+r^{2}\right)}{r^{2}\left(a^{2}-b^{2}\right)}
\end{aligned}
$$




$$
\begin{aligned}
& \max \sigma_{2}=\frac{P b^{2}\left(a^{2}+b^{2}\right)}{r^{2}\left(a^{2}-b^{2}\right)} \text { at } r=b \\
& \sigma_{3}=-\frac{P b^{2}\left(a^{2}-r^{2}\right)}{r^{2}\left(a^{2}-b^{2}\right)} \\
& \max \sigma_{3}=-P \quad a t \quad r=b \\
& \Delta a=\frac{P}{E} \frac{2 a b^{2}}{\left(a^{2}-b^{2}\right)} \\
& \Delta b=\frac{P b}{E}\left[\frac{\left(a^{2}+b^{2}\right)}{\left(a^{2}-b^{2}\right)}-v\right] \\
& \Delta l=-\frac{P v l}{E} \frac{2 b^{2}}{\left(a^{2}-b^{2}\right)}
\end{aligned}
$$

\section{Thick Walled Spherical Vessels}

Analytical solutions also exist for calculating the stress in a thick-walled sphere with the characteristic dimensions shown in the figure below (Roarks Formulas for Stress \& Strain 6th Edition, Chapter 12, Shells of Revolution, Pressure, Vessels \& Pipes, Table 32 and Page 639) [Young 1989]. In this case, a thick-walled vessel is also defined as one with a radius-to-wall thickness ratio less than 10 . The equations for stress and strain are:

$$
\begin{aligned}
& \sigma_{1}=\frac{P b^{3}\left(a^{3}+2 r^{3}\right)}{2 r^{3}\left(a^{3}-b^{3}\right)} \\
& \max \sigma_{1}=\frac{P}{2} \frac{\left(a^{3}+2 b^{3}\right)}{\left(a^{3}-b^{3}\right)} \text { at } r=b \\
& \sigma_{2}=\frac{P b^{3}\left(a^{3}+2 r^{3}\right)}{2 r^{3}\left(a^{3}-b^{3}\right)} \\
& \max \sigma_{2}=\frac{P}{2} \frac{\left(a^{3}+2 b^{3}\right)}{\left(a^{3}-b^{3}\right)} \quad \text { at } \quad r=b \\
& \sigma_{3}=-\frac{P b^{2}\left(a^{2}-r^{2}\right)}{r^{2}\left(a^{2}-b^{2}\right)} \\
& \max \sigma_{3}=-P \quad a t \quad r=b \\
& \Delta a=\frac{P a}{E} \frac{(1-v) b^{3}}{2\left(a^{3}-b^{3}\right)} \\
& \Delta b=\frac{P b}{E}\left[\frac{(1-v)\left(a^{3}+2 b^{3}\right)}{2\left(a^{3}-b^{3}\right)}+v\right]
\end{aligned}
$$


Farmer, Kramer \& Williams, Fatigue Life Prediction for Steels in Pulsating Irradiated Systems, LLNL-TR-554731, Lawrence Livermore National Laboratory, Livermore, California 94550
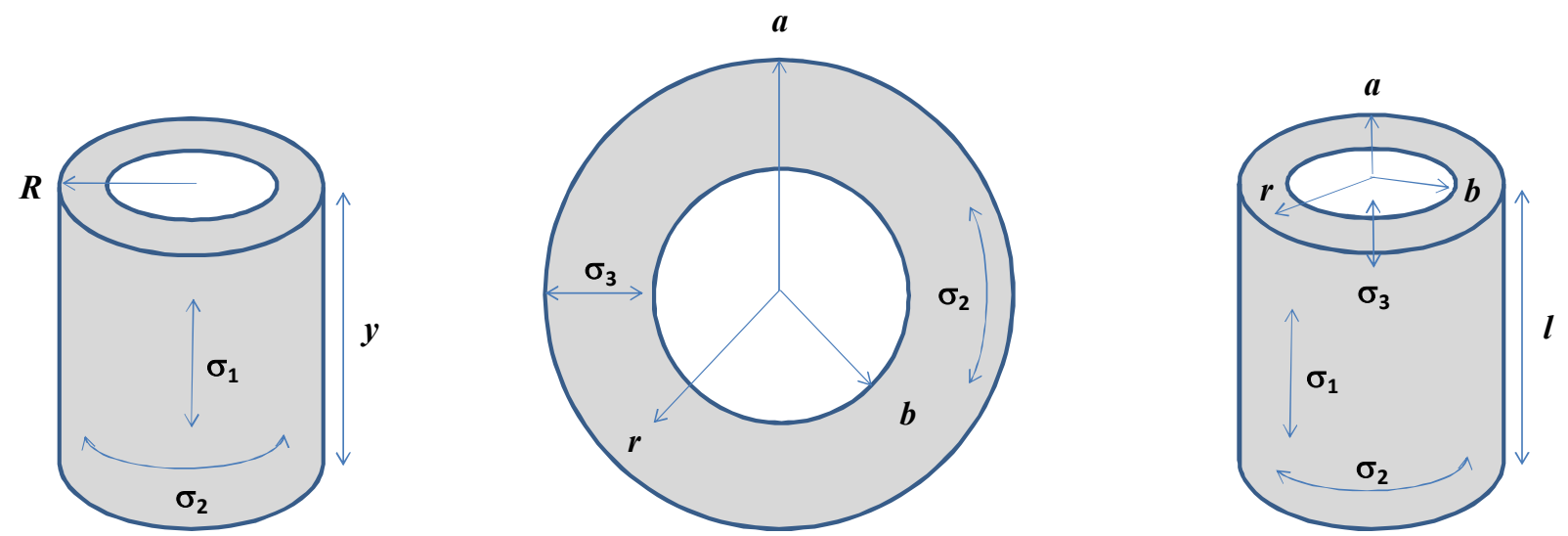

Figure 25 - Classical thin-walled cylinder, thick-walled cylinder, and thick-walled sphere used for analytical solutions for the calculation of static wall stresses. 
Farmer, Kramer \& Williams, Fatigue Life Prediction for Steels in Pulsating Irradiated Systems, LLNL-TR-554731, Lawrence Livermore National Laboratory, Livermore, California 94550

\section{APPENDIX B - PUBLISHED FATIGUE DATA}

Data Source: C. Vorpahl, A. Möslang, M. Rieth, Creep-fatigue interaction and related structure property correlations of EUROFER97 steel at $550^{\circ} \mathrm{C}$ by decoupling creep and fatigue load, Journal of Nuclear Materials, xxx (2011) xxx-xxx. [doi:10.1016/j.jnucmat.2010.12.262].
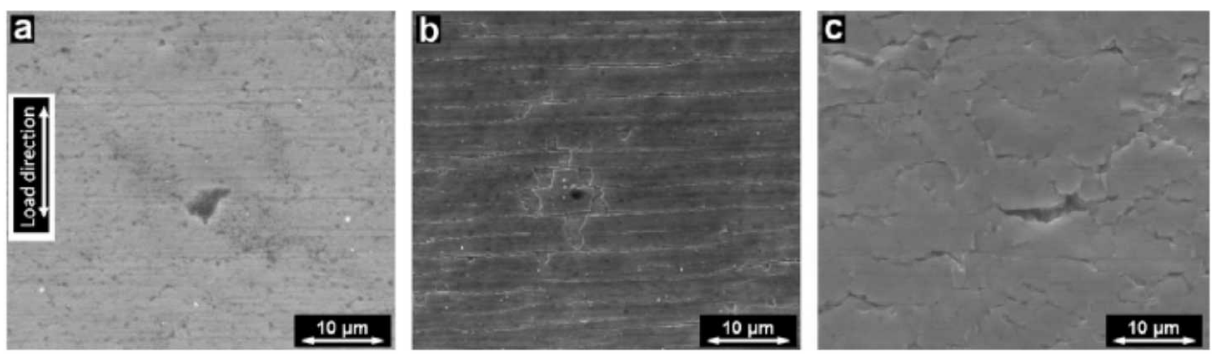

Fig. 3. Lateral surfaces of a specimen after pure fatigue at $\Delta \varepsilon=0.6 \%$ for 9258 cycles (a), after pure creep at $\sigma=180 \mathrm{MPa}$ for $165 \mathrm{~h}$ (b), and after creep-fatigue with $\Delta \varepsilon=0.6 \%$ for 5050 cycles and $\sigma=180 \mathrm{MPa}$ for $14.56 \mathrm{~h}$ (c). The load direction is always vertical.
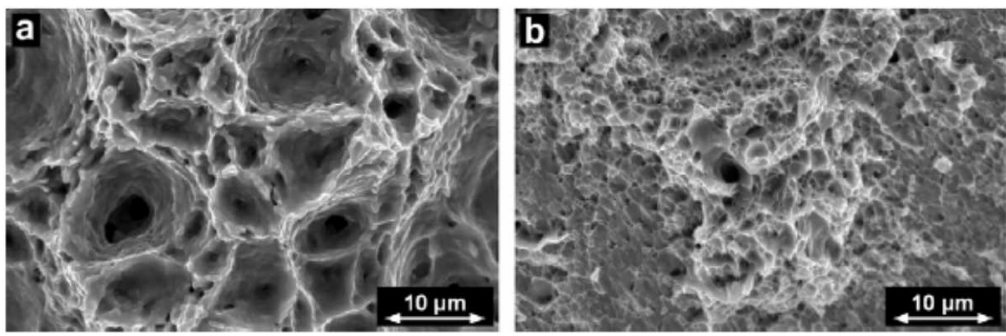

Fig. 4. Ductile dimple structures on the fracture surfaces (SEM) after creep-fatigue with $\Delta \varepsilon=0.6 \%$ for 5050 cycles and $\sigma=180 \mathrm{MPa}$ for $14.56 \mathrm{~h}$ (a) and after pure creep at $\sigma=180 \mathrm{MPa}$ for $165 \mathrm{~h}(\mathrm{~b})$.

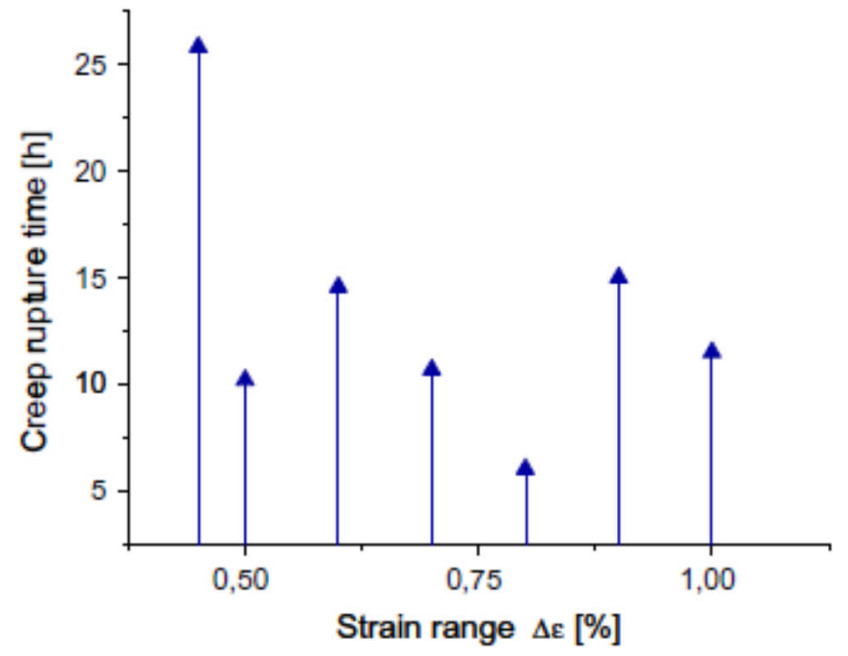

Fig. 2. Combined creep-fatigue tests at $550^{\circ} \mathrm{C}$ : after fatigue endurance to $50 \% \mathrm{~N}_{f}$, creep tests have been performed. The creep rupture time is shown for different prefatigued specimens. 
Farmer, Kramer \& Williams, Fatigue Life Prediction for Steels in Pulsating Irradiated Systems, LLNL-TR-554731, Lawrence Livermore National Laboratory, Livermore, California 94550

Data Source: C. Vorpahl, A. Möslang, M. Rieth, Creep-fatigue interaction and related structure property correlations of EUROFER97 steel at $550^{\circ} \mathrm{C}$ by decoupling creep and fatigue load, Journal of Nuclear Materials, xxx (2011) xxx-xxx. [doi:10.1016/j.jnucmat.2010.12.262].
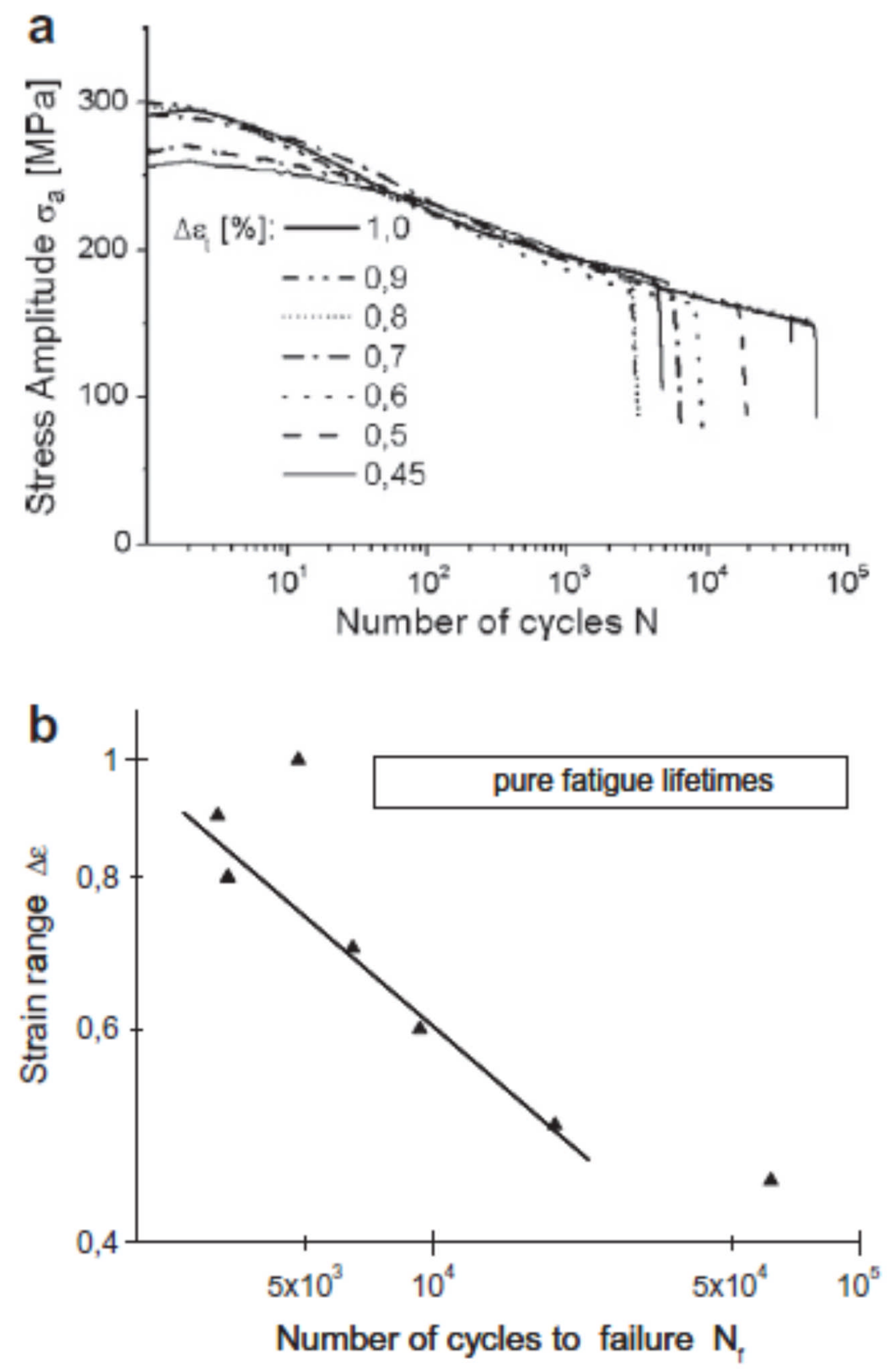

Fig. 1. Evolution of the positive stress amplitudes $\sigma_{a}$ as function of cycles $N$ during strain controlled pure fatigue testing for different strain ranges $\Delta \varepsilon$ at $550^{\circ} \mathrm{C}$ of EUROFER97 (a), and $\Delta \varepsilon$ vs. fatigue lifetime (b). 
Farmer, Kramer \& Williams, Fatigue Life Prediction for Steels in Pulsating Irradiated Systems, LLNL-TR-554731, Lawrence Livermore National Laboratory, Livermore, California 94550

Data Source: E. Gaganidze, C. Petersen, E. Materna-Morris, C. Dethloff, O. J. Weiß , J. Aktaa, A Povstyanko, A. Fedoseev, O. Makarov, V. Prokhorov, Mechanical properties and TEM examination of RAFM steels irradiated up to 70 dpa in BOR-60, Journal of Nuclear Materials, xxx (2011) xxx-xxx. [doi:10.1016/j.jnucmat.2010.12.047].

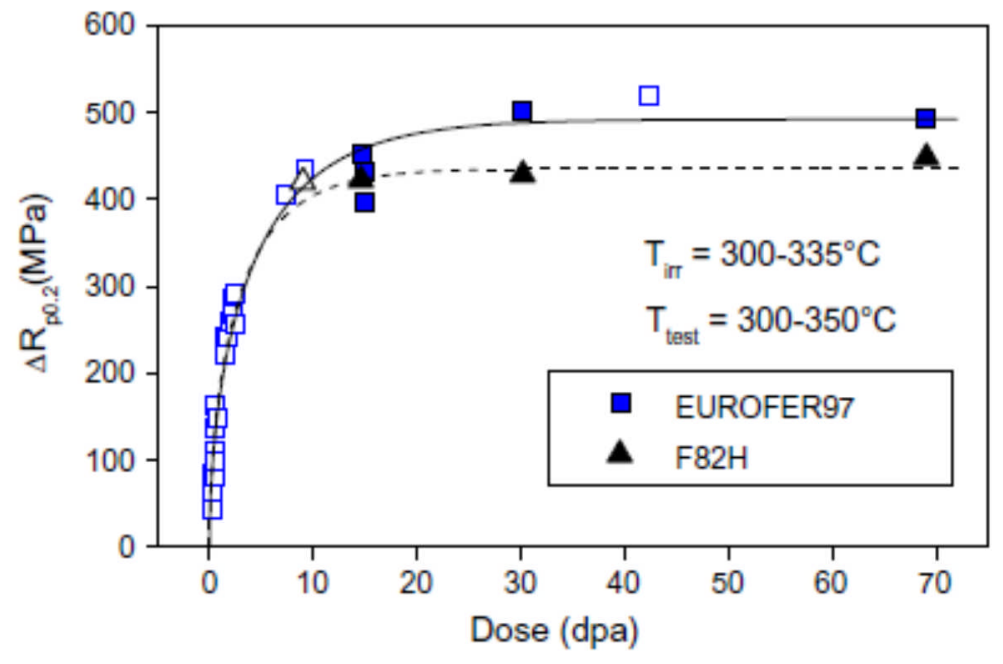

Fig. 1. Irradiation hardening vs. irradiation dose for EUROFER97 and F82 $\mathrm{H}$ steels for $T_{\text {irr }}=300-335^{\circ} \mathrm{C}$ and $T_{\text {test }}=300-350^{\circ} \mathrm{C}$ The full symbols represent KIT results. The open symbols are from the literature [9-11]. The solid line is a least square fit to the EUROFER97 data with Eq. (3). The dashed line is only a guide for eye.

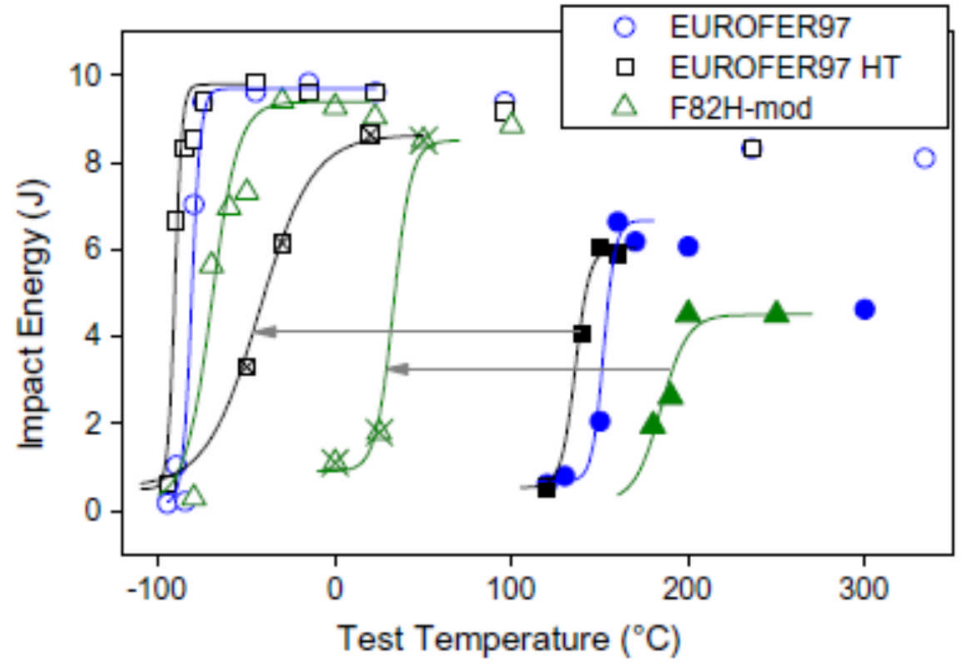

Fig. 3. Impact energy vs. test temperature for EUROFER97, EUROFER97 $\mathrm{HT}$ and F82 H-mod in unirradiated (open symbols) condition, after irradiation in BOR-60 up to $65-70 \mathrm{dpa} / 335-337^{\circ} \mathrm{C}$ (solid symbols) and after post-irradiation annealing at $550^{\circ} \mathrm{C}$ for $3 \mathrm{~h}$ (crossed symbols). The lines are fits to the ductile-to-brittletransition regions as described in [2]. The arrows indicate recovery of the impact properties after post-irradiation annealing. 
Farmer, Kramer \& Williams, Fatigue Life Prediction for Steels in Pulsating Irradiated Systems, LLNL-TR-554731, Lawrence Livermore National Laboratory, Livermore, California 94550

Data Source: E. Gaganidze, C. Petersen, E. Materna-Morris, C. Dethloff, O. J. Weiß , J. Aktaa, A Povstyanko, A. Fedoseev, O. Makarov, V. Prokhorov, Mechanical properties and TEM examination of RAFM steels irradiated up to 70 dpa in BOR-60, Journal of Nuclear Materials, xxx (2011) xxx-xxx. [doi:10.1016/j.jnucmat.2010.12.047].

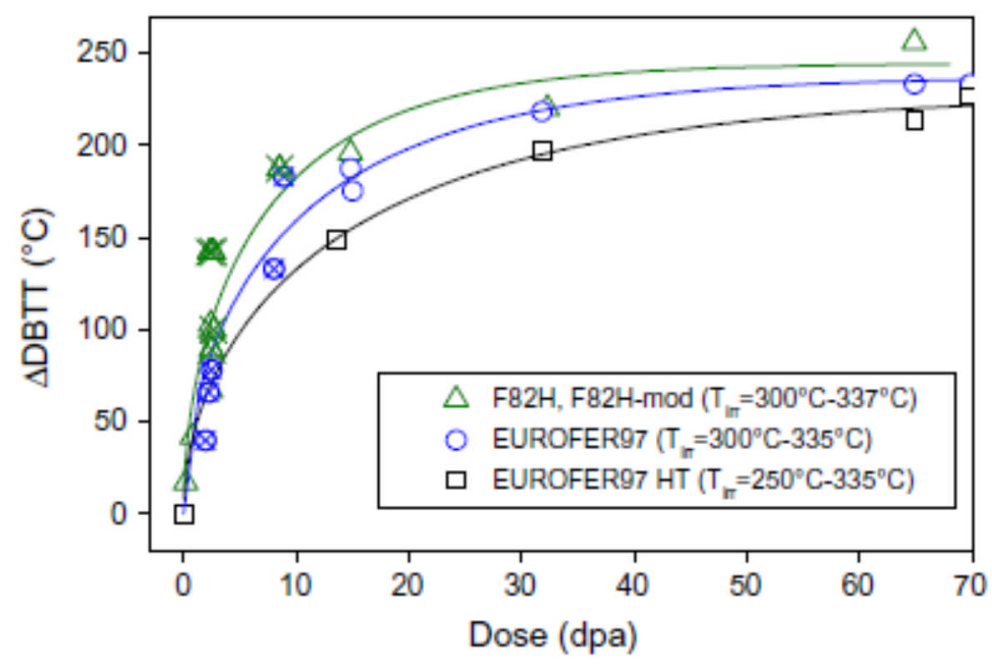

Fig. 4. Irradiation shifts of the DBTT vs. irradiation dose for EUROFER97, EUROFER97 HT and F82H steels. The open symbols represent KIT results and the crossed symbols are from [11]. The irradiation temperatures are indicated in the figure legend. The solid lines are a model description of the data, see text.

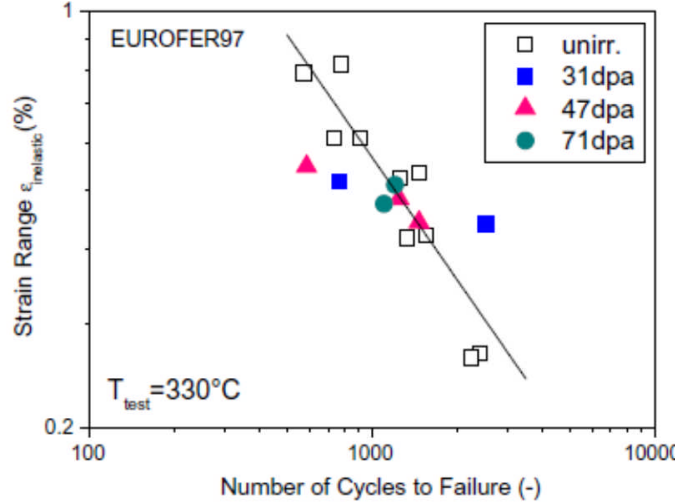

(a)

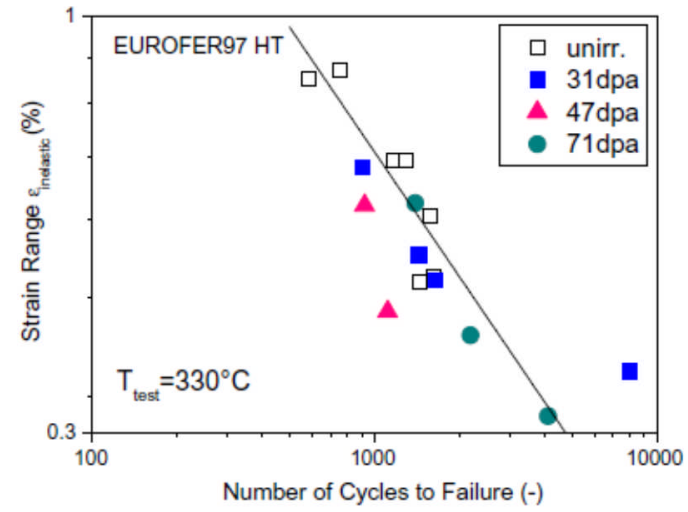

(b)

Fig. 5. Fatigue lifetime vs. inelastic strain range for unirradiated and irradiated $\left(T_{\text {ir }}=330-337^{\circ} \mathrm{C}\right)$ EUROFER 97 (a) and EUROFER97 HT (b). The lines represent the description of the unirradiated data by a Manson-Coffin relation. 
Farmer, Kramer \& Williams, Fatigue Life Prediction for Steels in Pulsating Irradiated Systems, LLNL-TR-554731, Lawrence Livermore National Laboratory, Livermore, California 94550

Data Source: J. Van den Bosch, R. W. Bosch, D. Sapundjiev, A. Almazouzi, Liquid metal embrittlement of ferritic-martensitic steel of liquid lead alloys, Journal of Nuclear Materials, 376 (2008) 322-329. [doi:10.1016/j.jnucmat.2008.02.008].

\begin{tabular}{|c|c|c|c|c|c|c|}
\hline Parameter & Units & $\mathrm{Pb}$ & $\mathrm{Li}$ & $\mathrm{Bi}$ & $\mathrm{Pb}-0.7 \mathrm{Li}$ & $\mathrm{Pb}-\mathrm{Bi}$ \\
\hline Atomic weight & $\mathrm{g} / \mathrm{mol}$ & 207.18 & 6.941 & 208.98 & 173.16 & 208.18 \\
\hline Neutron (th) absorption & Barn & 0.17 & - & & 12.3 & \\
\hline Melting temperature & ${ }^{\circ} \mathrm{C}$ & 327.4 & 180.69 & 271.0 & 235 & 123.5 \\
\hline Latent heat of melting & $\mathrm{kJ} / \mathrm{kg}$ & 23 & 0.00208 & 50.2 & 33.9 & 38.1 \\
\hline Volume change at melting & $\%$ & +3.5 & - & -3.32 & +3.5 & 0.0 \\
\hline Density $^{\mathrm{a}}$ & $\mathrm{kg} / \mathrm{m}^{3}$ & 10430 & $\sim 515$ & 9910 & 9150 & 10200 \\
\hline Thermal expansion ${ }^{a}$ & $1 / \mathrm{K}$ & $1.12 \times 10^{-4}$ & $0.56 \times 10^{-4}$ & & $1.23 \times 10^{-4}$ & \\
\hline Heat capacity ${ }^{a}$ & $\mathrm{~J} / \mathrm{kg} / \mathrm{K}$ & 147 & & & 188 & 146.5 \\
\hline Thermal conductivity & $\mathrm{W} / \mathrm{m} / \mathrm{K}$ & 15.4 & 0.847 & 13.3 & 17.1 & 13.2 \\
\hline Kinetic viscosity ${ }^{a}$ & $\mathrm{~m}^{2} / \mathrm{s}$ & $1.76 \times 10^{-7}$ & - & $1.42 \times 10^{-3}$ & $1.25 \times 10^{-7}$ & \\
\hline Surface tension ${ }^{a}$ & $\mathrm{~N} / \mathrm{m}$ & 0.44 & 0.28 & & 0.43 & \\
\hline Solubility of $\mathrm{Fe}^{\mathrm{a}}$ & at. $\%$ & $2.72 \times 10^{-4}$ & - & & - & \\
\hline Boiling temperature & ${ }^{\circ} \mathrm{C}$ & 1745 & 1347 & 1490 & $\sim 1600$ & 1670 \\
\hline Latent heat of boiling & $\mathrm{kJ} / \mathrm{kg}$ & 860 & - & 855.2 & $\sim 900$ & 856.7 \\
\hline Saturation pressure & bar & $5.1 \times 10^{-6}$ & - & & $2 \times 10^{-8}$ & \\
\hline
\end{tabular}

${ }^{\text {a }} T=500^{\circ} \mathrm{C}$. 
Farmer, Kramer \& Williams, Fatigue Life Prediction for Steels in Pulsating Irradiated Systems, LLNL-TR-554731, Lawrence Livermore National Laboratory, Livermore, California 94550

Data Source: J. Van den Bosch, R. W. Bosch, D. Sapundjiev, A. Almazouzi, Liquid metal embrittlement of ferritic-martensitic steel of liquid lead alloys, Journal of Nuclear Materials, 376 (2008) 322-329. [doi:10.1016/j.jnucmat.2008.02.008].
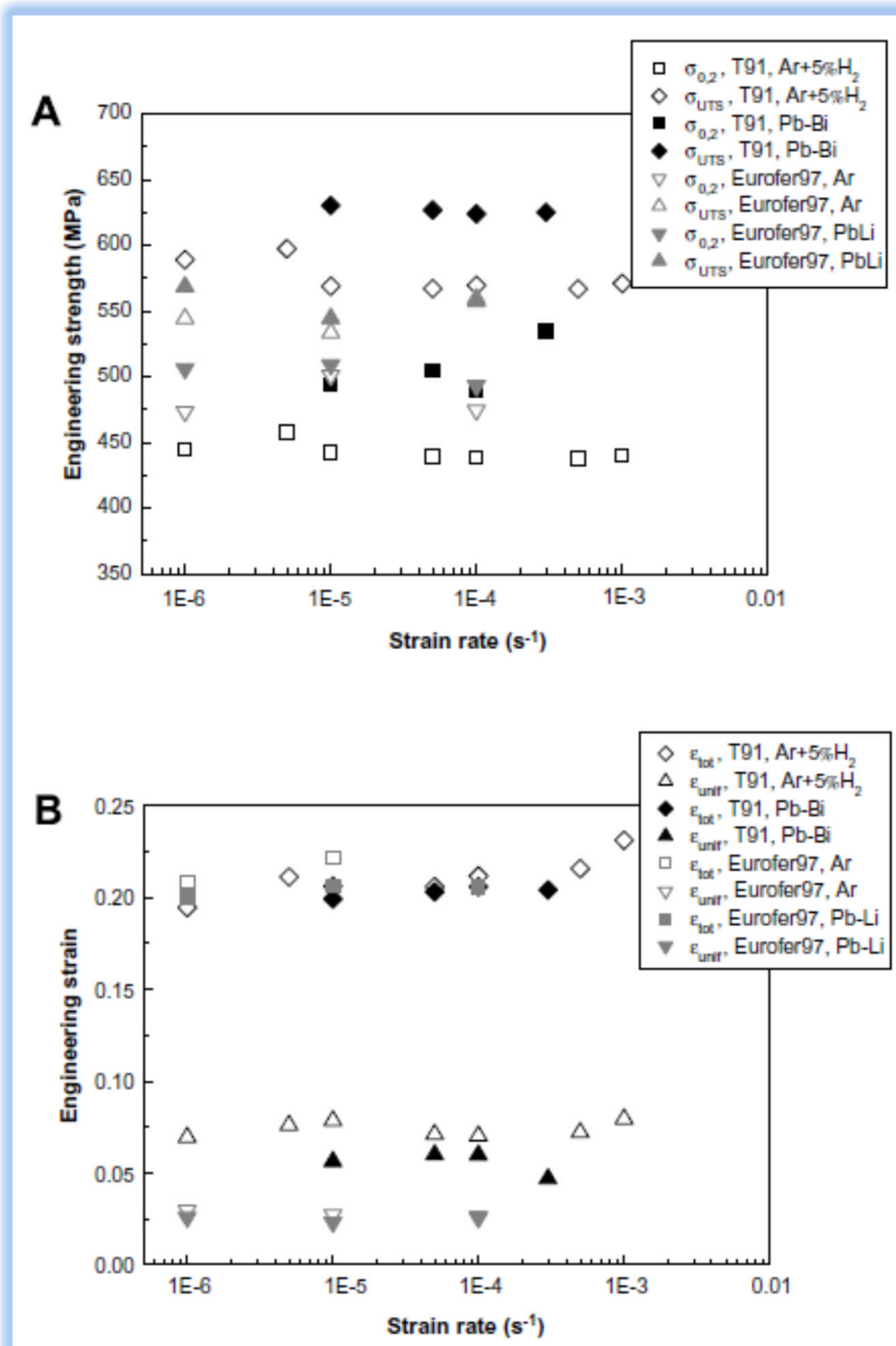

Fig. 1. Tensile results as function of strain rate. Full symbols for tests performed in liquid metal (T91 in PbBi; EUROFER97 in PbLi), empty symbols for tests performed in controlled gas atmosphere. Results on T91 at $245^{\circ} \mathrm{C}$ indicated in black, results on EEUROFER 97 at $250^{\circ} \mathrm{C}$ in dark gray. (A) Influence of the strain rate on the yield stress and the ultimate tensile strength; (B) influence of the strain rate on the uniform elongation and total elongation. 
Farmer, Kramer \& Williams, Fatigue Life Prediction for Steels in Pulsating Irradiated Systems, LLNL-TR-554731, Lawrence Livermore National Laboratory, Livermore, California 94550

Data Source: E. Materna-Morris, A. Möslang, R. Rolli b, H.-C. Schneider, Effect of helium on tensile properties and microstructure in $9 \%$ Cr-WVTa-steel after neutron irradiation up to 15 dpa between 250 and $450^{\circ} \mathrm{C}$, Journal of Nuclear Materials, 386-388 (2009) 422-425. [doi:10.1016/j.jnucmat.2008.12.157].

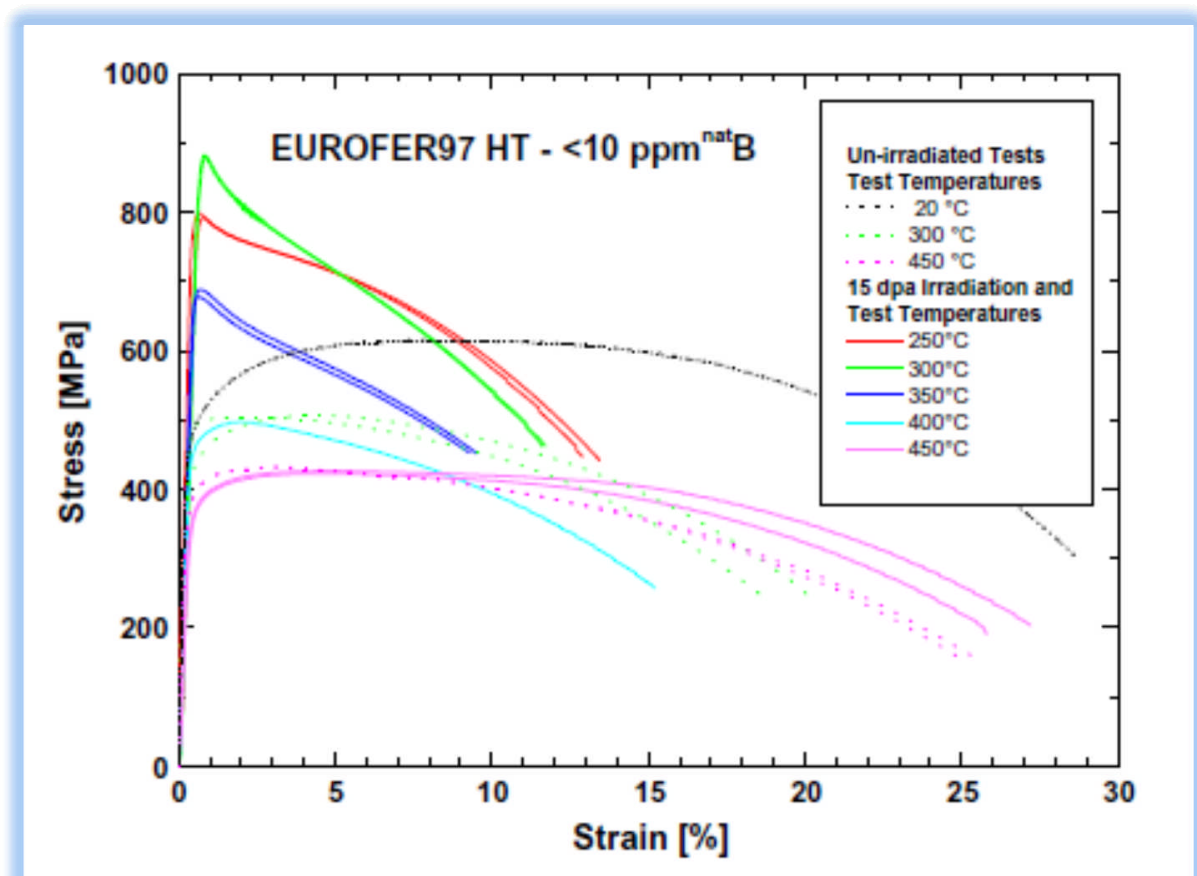

Fig. 1. Tensile properties of EUROFER97. 
Farmer, Kramer \& Williams, Fatigue Life Prediction for Steels in Pulsating Irradiated Systems, LLNL-TR-554731,

Lawrence Livermore National Laboratory, Livermore, California 94550

Data Source: E. Materna-Morris, A. Möslang, R. Rolli b, H.-C. Schneider, Effect of helium on tensile properties and microstructure in $9 \% \mathrm{Cr}-W V T a-$ steel after neutron irradiation up to 15 dpa between 250 and $450^{\circ} \mathrm{C}$, Journal of Nuclear Materials, 386-388 (2009) 422-425. [doi:10.1016/j.jnucmat.2008.12.157].

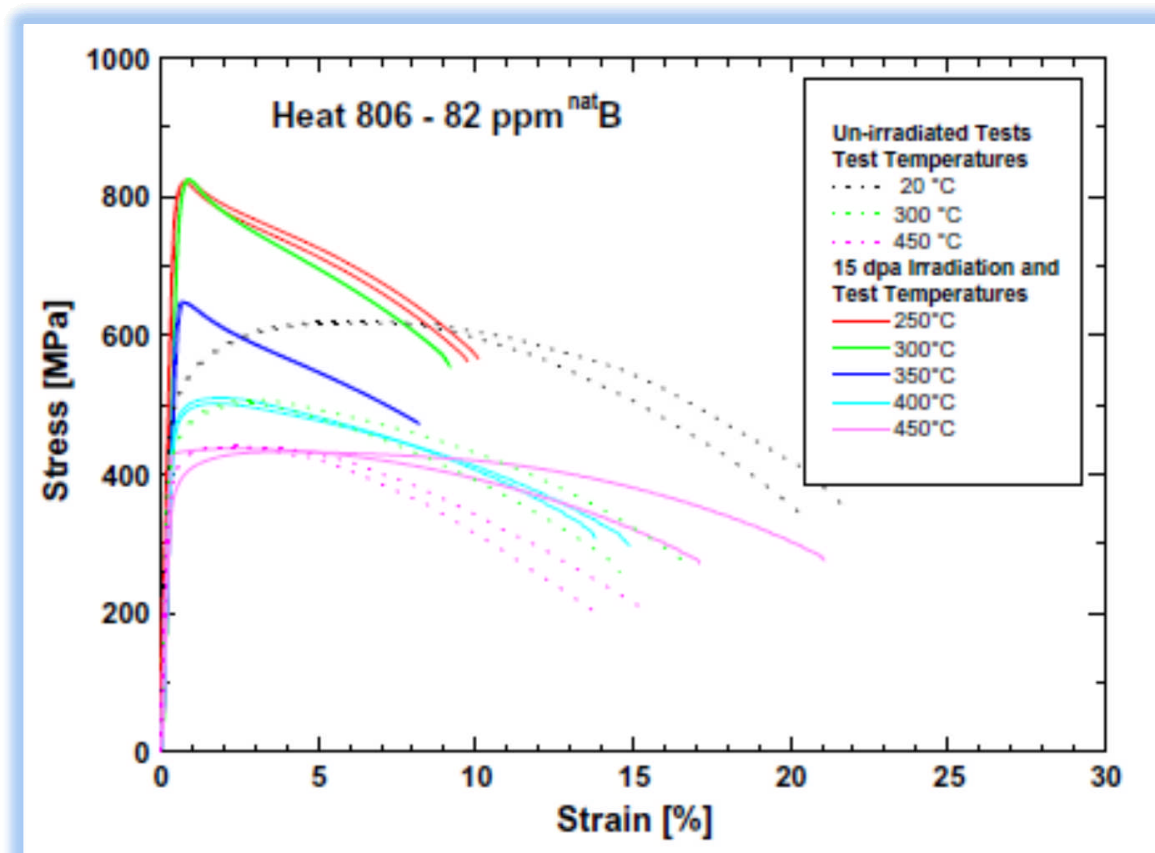

Fig. 2. Tensile properties of heat 806 .

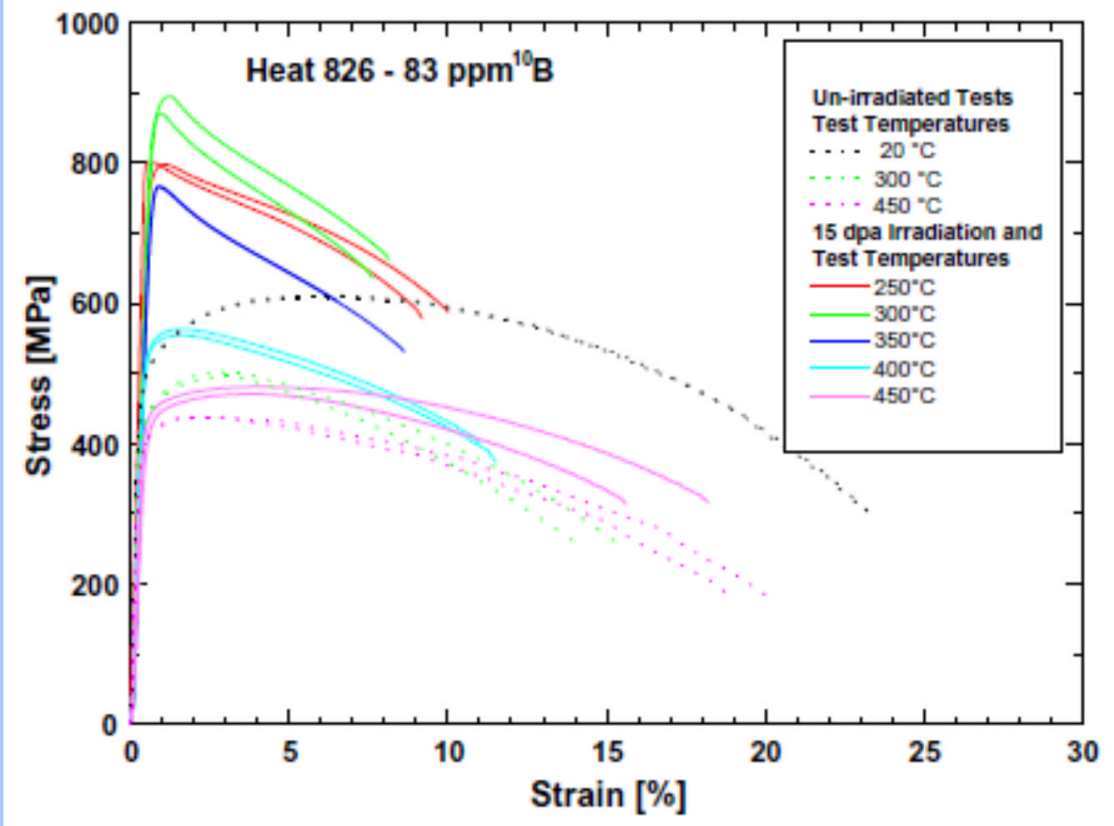

Fig. 3. Tensile properties of heat 826 . 